\title{
EVIDENCE THAT THE ASSOCIATION BETWEEN EXERCISE INTENSITY AND INSULIN SENSITIVITY IS SEX DEPENDENT
}

by

Kaitlyn Anne Hougham

A thesis submitted to the School of Kinesiology and Health Studies

In conformity with the requirements for

the degree of Master of Science

Queen's University

Kingston, Ontario, Canada

(June, 2011)

Copyright (C) Kaitlyn Anne Hougham, 2011 


\begin{abstract}
The purpose of this study was to determine if, after adjusting for the contribution of exercise dose, exercise intensity was associated with the improvement of insulin sensitivity. Abdominally obese, sedentary men $(n=16$, [mean $\pm S D$ ] age: $45.0 \pm 7.5 \mathrm{yr}$; waist circumference: $108.6 \pm 5.3 \mathrm{~cm})$ and women $(n=18$, [mean $\pm S D$ ] age: $42.3 \pm 6.2 \mathrm{yr}$; waist circumference: $100.1 \pm 8.2 \mathrm{~cm}$ ) performed daily, supervised exercise for 3 and 4 months, respectively. Exercising at a self selected exercise intensity, men were required to expend expended $700 \mathrm{kcal}$ per session and women $500 \mathrm{kcal}$ per session. Exercise intensity and dose were determined using heart rate and oxygen consumption data obtained from repeated graded exercise tests. Insulin sensitivity was determined by hyperinsulinemic euglycemic clamp. Insulin sensitivity improved in both men and women (change score: $\mathrm{men}=7.2 \pm 5.4 \mathrm{mg} / \mathrm{kgskm} / \mathrm{min}$, women $=5.8 \pm 7.1 \mathrm{mg} / \mathrm{kgskm} / \mathrm{min}$ ) $(p<0.05)$. Exercise intensity was associated with the improvements in insulin sensitivity in men (unstandardized regression coefficient $(\beta)=0.43, p=0.02$ ). Adjusting for exercise dose, the change in abdominal adipose tissue (AT), or the change visceral AT did not alter this association $(p<0.05)$. Exercise intensity was not associated with the improvement of insulin sensitivity in women $(\beta=-0.11, p=0.7)$. Adjusting for exercise dose, the change in abdominal or visceral AT did not change the association in women $(p>0.05)$. Our findings suggest that exercise intensity is independently associated with the improvement of insulin sensitivity in abdominally obese men but not women.
\end{abstract}




\section{Co-Authorship}

Writing of the manuscript contained within this dissertation (Chapter 3 ) and all statistical analyses were performed by Kaitlyn A. Hougham. Critical revisions for important intellectual content were provided by Dr. Robert Ross. 


\section{Acknowledgements}

To begin, I would like to thank Dr. Robert Ross. Thank you for providing me with the opportunity to study under your supervision in the Cardiometabolic Lifestyle Research Unit. From your Malcolm Gladwell quotes reminding me not to fear failure, to your words of encouragement telling me to, "roll up my sleeves and get some sweat on my brow", I appreciate your support and guidance over the past two years. The knowledge which I have gained during the creation of this dissertation is invaluable, thank you for helping me transition from an undergraduate student to a young investigator.

My peers within the Cardiometabolic Lifestyle Research Unit contributed to this thesis in many ways. Peter - although we only worked together for a short period of time, I am very grateful for the advice and knowledge that you shared with me. Your wisdom undoubtedly contributed to this dissertation. Trevor and James - your willingness to help and your easy going approach helped make this past year very enjoyable. Ashlee whether it was a discussion about statistics, or one of my many questions about manuscript writing, you were always eager to help. I cannot thank you enough for your friendship, patience and guidance. Morgan - you have become one of my closest friends. Thank you for your assistance and support throughout the creation of this dissertation. Your sense of humor and outgoing personality helped to make the past two years extremely fun and memorable.

This thesis would not have been possible without my family. Dad, Mom, Jackie and Kent - I want to express my gratitude to you for your ongoing support and encouragement. From helping me move two times in less than three months, to our 
frequent phone conversations, you have always been there for me. You helped me to stay motivated and inspired during the creation of this dissertation. I could not have done this without you! Grandma and Nana - thank you for cheering me on over the past two years and always encouraging me to follow my dreams.

Lastly, I would like to thank Cole. Whether it was attending my conference presentations, or listening to me vent for hours when things were not going as planned, you have always supported me. I am extremely grateful for your patience during the creation of this dissertation - I know at times it wasn't easy. You are my best friend and I look forward to starting the next chapter of our lives together. 


\section{Table of Contents}

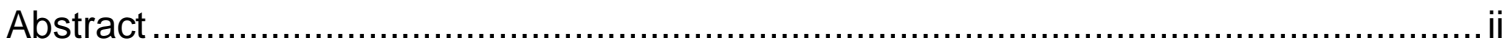

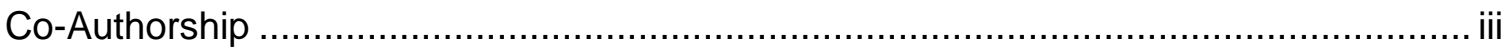

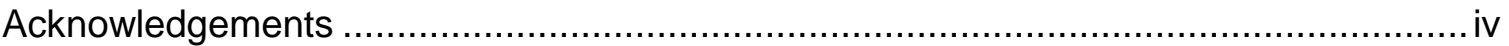

Chapter 1 . General Introduction......................................................................... 1

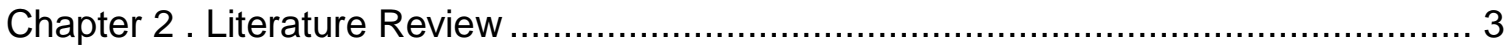

2.1 Introduction

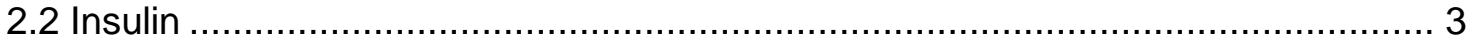

2.2.1 Insulin Signaling .................................................................................. 3

2.2.2 The Physiological Effects of Insulin..................................................... 4

2.2.3 Insulin Sensitivity ........................................................................... 4

2.2.4 The Presentation of Skeletal Muscle Insulin Resistance ............................... 5

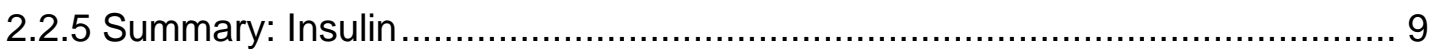

2.3 The Pathophysiology of Insulin Resistance: The Lipocentric View ....................10

2.3.1 Ectopic Fat Deposition .....................................................................

2.3.2 Intramuscular Triglycerides and Lipotoxic Metabolites ................................12

2.3.3 Lipotoxic Metabolites and the Skeletal Muscle Insulin Signaling Cascade .....14

2.3.4 Ectopic Lipid Accumulation, Adipokines and Insulin Resistance ...................16

2.3.5 Summary: The Pathophysiology of Insulin Resistance................................17

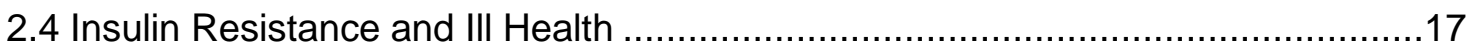

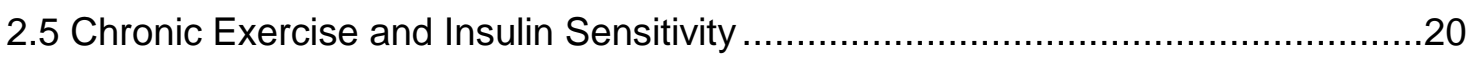

2.5.1 Acute Effects of Exercise on Insulin Sensitivity .......................................21

2.5.2 The Presentation of Chronic Exercise Induced Improvements In Skeletal

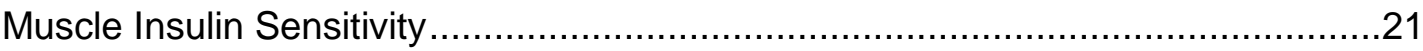

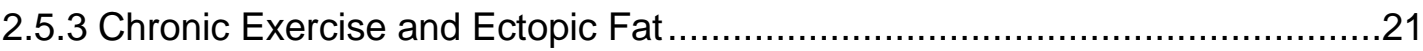

2.5.4 Chronic Exercise, Intramuscular Triglycerides, Lipotoxic Metabolites ............22

2.5.5 Chronic Exercise and Skeletal Muscle Insulin Signaling .............................23

2.5.5.1 Chronic Exercise May Increase Insulin Stimulated Glucose Disposal via a

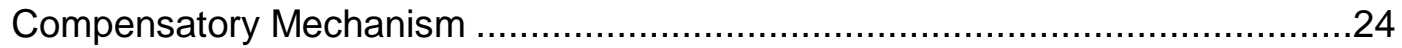

2.5.5.1.1 Hexokinase Expression: Diet / Exercise Interactions.........................25

2.5.6 Summary: Chronic Exercise and Skeletal Muscle Insulin Sensitivity ..............25 
2.6 Exercise Intensity and the Improvement of Insulin Sensitivity

2.6.1 Exercise Intensity Is Associated With the Improvement of Insulin Sensitivity .28

2.6.1.1 Continuum vs. Threshold Effect

2.6.2 Exercise Intensity Is Not Associated With the Improvement of Insulin

Sensitivity.

2.6.3 High Intensity Interval Training and the Improvement of Insulin Sensitivity ....33

2.6.4 Mechanism by Which Exercise Intensity Might Independently Effect Insulin

Sensitivity .34

2.6.5 Summary: Exercise Intensity and Insulin Sensitivity ..................................35

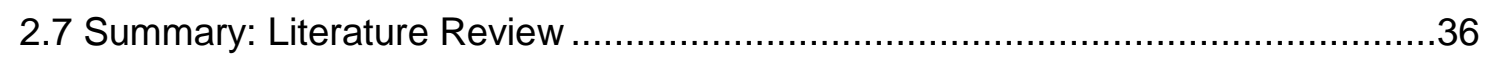

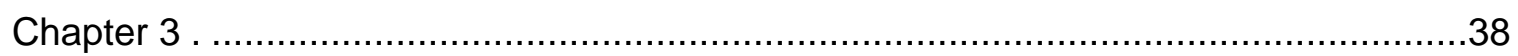

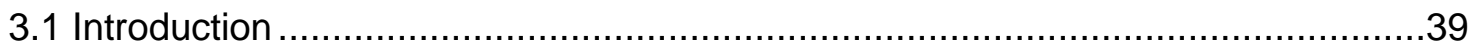

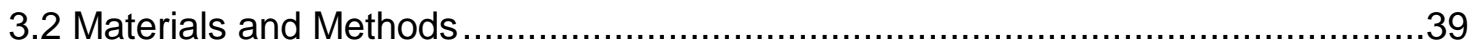

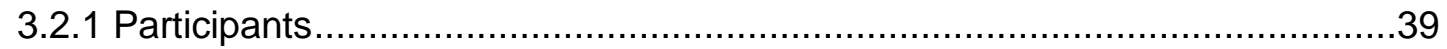

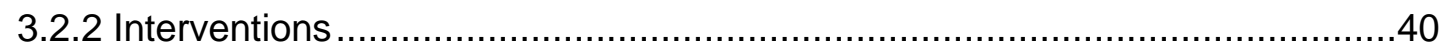

3.2.3 Measurement of Cardiorespiratory Fitness ...............................................41

3.2.4 Measurement of Insulin Sensitivity..................................................... 41

3.2.5 Measurement of Adipose Tissue and Skeletal Muscle Tissue......................42

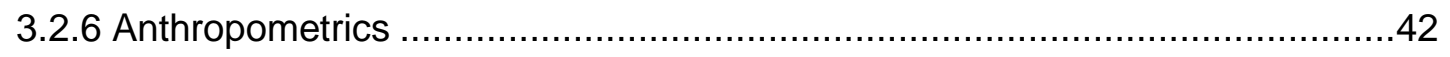

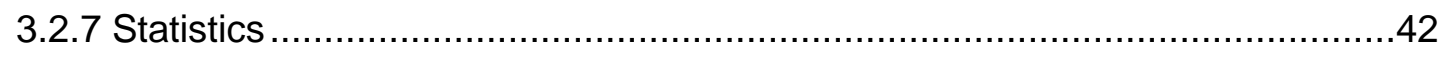

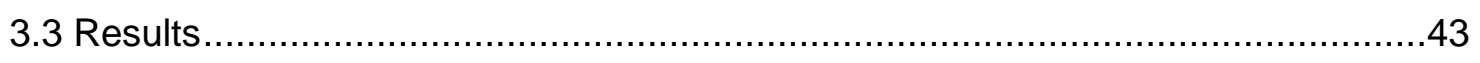

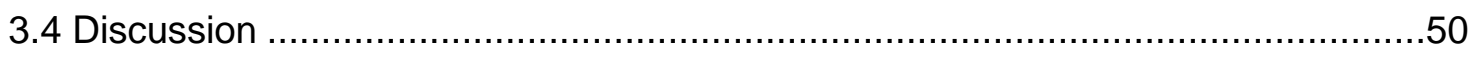

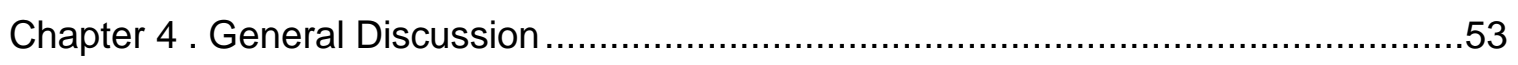

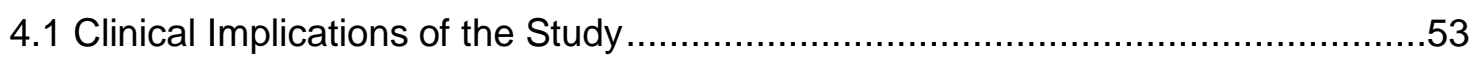

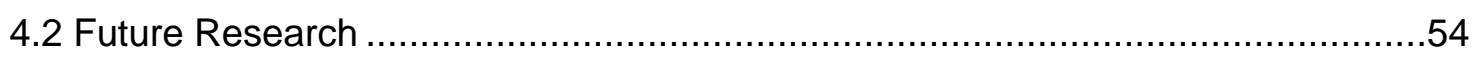

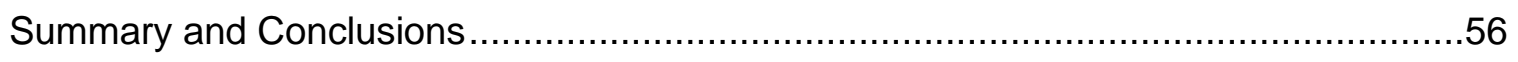

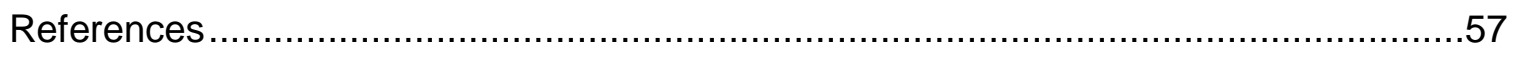

Appendix A Example of a Consent Form ........................................................ 70

Appendix B Example of a Medical Questionnaire ................................................ 79

Appendix C Example of an Anthropometric Data Acquisition Protocol ..........................87

Appendix D Example of a Graded Exercise Test Protocol ........................................91

Appendix E Example of a Hyperinsulinemic Euglycemic Clamp Protocol .....................94 
Appendix F Example of a MRI Acquisition Protocol ...............................................

Appendix G Example of Statistical Analysis Used to Derive Results for Manuscript ....103 


\section{List of Tables}

\section{Chapter 2 Tables:}

Table 2-1. Examples of the Physiological Effects of Insulin ....................................... 6

Table 2-2. In Vivo Insulin Sensitivity Measurement Techniques................................... 7

Table 2-3. Physiological Abnormalities Associated With Insulin Resistance. .................19

Table 2-4. Research Examining the Effect of Exercise Intensity on Insulin Sensitivity. ..27

\section{Chapter 3 Tables:}

Table 3-1 Baseline and Follow-Up Participant Characteristics....................................46

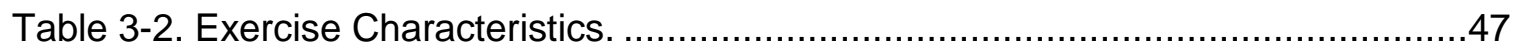

Table 3-3. Associations between Exercise Intensity and the Improvement of Insulin

Sensitivity. 


\section{List of Figures}

\section{Chapter 2 Figures:}

Figure 2-1. An Example of a Skeletal Muscle Signal Transduction Pathway Stimulated by Insulin Binding

Figure 2-2. Impairments in an Insulin Signal Transduction Pathway Brought About by Lipotoxic Metabolites ............................................................................................ 16

Figure 2-3. Schematic Diagram Representing the Lipocentric View............................18

\section{Chapter 3 Figures:}

Figure 3-1. Exercise Intensity (Solid Bars) and the Improvement in Insulin Sensitivity (Open Bars) In Men (A) and Women (B). 


\section{Chapter 1. General Introduction}

Insulin sensitivity is defined as the concentration of insulin that is required to cause $50 \%$ of its maximal effect on glucose transport (1). As the majority of insulin stimulated glucose transport occurs within skeletal muscle (2), insulin sensitivity largely refers to the sensitivity of skeletal muscle to insulin. The pathophysiology of impaired insulin stimulated glucose uptake (also called insulin resistance hereafter) is poorly understood. A current hypothesis suggests that the accumulation of lipid in ectopic sites may impair insulin signaling. Regardless of the uncertainties about the etiology of insulin resistance, it is generally accepted that impaired insulin stimulated glucose disposal is a primary antecedent for cardiovascular disease $(3,4)$.

For over 30 years, chronic exercise has been recognized as a strategy for the improvement of insulin sensitivity (5). However, research examining the independent effect of exercise intensity on insulin sensitivity has yielded equivocal results $(6,7,8,9$, $10,11,12)$. In other words it is not clear if, independent of dose (caloric expenditure), higher intensity exercise results in a greater improvement of insulin sensitivity.

Gaining knowledge about the effect of exercise intensity on insulin sensitivity is important. Isolating the independent contribution of exercise intensity will allow clinicians to prescribe specific exercise protocols aimed at reducing insulin resistance and preventing cardiovascular disease. This is paramount as cardiovascular disease is now the number one global cause of mortality (13).

The following literature review (Chapter 2) will discuss; the physiological effects of insulin, the pathophysiology of insulin resistance, health effects associated with insulin resistance, the effects of exercise on insulin sensitivity, and lastly the independent effect of exercise intensity on insulin sensitivity. In the manuscript found in Chapter 3 we 
investigate the independent effects of exercise intensity on insulin sensitivity in men and women. Subsequently, in Chapter 4, the implications of our investigation and the future directions of this field of inquiry are discussed. 


\section{Chapter 2. Literature Review}

\subsection{Introduction}

This review discusses topics germane to the study found in Chapter 3 . This is not intended to be an extensive review of the mechanisms that are proposed to be involved in the development of insulin resistance, or those thought to participate in the improvement of insulin sensitivity following chronic exercise. As insulin stimulated glucose disposal largely occurs at the skeletal muscle (2), the focus of this discussion is primarily skeletal muscle insulin resistance. Please note that for the purposes of this review, exercise is defined as aerobic exercise.

\subsection{Insulin}

Insulin was first discovered in 1922 by Banting and Best (14). A peptide hormone, insulin is secreted from $\beta$ cells within the islets of Langerhans in response to increases in circulating glucose. Described below, insulin binds to cell surface receptors thereby stimulating the transduction of a complex signaling cascade. By way of this signaling cascade, insulin regulates an array of physiological processes including carbohydrate and lipid metabolism. The sensitivity of target tissues for insulin largely regulates the action of this important hormone.

\subsubsection{Insulin Signaling}

The insulin receptor (IR) is a heterotetrameric glycoprotein composed of $2 \alpha$ and $2 \beta$ subunits. The $\alpha$ subunits act as the insulin binding domain whereas the $\beta$ subunits have tyrosine kinase activity. Insulin binding activates the tyrosine kinase resulting in the autophosphorylation of the IR and the phosphorylation of several intracellular proteins $(15,16)$. The phosphotyrosine residues on these intracellular proteins act as 
docking sites for proteins with specific Src-homology-2 (SH2) domains (17). Binding to the phosphorylation motifs activates these SH2 containing molecules (18). Once activated $\mathrm{SH} 2$ domain containing proteins stimulate a large number of signal transduction pathways. These pathways, collectively called the insulin signaling cascade, regulate important physiological processes largely by altering the activation state of key regulatory enzymes.

Figure 2-1 illustrates a signal transduction pathway stimulated by insulin binding. Phosphotidylinositol-3-phosphates kinase (PI3K) contains an $\mathrm{SH} 2$ domain on its p85 regulatory subunit. PI3K binds to the phosphotyrosine residue of IRS-1, an intracellular protein phosphorylated by the IR. PI3K is activated upon binding to the phosphotyrosine residue (18). Through a series of complex pathways, the activated PI3K then increases glucose disposal. More specifically, PI3K activates protein kinase B (Akt/PKB), resulting in the translocation of GLUT4 (glucose transporter type 4) (19) and the stimulation of the glycogenic enzyme glycogen synthase (GS) $(20,21)$. Through a separate pathway, PI3K also stimulates the transcription of hexokinase (22)

\subsubsection{The Physiological Effects of Insulin}

Target tissues for insulin action include adipose tissue, skeletal muscle, and the liver. Often described as an 'anabolic hormone', a primary outcome of the insulin cascade is the storage of carbohydrate and lipid (23). Table 2-1 lists some of the physiological processes regulated by insulin. Also listed is an example of a specific molecule within each of these processes upon which insulin acts.

\subsubsection{Insulin Sensitivity}

As alluded to previously, although insulin regulates many physiological processes, insulin sensitivity specifically refers to the ability of insulin to stimulate 
glucose disposal. A variety of methods can be employed to assess insulin sensitivity. Table 2-2 presents a brief summary of the most commonly used in vivo techniques. For more detailed information readers are encouraged to reference reviews written by Ferrannini et al. (24), Muniyappa et al. (25), and Wallace et al. (26).

Figure 2-1. An Example of a Skeletal Muscle Signal Transduction Pathway Stimulated by Insulin Binding

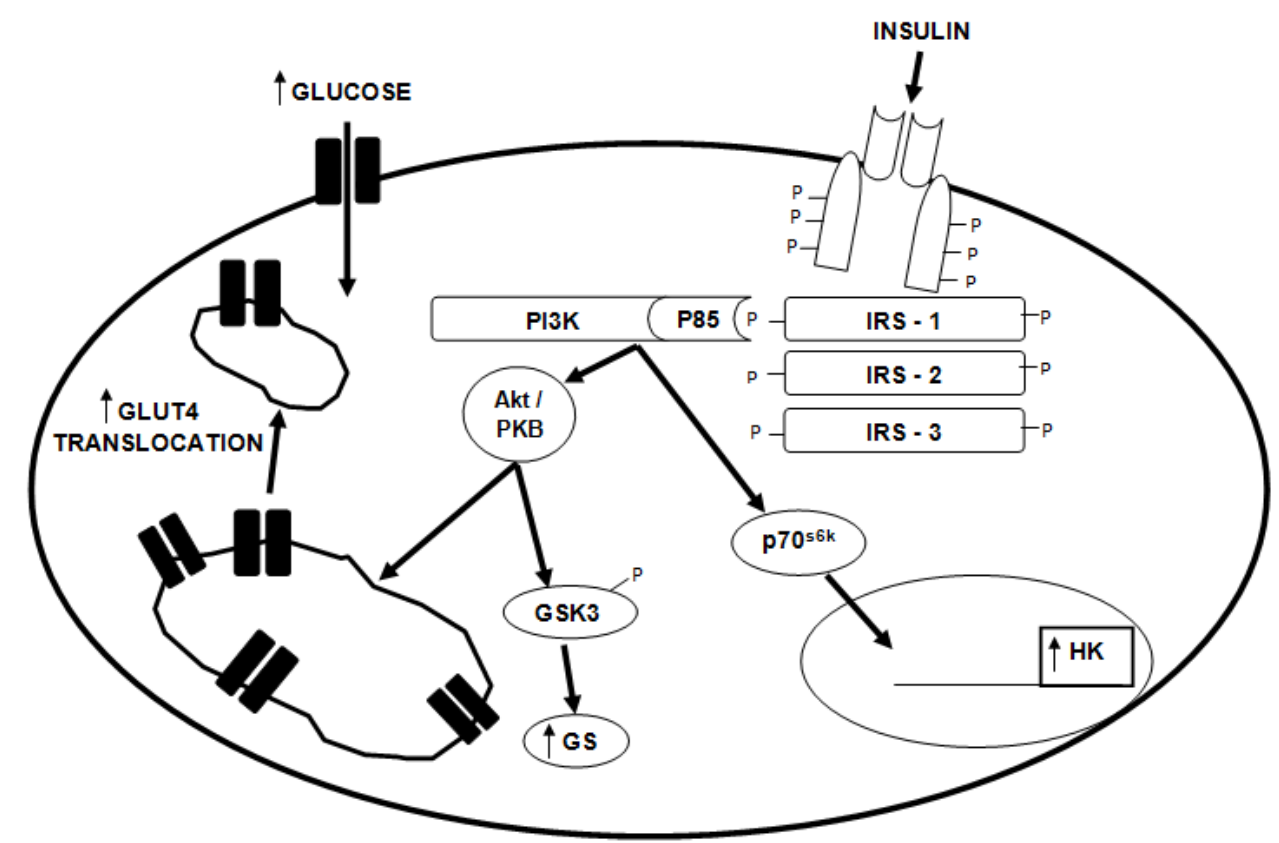

\subsubsection{The Presentation of Skeletal Muscle Insulin Resistance}

A decrease in insulin sensitivity is interpreted as a rightward shift in the insulin dose response curve and a corresponding increase in the concentration of insulin that is required to cause $50 \%$ of maximum glucose disposal (1). As is illustrated in Figure 2-1, decreased insulin stimulated glucose disposal may be the result of impaired insulin action at one of several sites. Normally, insulin stimulates glucose uptake by increasing the translocation of GLUT4 to the plasma membrane (19). Once inside the myocyte, 
Table 2-1. Examples of the Physiological Effects of Insulin

\begin{tabular}{|c|c|c|c|}
\hline $\begin{array}{l}\text { Physiological } \\
\text { Process }\end{array}$ & Effect of Insulin & Primary Location(s) & $\begin{array}{l}\text { Example of Molecule Regulated By } \\
\text { Insulin }\end{array}$ \\
\hline $\begin{array}{l}\text { De Novo } \\
\text { Lipogenesis }\end{array}$ & $\uparrow$ & $\begin{array}{l}\text { Adipose Tissue } \\
\text { Liver }\end{array}$ & Fatty acid synthase (27) \\
\hline Gluconeogenesis & $\downarrow$ & Liver & Phosphoenolpyruvate carboxykinase (28) \\
\hline Glucose Uptake & $\uparrow$ & $\begin{array}{l}\text { Striated Muscle } \\
\text { Adipose Tissue }\end{array}$ & GLUT4 (29) \\
\hline Glycogenesis & $\uparrow$ & $\begin{array}{l}\text { Liver } \\
\text { Striated Muscle }\end{array}$ & Glycogen synthase kinase $3(20)$ \\
\hline Glycogenolysis & $\downarrow$ & $\begin{array}{l}\text { Liver } \\
\text { Striated Muscle }\end{array}$ & Protein phosphatase 1 (21) \\
\hline Glycolysis & $\uparrow$ & $\begin{array}{c}\text { Liver } \\
\text { Striated Muscle } \\
\text { Adipose Tissue }\end{array}$ & Pyruvate dehydrogenase (30) \\
\hline Lipolysis & $\downarrow$ & $\begin{array}{c}\text { Adipose Tissue } \\
\text { Liver } \\
\text { Skeletal Muscle }\end{array}$ & Hormone sensitive lipase (31) \\
\hline Vasodilation & $\uparrow$ & Endothelial cells & Endothelial nitric oxide synthase (32) \\
\hline
\end{tabular}


Table 2-2. In Vivo Insulin Sensitivity Measurement Techniques.

\begin{tabular}{|c|c|c|c|}
\hline Method & Summary & $\begin{array}{l}\text { Intrasubject } \\
\text { Coefficient of } \\
\text { Variation }\end{array}$ & $\begin{array}{l}\text { Correlation } \\
\text { With The } \\
\text { Clamp }\end{array}$ \\
\hline $\begin{array}{l}\text { Hyperinsulinemic } \\
\text { Euglycemic } \\
\text { Clamp }\end{array}$ & $\begin{array}{l}\text { Provides a direct measure of whole body glucose disposal in response } \\
\text { to exogenous hyperinsulinemia. Results are often described as the rate } \\
\text { of glucose disposal relative to lean tissue. }\end{array}$ & $10 \%(33,34)$ & $\mathrm{N} / \mathrm{A}$ \\
\hline $\begin{array}{l}\text { Homeostatic } \\
\text { Model } \\
\text { Assessment }\end{array}$ & $\begin{array}{l}\text { A paradigm model that derives an estimate of insulin sensitivity (HOMA- } \\
\text { IR) and } \beta \text { cell function (HOMA1-\% } \beta \text { ) from measurements of fasting } \\
\text { plasma insulin and glucose. }\end{array}$ & $\begin{array}{c}10 \%-50 \% \\
(34,35)\end{array}$ & $\begin{array}{c}r=0.70^{*}(35, \\
36)\end{array}$ \\
\hline $\begin{array}{c}\text { Insulin } \\
\text { Suppression Test }\end{array}$ & $\begin{array}{l}\text { Determines the ability of exogenous insulin to mediate the disposal of } \\
\text { glucose when endogenous insulin secretion is suppressed using } \\
\text { somatostatin. Results are expressed as steady state plasma glucose. }\end{array}$ & $7 \%(37)$ & $r=0.98(38)$ \\
\hline Minimal Model & $\begin{array}{l}\text { A minimal model that derives an insulin sensitivity index (ISI) using the } \\
\text { results from an intravenous glucose tolerance test. The ISI provides a } \\
\text { measure of the fractional glucose disappearance per insulin } \\
\text { concentration unit. }\end{array}$ & $20 \% \dagger(39)$ & $\begin{array}{c}r=0.80 \dagger(40, \\
41)\end{array}$ \\
\hline $\begin{array}{l}\text { Oral Glucose } \\
\text { Tolerance Test } \\
\text { and Related } \\
\text { Indices }\end{array}$ & $\begin{array}{l}\text { Direct measure of glucose tolerance via oral administration of a glucose } \\
\text { load. Various outcomes are used as estimates of insulin sensitivity such } \\
\text { as area under the glucose or insulin curve. Many insulin sensitivity } \\
\text { indices have been derived using oral glucose tolerance test results. }\end{array}$ & $\begin{array}{c}10-40 \% \ddagger \\
(42,43)\end{array}$ & $\begin{array}{c}r=0.50- \\
0.90(44,45)\end{array}$ \\
\hline \multicolumn{4}{|c|}{$\begin{array}{l}\text { Abbreviations - CV: Coefficient of variation, OGTT: Oral glucose tolerance test, r: Spearman's correlation coefficient. } \\
\text { All correlation coefficients } p<0.05 \\
\text { * This is the HOMA1 technique. HOMA-IR is logarithmically transformed in order to perform this correlation. While this is the correlation } \\
\text { typically observed in the literature, lower correlations have been reported (34). } \\
\dagger \text { Tolbutin boosted procedure. } \\
\ddagger \text { The large range is due to different CV for glucose vs. insulin measures. OGTT derived glucose measures (e.g. fasting glucose) have } \\
\text { CV from } 10-20 \% \text {. Conversely OGTT derived insulin measures (e.g. } 2 \text { hour specific insulin) have CV as high as } 40 \%(42,43)\end{array}$} \\
\hline
\end{tabular}


insulin maintains the gradient for glucose over the plasma membrane by stimulating hexokinase expression (22). Hexokinase phosphorylates glucose creating glucose-6phosphate. Next, glucose-6-phosphate either enters glycolysis to be oxidized, or it is stored as glycogen. Insulin regulates this step in the glucose disposal pathway by increasing the activity of glycogenic $(20,21)$ and glycolytic enzymes $(30)$.

A considerable amount of research has been conducted in an effort to identify which of step in the glucose disposal pathway is impaired in those with insulin resistance. Research has demonstrated that insulin stimulated oxidative glucose disposal is maintained, whereas non-oxidative glucose disposal is significantly decreased, in those with insulin resistance $(46,47)$. Therefore, it is generally accepted that glycogen synthesis represents a major pathway affected by impaired insulin stimulated glucose disposal (46). The attenuated insulin stimulated glycogen formation is partially attributed to the impaired activation glycogenic enzymes, like GS (48). Despite the decreased non-oxidative glucose disposal, it is unclear if glycogen content is changed in those with insulin resistance $(49,50,51)$.

It has been reported that the insulin stimulated increase in glucose-6-phosphate is attenuated in insulin resistant individuals when compared to healthy controls (52). Thus, while glycogen synthesis represents a major pathway affected by impaired insulin stimulated glucose disposal, the rate limiting step likely occurs prior to glycogen synthesis (53). Research using magnetic resonance spectroscopy has identified GLUT4 translocation as the rate limiting step in insulin stimulated glucose disposal (54). However, research using the triple tracer technique found that glucose phosphorylation (i.e. hexokinase) is limiting (55). This is supported by findings that insulin induced hexokinase expression is decreased in obese and type 2 diabetic individuals (56). It is 
difficult to reconcile these different findings, in large measure due to methodological differences (46).

In summary, insulin resistant individuals have decreased insulin stimulated glucose disposal. In large measure, this can be attributed to impaired insulin stimulated GLUT4 translocation, and/or the regulation of hexokinase expression by insulin. This decreased insulin sensitivity translates to decreased non-oxidative glucose disposal, likely in part due to decreased activation of GS by insulin. PI3K signaling (Figure 2-1) is central to insulin stimulated glucose transport and phosphorylation, as will be discussed later in this review, the activation of this kinase by insulin is largely implicated in the onset of insulin resistance.

A compensatory increase in pancreatic insulin secretion allows for normoglycemia to be maintained despite these impairments in insulin - stimulated glucose disposal. However, in those individuals with impaired glucose tolerance and type II diabetes, the increased insulin is not sufficient and hyperglycemia ensues. As is discussed below, this increase in insulin contributes to the ill health which is associated with insulin resistance.

\subsubsection{Summary: Insulin}

The binding of insulin to its receptor stimulates a cascade of signaling events. These insulin stimulated signaling pathways regulate several physiological processes including glucose metabolism. Insulin sensitivity specifically refers to the ability of insulin to stimulate glucose disposal. Research suggests that impaired insulin stimulated glucose disposal occurs as a result of impaired stimulation of GLUT4 translocation and hexokinase transcription by insulin. These impairments ultimately result in decreased non-oxidative glucose disposal. 


\subsection{The Pathophysiology of Insulin Resistance: The Lipocentric View}

The pathophysiology of insulin resistance is not fully understood. One prominent paradigm, called the lipocentric view (53) (or ectopic fat model), describes a complex set of interactions between adipose tissue, skeletal muscle, and the liver. Simply put, the underpinning of this model is the strong association between the accumulation of lipid in ectopic sites (e.g. skeletal muscle, liver) and the development of insulin resistance. The lipocentric view will be briefly explored subsequently.

A few limitations of the following discussion warrant mention. Firstly, the discussion to follow is a simplified version of the lipocentric view. While out of the scope of this review, the liver and pancreas are integral components of this proposed pathophysiology. Additionally, due to necessity, some of the research presented below was conducted on type II diabetic individuals and their insulin resistant relatives. While individuals with type II diabetes and their relatives have impaired insulin stimulated glucose disposal, readers are reminded that there are a number of physiological abnormalities which may confound generalization to other, non-diabetic, populations.

\subsubsection{Ectopic Fat Deposition}

As was alluded to in Table 2-2, insulin stimulates lipogenesis and inhibits lipolysis (57). Specifically, insulin increases the activity of lipoprotein lipase (LPL) (58) and the expression of lipogenic enzymes, (59) while inhibiting hormone sensitive lipase (HSL) (31). Adipose tissue can become resistant to insulin, resulting in impaired clearance of circulating lipids and increased lipolysis in the presence of insulin (60). In other words, insulin resistant adipose tissue has an increased lipolytic rate and decreased lipid deposition during postprandial conditions. This results in the "overflow" of lipid from adipose tissues. 
Subcutaneous adipose tissue insulin resistance is proposed to play a role in the development of skeletal muscle insulin resistance. Lipid overflow from subcutaneous adipose tissue may result in the accumulation of lipid in less desirable locations such as skeletal and cardiac muscle, the liver, and visceral adipose tissue $(57,61)$. Evidence suggests that ectopic lipid accumulation contributes to the development of insulin resistance, whereas the deposition of lipid in subcutaneous adipose tissue is protective (61). For example, individuals matched for subcutaneous abdominal obesity but with either high or low visceral adipose tissue have significantly different levels of insulin sensitivity $(62,63)$. Conversely, insulin sensitivity is not different in individuals matched for visceral fat with either high or low subcutaneous adiposity $(62,63)$. Thus, it has been suggested that an individual's ability to cope with positive energy balance likely determines their susceptibility to developing skeletal muscle insulin resistance (61). In other words, those who can deposit excess lipid in subcutaneous adipose tissue are likely to have better metabolic health than those who develop adipose tissue insulin resistance and ectopic lipid accumulation. The cause of subcutaneous adipose tissue insulin resistance, and in turn the accumulation of ectopic lipid, remains poorly understood. It is likely the combined result of genetics $(64,65)$ and environmental factors such as smoking (66).

Research conducted on human and animal models of lipodystrophy supports the notion that impaired lipid deposition in insulin resistant subcutaneous adipose tissue results in the accumulation of lipid in ectopic sites and ultimately insulin resistance. Lipodystrophy is a condition characterized by partial or complete lack of adiposity. Individuals with lipodystrophy have extreme visceral lipid accumulation (67), and insulin resistance (67). Rodent models of lipdystrophy have lipid accumulation in tissues such as liver, skeletal and cardiac muscle, and extreme insulin resistance (68). Importantly, all 
aspects of the rodent lipodystrophy phenotype are alleviated in a dose response fashion with surgical implantation of adipose tissue (68).

Ectopically located lipids are hypertrophied and lipolytic. These lipids are resistant to the antilipolytic effect of insulin (69) while having increased sensitivity for the lipolytic effect of catecholamines (70). Accordingly, in addition to the elevated release of free fatty acids (FFA) from insulin resistant subcutaneous adipose tissue, ectopic fat also increases circulating lipid concentrations. As is discussed below, these increased circulating FFA are proposed to play a causal role in the development of insulin resistance.

\subsubsection{Intramuscular Triglycerides and Lipotoxic Metabolites}

There is a great deal of evidence to suggest that elevated levels of plasma FFA, resulting from insulin resistant adipose tissue and ectopic lipid accumulation, are involved in the pathogenesis of skeletal muscle insulin resistance. For example, in healthy controls there is a dose response relationship between exposure to FFA, via lipid infusion, and impairments in insulin signaling (71). It is postulated that elevations in FFA result in the accumulation of intramuscular triglycerides (IMTG) and that IMTG play a causal role in the development of insulin resistance. A strong negative correlation has been reported between insulin stimulated glucose disposal and the accumulation of IMTG (72). Furthermore, the development of insulin resistance after lipid infusion is directly associated with increases in skeletal muscle IMTG (73). However, given that triglycerides are metabolically inert, and endurance athletes with high insulin sensitivity have elevated IMTG, the role of triglycerides in the development of insulin resistance has been challenged (74).

Endurance athletes accumulate IMTG via an adaptive process brought about by repeated bouts of increased energy demand. Conversely, sedentary individuals develop 
IMTG due to a mismatch between supply and demand. Hence in endurance athletes, but not in sedentary individuals, the accumulation of IMTG in myocytes is matched by increased fat oxidation. Consequentially, when compared to endurance athletes, insulin resistant individuals have far less IMTG depletion/repletion cycles (75). Furthermore the matching of IMTG lipolysis and beta oxidation is suggested to be poor in those with impaired insulin sensitivity, in part because of an excess IMTG (75). Importantly, this lack of IMTG turnover and impaired coupling of lipolysis to lipid oxidation is proposed to results in the formation of lipotoxic metabolites such as FACoA (fatty acyl coenzyme A) and DAG (diacylglycerol) (75). There is some evidence that these metabolites play a causative role in the development of skeletal muscle insulin resistance $(76,77)$. Therefore it has been proposed that the accumulation of IMTG is associated with insulin resistance in sedentary individuals because it is a marker of increased lipotoxic metabolites.

In addition to the increased FFA supply, IMTG (and therefore lipotoxic metabolites) accumulation in the skeletal muscle of those with insulin resistance may be a result of decreased fat oxidation. This is evidenced by a negative correlation between rates of fasting lipid oxidation and insulin sensitivity (72). It has been postulated that this decreased lipid oxidation may be the result of a decrease in mitochondrial content and function $(78,79)$. This is a contentious issue however, as others challenge the role of mitochondrial dysfunction in the development of insulin resistance (80). Another notion which has been put forth is that fat oxidation may be decreased in those with insulin resistance due to an exaggerated distance between mitochondria and IMTG containing lipid droplets $(81,82)$. While the etiology of these postulated mitochondrial defects remains unknown, it has been suggested that lipotoxic metabolite accumulation may play a causal role $(46)$. 
In summary, the available evidence suggests that insulin resistant adipose tissue and excess lipolytic ectopic lipid results in increased delivery of FFA to the skeletal muscle. This increase in FFA is proposed to elevate skeletal muscle IMTG without a concomitant increase in lipid turnover. Consequentially, lipotoxic metabolites accumulate. Lipotoxic metabolites may also impair skeletal muscle oxidative capacity thus furthering the mismatch between fatty acid supply and demand. As is discussed below, lipotoxic metabolites are proposed to impair insulin signaling thereby decreasing insulin stimulated glucose disposal.

\subsubsection{Lipotoxic Metabolites and the Skeletal Muscle Insulin Signaling Cascade}

While it has been postulated that insulin resistance may be an acquired or hereditary genetic defect, investigators have not been able to locate abnormalities in the GLUT4 (83), hexokinase (84), or GS (85) genes. Thus an alternative hypothesis is that lipotoxic metabolites impair insulin signaling.

Research has demonstrated that lipotoxic metabolites, such as DAG and FACoA, are strong activators of protein kinase C (PKC), a serine/threonine kinase (86). In skeletal muscle, lipotoxic metabolites activate the PKC isoform, PKC $(87)$. PKC $\theta$ phosphorylates the IR and intracellular proteins (88). The activation of PKCO by lipotoxic metabolites has been demonstrated using lipid infusion studies. Studies conducted on both rodents (88) and humans (76) have reported that lipid infusion increases skeletal muscle FACoA and DAG. The increase in lipotoxic metabolites following lipid infusion was found to be associated with increased PKC $\theta$ activity, and consequentially, serine phosphorylation of IRS-1 $(76,88)$.

Serine phosphorylation has been implicated in the development of insulin resistance. Serine phosphorylation negates the ability of the IR and IRS-1 to undergo tyrosine phosphorylation (89), and induces the degradation of IRS-1 (90). As was 
previously mentioned, proteins with the $\mathrm{SH} 2$ domains such as $\mathrm{PI} 3 \mathrm{~K}$, require phosphotyrosine motifs in order to bind to intracellular proteins and become activated. Given the central role of PI3K in insulin stimulated glucose disposal, it seems reasonable that the impaired activation of this kinase, as a result of PKC $\theta$ induced serine phosphorylation, is associated with the development of insulin resistance. Cusi and colleagues found that the association between PI3K and IRS-1 was decreased in the skeletal muscle of type II diabetic and obese non-diabetic individuals (91). Importantly, they reported that the association between IRS and PI3K was strongly correlated with insulin stimulated glucose disposal. The importance of serine phosphorylation in the development of insulin resistance was well illustrated by Morino et al. who demonstrated that by preventing IRS-1 serine phosphorylation, the development of skeletal muscle insulin resistance following high fat feeding was prevented (92). Similarly, Kim and colleagues found that the inhibition of skeletal muscle PKC $\theta$ protected rats from fat induced insulin resistance (87).

In summary, lipotoxic metabolites activate PKC $\theta$ which, via serine phosphorylation, prevents IR and IRS tyrosine phosphorylation. Decreased tyrosine phosphorylation of IRS-1 impairs the activation of PI3K by insulin. The impaired activation of $\mathrm{PI} 3 \mathrm{~K}$ is strongly associated with insulin resistance. While there are still more questions than answers, it is likely that the impaired activation of PI3K by insulin is largely responsible for the decreased insulin stimulated GLUT4 translocation and glucose phosphorylation observed in those with insulin resistance. A summary of the role of lipotoxic metabolites in the development of insulin resistance is illustrated in

\section{Figure 2-2.}


Figure 2-2. Impairments in an Insulin Signal Transduction Pathway Brought About by Lipotoxic Metabolites

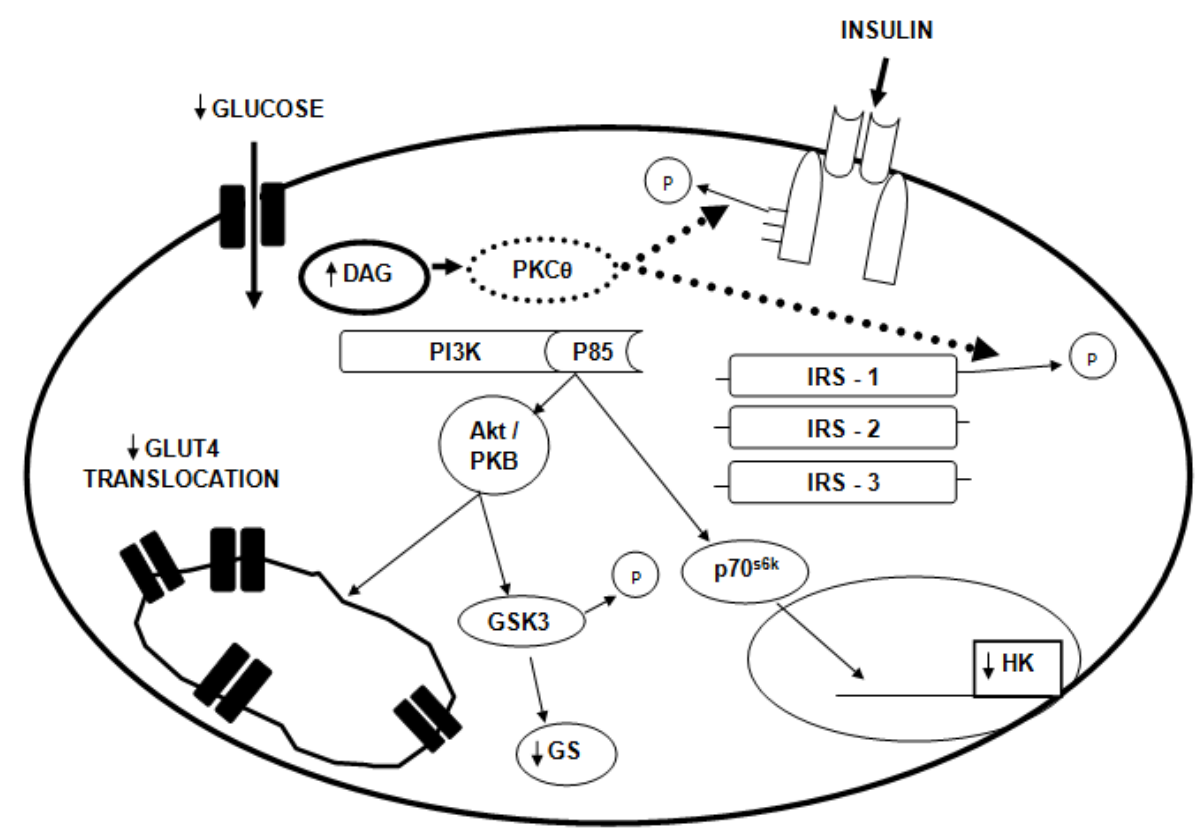

\subsubsection{Ectopic Lipid Accumulation, Adipokines and Insulin Resistance}

A detailed discussion of adipokines is out of the scope of this review. Readers are encouraged to read reviews written by Antuna-Puente (93), Rabe (94), and Wozniack (95) for more information. Briefly, adipose tissue acts as an endocrine organ secreting bioactive peptides called adipokines. Adipokines can act locally or distally through autocrine, paracrine, or endocrine effects (96). Adipokines are proposed to participate in the development of insulin resistance. In line with this notion, visceral adipose tissue, an ectopic fat, secretes a very different adipokine profile than subcutaneous adipose tissue. TNF $\alpha$ (tumor necrosis factor $\alpha$ ) was the first secreted product from adipose tissue to be proposed as a molecular link between obesity and insulin resistance (97). Since the discovery of TNFa, over a dozen adipokines have been identified. 


\subsubsection{Summary: The Pathophysiology of Insulin Resistance}

While there are many proponents of the lipocentric view, it is important to note

that several different causes have been proposed. A schematic diagram representing the lipocentric view found in this review is presented in Figure 2-3. This is a simplified approach to what is likely a very complex physiological process. The most important component of the lipocentric view, present in all models, is adipose tissue dysregulation.

\subsection{Insulin Resistance and III Health}

One of the primary reasons that insulin sensitivity has been so vastly researched is that a decrease in insulin stimulated glucose disposal is strongly correlated with ill health. Raven has stated that insulin resistance is not a disease per se, rather it is a physiological change which increases ones risk of developing an array of abnormalities (98). Table 2-3 provides a list of some of the abnormalities which are most strongly associated with impaired insulin stimulated glucose disposal. These abnormalities drastically increase ones risk of developing cardiovascular disease. Accordingly, prospective studies have repeatedly demonstrated a strong association between insulin resistance and cardiovascular disease $(3,4)$.

Cardiovascular disease is the number one global cause of mortality (13). According to the World Health Organization, in 2004 there were 17.1 million global cardiovascular disease deaths and by 2030 this is estimated to increase to 24 million (13). Thus, given the global burden of cardiovascular disease and the strong association between cardiovascular disease and insulin resistance, establishing treatment options designed to improve insulin sensitivity is paramount.

As is discussed next, chronic exercise can dramatically increase one's insulin sensitivity. Accordingly, exercise can be used as a treatment strategy for insulin resistance and to prevent cardiovascular disease. Unfortunately, however, the exercise 
Figure 2-3. Schematic Diagram Representing the Lipocentric View

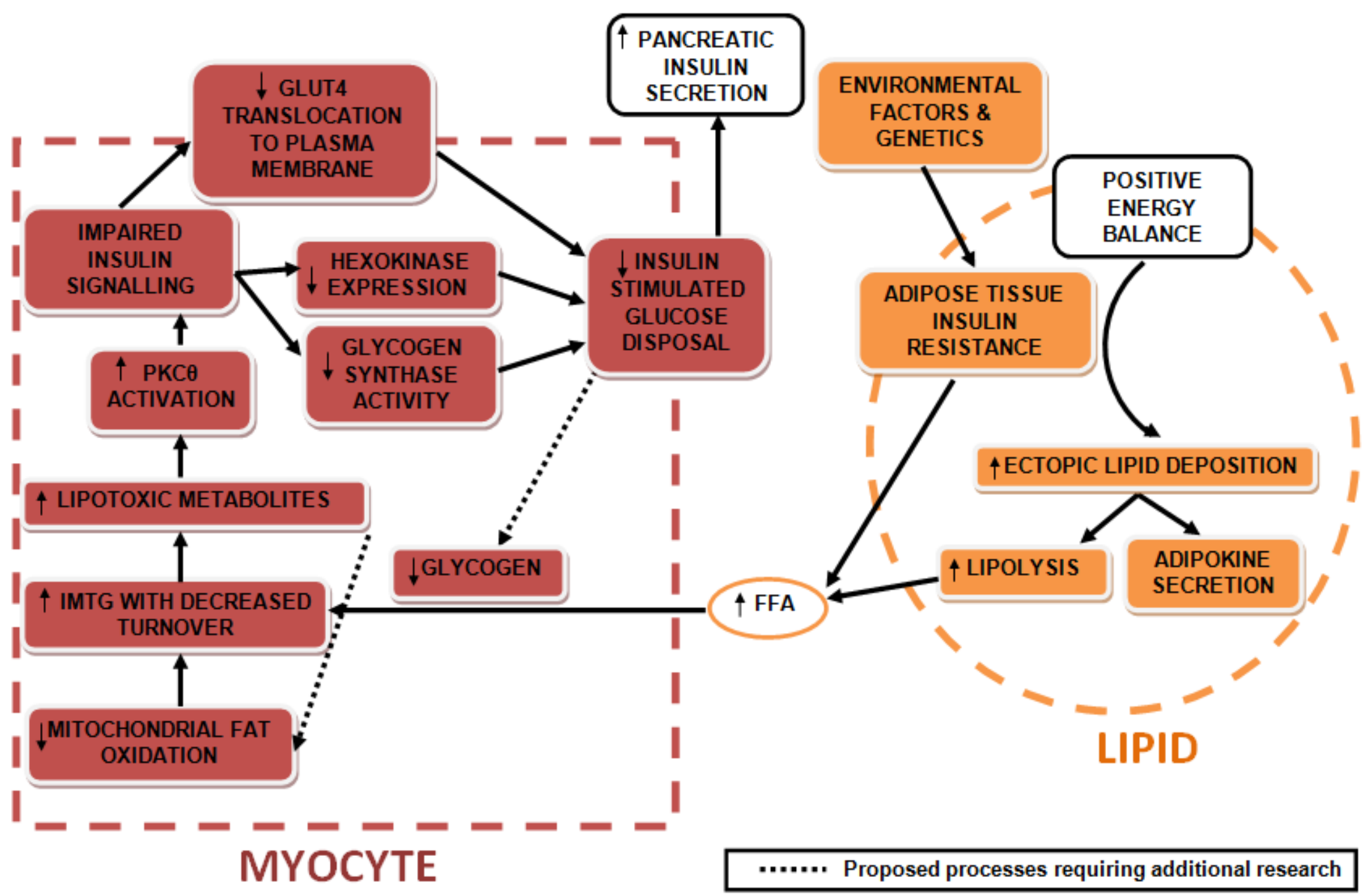


Table 2-3. Physiological Abnormalities Associated With Insulin Resistance.

\begin{tabular}{|c|c|c|c|c|}
\hline Abnormality & $\begin{array}{c}\text { Unadjusted } \\
\text { Correlation With } \\
\text { Insulin } \\
\text { Sensitivity } \\
\end{array}$ & $\begin{array}{c}\text { Adjusted } \\
\text { Correlated With } \\
\text { Insulin Sensitivity }\end{array}$ & $\begin{array}{l}\text { Insulin Sensitivity } \\
\text { Measurement } \\
\text { Technique }\end{array}$ & Variables Adjusted For \\
\hline Uric acid concentration (99) & $0.69, p<0.001$ & $0.47, p<0.001$ & IST & $\begin{array}{l}\text { Abdominal obesity, age } \\
\text { sex \& total obesity }\end{array}$ \\
\hline Plasma triglycerides (99) & $0.59, p<0.001$ & $0.48, p<0.01$ & IST & $\begin{array}{c}\text { Abdominal obesity, age } \\
\text { sex \& total obesity }\end{array}$ \\
\hline HDL cholesterol (100) & $-0.41, p<0.001$ & $-0.46, p<0.001$ & IST & Sex \\
\hline $\begin{array}{l}\text { Decreased LDL partial } \\
\text { diameter }(101)\end{array}$ & $0.44, p<0.001$ & $0.39, p<0.001$ & IST & Age, BMI \& sex \\
\hline $\begin{array}{l}\text { Increased blood pressure } \\
\qquad(102)\end{array}$ & $\begin{array}{c}\text { Systolic } \\
0.18, p<0.005 \\
\text { Diastolic } \\
0.34, p<0.0001\end{array}$ & $\begin{array}{c}\text { Systolic } \\
0.15, p<0.01 \\
\text { Diastolic } \\
0.19, p<0.01\end{array}$ & Clamp & $\begin{array}{c}\text { Age, BMI, fasting insulin } \\
\& \text { sex }\end{array}$ \\
\hline $\begin{array}{l}\text { Increased plasminogen } \\
\text { activator inhibitor } 1 \text { (103) }\end{array}$ & $0.43, p<0.0001$ & $0.31, p<0.0001$ & Minimal Model & Age, BMl ethnicity \& sex \\
\hline Increased fibrinogen (103) & $0.24, p<0.6001$ & $0.10, p<0.0001$ & Minimal Model & $\begin{array}{c}\text { Age, BMI, ethnicity \& } \\
\text { sex }\end{array}$ \\
\hline $\begin{array}{l}\text { Soluble adhesion factor } \\
\text { (sE-selectin) (104) }\end{array}$ & $0.54, p<0.005$ & $0.62, p<0.05$ & IST & $\begin{array}{c}\text { Age, BMI, plasma } \\
\text { triglycerides, } \\
\text { HDL \& LDL cholesterol, } \\
\text { \& sex }\end{array}$ \\
\hline
\end{tabular}


exposure(s) which can evoke the optimal improvement in insulin sensitivity is still poorly understood. More specifically, it remains unknown if exercise intensity can independently influence insulin sensitivity. Thus, although exercise is an effective strategy for the reduction of insulin resistance, and hence the global burden of cardiovascular disease, additional research is needed to maximize the benefit from this lifestyle change.

While exercise is theoretically an ideal treatment strategy for the improvement of insulin sensitivity, the practical application of this in a clinical setting is challenging. The convenience of pharmaceutical treatment options is likely to deter patients from adopting exercise to improve their insulin sensitivity. Additionally, stimulating behavior change, particularly with respect to physical activity, is difficult. For example, more than $80 \%$ of the population fails to meet the current physical activity guidelines (105). In other words, in spite of expert recommendations, the majority of the population has failed to adopt an active lifestyle.

\subsection{Chronic Exercise and Insulin Sensitivity}

Björntorp et al. (5) and Richter et al. (106) were among the first to demonstrate that exercise can increase insulin sensitivity. In the more than 30 years since these preliminary findings, considerable insight has been gained into the efficacy of exercise to improve insulin sensitivity. A brief description of the acute effects of exercise on insulin sensitivity is given below. This is followed by the general presentation of chronic exercise induced improvements in skeletal muscle insulin sensitivity. Subsequently, available literature written on the mechanisms by which chronic exercise improves skeletal muscle insulin sensitivity is discussed. 


\subsubsection{Acute Effects of Exercise on Insulin Sensitivity}

Via a series of intramyocellular events acute exercise stimulates an early and late phase increase in skeletal muscle glucose transport. Briefly, the early phase of elevated glucose uptake is attributed to an increased translocation of glucose transporters (GLUT4) $(107,108)$. This increase in GLUT4 translocation reverses within 2-3 hours and is replaced by the late phase of increased glucose uptake which lasts between 18-48 hours $(109,110)$. While it is often stated that this late phase is the consequence of enhanced insulin sensitivity, the elevated glucose uptake is not specific to insulin (111). It has been proposed that the late phase elevated glucose uptake may be the consequence of contraction induced increases in GLUT 4 protein content. This is evidenced by a nearly $50 \%$ increases in GLUT 4 expression in skeletal muscle following a single bout of exercise $(112,113)$.

\subsubsection{The Presentation of Chronic Exercise Induced Improvements In Skeletal Muscle Insulin Sensitivity}

Chronic exercise improves insulin stimulated glucose disposal and consequentially increases in non-oxidative glucose disposal (114). In fact, nearly all of the additional glucose which is taken up as a result of improved insulin sensitivity following chronic exercise is directed to glycogen formation (6). It has been reported that this increased glycogenesis results in increased glycogen content (115). As a result of the improved glucose regulation, fasting insulin levels generally have a trend to improve (lower) following training (116). However significant changes in fasting insulin are not always found (117).

\subsubsection{Chronic Exercise and Ectopic Fat}

The underpinning of the lipocentric model is the accumulation of ectopic lipid. There is a preferential reduction of ectopic lipid, specifically visceral adipose tissue, with 
chronic exercise $(118,119,120)$. While the mechanism responsible for the preferential reduction in visceral lipid is poorly understood, the negative energy expenditure brought about by exercise, and the improvement in adipose tissue insulin sensitivity (121), likely contribute. With less ectopic fat and improvements in adipose tissue insulin sensitivity, circulating levels of FFA decrease. For example, following aerobic training, previously sedentary obese men (122) as well as obese type II diabetic men (123) have decreased circulating FFA.

\subsubsection{Chronic Exercise, Intramuscular Triglycerides, Lipotoxic Metabolites}

Although circulating levels of FFA decrease with exercise, it is not clear if IMTG also decrease. Recently, Dubé and colleagues found that following 16 weeks of moderate intensity exercise training, obese men and women have increased IMTG (115). As aforementioned, Goodpaster and colleagues have described an "athlete's paradox" in which highly insulin sensitive endurance athletes have elevated IMTG content (74). This occurs as an adaptive process to repeated periods of energy expenditure. It is likely that the duration and type of training dictate whether IMTG will change in insulin resistant individuals following exercise training.

Regardless of IMTG content, training decreases the concentration of lipotoxic metabolites. In the same study described above, Dubé et al. report that despite increased IMTG, lipotoxic metabolites were decreased following training (115). Similarly, in a study conducted by Bruce and colleagues, following 8 weeks of endurance training obese participants had improvements in insulin sensitivity and decreases in lipotoxic metabolites without altering IMTG (124). There are 2 pathways by which chronic exercise may decrease lipotoxic metabolites. Firstly, training results in more frequent bouts of energy expenditure thereby increasing IMTG turnover. Secondly, exercise training results in improved mitochondrial function $(125,126)$. Improvements in 
mitochondrial function would increase oxidative capacity thereby resulting in increased IMTG turnover as well as better matching between oxidation and lipolysis.

\subsubsection{Chronic Exercise and Skeletal Muscle Insulin Signaling}

While investigators have examined the effect of exercise on lipotoxic metabolites, the direct effects of exercise on PKC $\theta$ activity remains unknown. However, PKC $\theta$ is proposed to impair insulin signaling, and the effect of chronic exercise on insulin signaling has been examined, with conflicting results being produced (127). Kirwan and colleges found that insulin stimulated IRS-1 associated PI3K activation was significantly greater in endurance trained athletes when compared to sedentary adults (128). Likewise, following 6 weeks of training, rats were found to have increased IR and IRS-1 phosphorylation, and increased IRS-1 associated PI3K activity (129). Moreover, following exercise training, previously sedentary individuals were found to have improved insulin stimulated PI3K activation (130). Conversely, Frøsig et al. reported that while 3 weeks of one-legged knee extensor exercise resulted in $60 \%$ more insulin stimulated glucose disposal, basal and insulin stimulated IRS-1 associated PI3K activity were reduced (131). Recall, reduced IRS-1 association with PI3K represents decreased IRS-1 tyrosine phosphorylation. Similarly, Christ-Roberts and colleagues found that exercise training did not improve insulin stimulated PI3K signaling in overweight nondiabetic and diabetic participants (132). These findings have been also been produced in obese Zucker rats (133).

In summary, it remains to be determined if exercise induced improvements in insulin sensitivity are attributable to improvements in insulin signal transduction. The discrepant research is likely in part due to differences in the training stimulus, training status, and the muscle and/or fiber type being assessed (127). 


\subsubsection{Chronic Exercise May Increase Insulin Stimulated Glucose Disposal via a Compensatory Mechanism}

The laboratory of John Ivy has put forth a hypothesis by which exercise may stimulate increases in insulin stimulated glucose disposal in the absence of improvements in insulin signaling. It is proposed that exercise creates a compensatory

mechanism by which impaired insulin signaling is bypassed, rather than corrected. More specifically, it is suggested that exercise moves GLUT4 from a plasma membrane associated state to the cell surface via mechanisms distinct from the insulin signaling cascade $(132,134)$. As GLUT4 transcription is regulated by contraction (135), aerobic training results in increased GLUT4 content in both lean (136) and obese individuals (132). Accordingly, more GLUT4 will be moved from the plasma membrane associated state to the cell surface in those that have exercised. Consequentially, insulin will stimulate excess glucose uptake in those that are trained despite impaired insulin signaling.

Evidence supporting this notion comes from 2 similar trials using obese Zucker rats $(137,138)$. When compared to controls, exercise trained rats had more GLUT4 associated with the plasma membrane during the basal state, and a marked increase in insulin stimulated glucose disposal. However, when compared to the basal conditions, insulin did not elevate GLUT 4 trafficking $(137,138)$. Thus, although the trained obese rats had increased amounts of insulin stimulated glucose disposal, the insulin stimulated GLUT4 trafficking known to facilitate this did not occur $(137,138)$. These results suggest that in the trained rodents insulin stimulated glucose uptake by way of a mechanism other than the insulin signaling cascade.

Muscle contractions also increase the protein expression of hexokinase (139) and stimulate the activity of GS (140). In the one legged knee extensor exercise trial conducted by Frøsig et al., training resulted in a $60 \%$ increase in insulin stimulated 
glucose disposal (131). Despite the reduction in IRS-1 associated PI3K activity, the increase in glucose disposal coincided with increased activity of GS and expression of GLUT 4 and hexokinase. The authors concluded, like Ivy and colleagues, that improvements in insulin sensitivity following chronic exercise are likely the result of contraction induced increases in protein content rather than improvements in insulin signaling.

\subsection{Hexokinase Expression: Diet / Exercise Interactions}

Given the above notion, that alterations in hexokinase expression may be associated with the improvement of insulin sensitivity brought about by chronic exercise, it is important to briefly discuss diet / exercise interactions. Recall, like skeletal muscle contraction, insulin stimulates the expression of hexokinase within the skeletal muscle of insulin sensitive individuals. For example, 4 hours of insulin infusion increases the expression, protein content and action of hexokinase within the skeletal muscle of healthy human participants (22). While the nutritional regulation of hexokinase has yet to be extensively studied, this effect of insulin on hexokinase, taken together with preliminary findings in humans (141), suggests that dietary intake may influence hexokinase activity. As hexokinase expression is a postulated avenue by which chronic exercise may increase insulin sensitivity, researchers should be cognoscente of the confounding effects of diet.

\subsubsection{Summary: Chronic Exercise and Skeletal Muscle Insulin Sensitivity}

In summary, chronic exercise increases insulin stimulated glucose uptake in the skeletal muscle. Most of the additional glucose absorbed by the skeletal muscle as a consequence of exercise training enters non-oxidative glucose disposal. Lipotoxic metabolites are proposed to impair insulin signaling and their accumulation within the skeletal muscle is attenuated as a result of chronic exercise. However, because 
research into the effect of exercise on skeletal muscle insulin signaling has yielded discrepant findings, it is not clear if decreases in lipotoxic metabolites are the cause of exercise induced improvements in insulin sensitivity. It has recently been proposed that exercise may create a compensatory mechanism by which insulin may bypass the damaged signaling cascade and stimulate glucose uptake.

Thus, while we have known for over 30 years that exercise can improve insulin sensitivity, the molecular mechanisms through which this occurs remain poorly understood. In addition to these uncertainties, the independent effect of exercise intensity on insulin sensitivity is also an area of considerable debate.

\subsection{Exercise Intensity and the Improvement of Insulin Sensitivity}

Chronic exercise prescriptions are characterized by the variables, dose (caloric expenditure), duration (time), and intensity. While it is well accepted that exercise improves insulin sensitivity, the independent contribution of each of these variables remains unclear. More specifically, research into the independent effect of exercise intensity on insulin sensitivity has yielded discrepant results. Whereas some have found that exercise intensity independently effects insulin sensitivity $(6,7,8,9)$, others have produced opposing results $(10,11,12)$. Isolating the independent contributions of exercise dose, duration, and intensity is important for clinicians wishing to prescribe exercise as a treatment for insulin resistance. For this reason, in Chapter 3, the independent effect of exercise intensity on insulin sensitivity will be investigated.

Outlined below is a summary of investigations examining the effect of exercise intensity on insulin sensitivity, as well as their respective limitations. A summary of each of these studies is also found in Table 2-4. A brief summary of literature written on high intensity interval training and insulin sensitivity is also provided. Lastly, a potential mechanism through which exercise intensity might independently improve insulin 
Table 2-4. Research Examining the Effect of Exercise Intensity on Insulin Sensitivity.

\begin{tabular}{|c|c|c|c|c|c|c|c|}
\hline First Author & $\begin{array}{l}\text { Study } \\
\text { Type }\end{array}$ & Length & \# & Sex & $\begin{array}{c}\text { Age } \\
\text { (years) }\end{array}$ & Training Protocol & Result \\
\hline Seals (9) & NR & 12 months & 21 & $\mathrm{M} / \mathrm{F}$ & $63 \pm 1.5$ & $\begin{array}{l}\text { LI: } 60 \% \text {, HI: } 80-90 \% \text { of } \mathrm{HRmax} \\
\sim 30 \text { minutes, } 3-4 \text { days / week }\end{array}$ & $\begin{array}{l}\text { LI: } \uparrow \\
\text { HI: } \uparrow \uparrow\end{array}$ \\
\hline Kang (8) & NR & 1 week & 6 & M & $43 \pm 2.5$ & 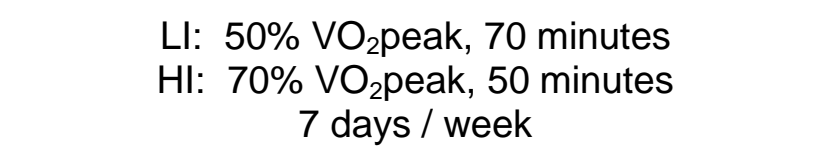 & $\begin{array}{l}\text { LI: }= \\
\text { HI: } \uparrow\end{array}$ \\
\hline DiPietro (7) & $\mathrm{RCT}$ & 9 months & 25 & $\mathrm{~F}$ & $73 \pm 10$ & $\begin{array}{c}\text { LI: } 65 \%, \mathrm{HI}: 80 \% \mathrm{VO}_{2} \text { peak } \\
300 \mathrm{kcal} / \text { session, } 4 \text { days / week }\end{array}$ & $\begin{array}{l}\mathrm{LI}:= \\
\mathrm{HI}: \uparrow\end{array}$ \\
\hline Coker (6) & $\mathrm{RCT}$ & 3 months & 21 & $\mathrm{M} / \mathrm{F}$ & $74 \pm 1$ & $\begin{array}{c}\text { LI: } 50 \% \mathrm{VO}_{2} \text { peak, HI: } 75 \% \mathrm{VO}_{2} \text { peak } \\
1000 \mathrm{kcal} / \text { week, 4-5 days / week }\end{array}$ & $\begin{array}{l}\text { LI: }= \\
\mathrm{HI}: \uparrow\end{array}$ \\
\hline Hughes (12) & NR & 3 months & 18 & $\mathrm{M} / \mathrm{F}$ & $64 \pm 2$ & $\begin{array}{c}\text { LI: } 50 \% \text {, HI: } 75 \% \text { HRR } \\
55 \text { minutes, } 4 \text { days / week }\end{array}$ & $\begin{array}{l}\text { LI: } \uparrow \\
\mathrm{HI}: \uparrow\end{array}$ \\
\hline Houmard (11) & $\mathrm{RCT}$ & 6 months & 154 & $\mathrm{M} / \mathrm{F}$ & $\sim 52$ & $\begin{array}{l}\text { LD/LI: } 40-55 \% \text { of } \mathrm{VO}_{2} \text { peak, } 1200 \mathrm{kcal} / \text { week } \\
\text { LD/HI: } 65-80 \% \text { of } \mathrm{VO}_{2} \text { peak, } 1200 \mathrm{kcal} / \text { week } \\
\mathrm{HD} / \mathrm{HI}: 65-80 \% \text { of } \mathrm{VO}_{2} \text { peak, } 2000 \mathrm{kcal} / \text { week }\end{array}$ & $\begin{array}{l}\text { LD/LI: } \uparrow \uparrow \\
\text { LD/HI: } \uparrow \\
\mathrm{HD} / \mathrm{HI}: \uparrow \uparrow\end{array}$ \\
\hline $\begin{array}{c}\text { O’Donovan } \\
(10)\end{array}$ & $\mathrm{RCT}$ & 6 months & 36 & M & $\sim 41$ & $\begin{array}{c}\text { LI: } 60 \% \text {, HI: } 80 \% \mathrm{VO}_{2} \text { peak } \\
400 \mathrm{kcal} / \text { session, } 3 \text { days / week }\end{array}$ & $\begin{array}{l}\text { LI: } \uparrow \\
\mathrm{HI}: \uparrow\end{array}$ \\
\hline
\end{tabular}


sensitivity is described.

\subsubsection{Exercise Intensity Is Associated With the Improvement of Insulin Sensitivity}

The laboratory of J. Holloszy published one of the first reports examining the effect of exercise intensity on insulin sensitivity (9). Sedentary, older (63 \pm 1.5 years), men and women participated in this study. Of the 24 participants, 10 were assigned to a non-exercise control group whereas 11 completed a 12 month exercise protocol. The exercise protocol consisted of 6 months of low intensity exercise (3-4 days of unsupervised walking at $\sim 60 \%$ of maximum heart rate for 30 minutes) followed by 6 months of high intensity training (3-4 of supervised jogging at $80-90 \%$ of maximum heart rate for 30-45 minutes). Insulin sensitivity was measured by an oral glucose tolerance test (OGTT) 14 hours after the last training session. The high intensity exercise resulted in a significant improvement in insulin sensitivity whereas the low intensity exercise did not. However, the high intensity exercise protocol also required a greater dose of exercise making it difficult to discern whether the improvements observed following the high intensity protocol were attributable to the elevated intensity, the dose, or both. It is possible, due to the decreased dose and low intensity, that investigators were underpowered to detect an improvement following the low intensity training. Additionally, the low intensity exercise was self reported. This may confound results as concern has been raised regarding the accuracy of self reported exercise data (142). Lastly, insulin sensitivity was measured 14 hours post- exercise, undoubtedly capturing some of the acute effects of the most recent training session.

Kang and colleagues used a counterbalanced study design to examine the effects of exercise intensity on insulin sensitivity (8). Participants included 6 obese men with normal glucose tolerance ( $43 \pm 2.5$ years) and 6 men with type II diabetes $(44 \pm 1.6$ 
years). All of the participants completed a 7 day exercise program in a counterbalanced order at 2 week intervals. During the 7 day training period, participants exercised at $50 \%$ peak oxygen consumption ( $\mathrm{VO}_{2}$ peak) for 70 minutes or at $70 \% \mathrm{VO}_{2}$ peak for 50 minutes. As measured by an OGTT 24 hours after the last exercise session, the type II diabetic participants had no improvements in insulin sensitivity. Interestingly, despite being matched for exercise dose, the obese men had improvements in insulin sensitivity following high intensity, but not low intensity training. It should be considered that training was only 1 week in duration, sample size was very small, and that participants were asked to maintain body weight.

DiPietro et al. preformed a well designed investigation wherein the relationship between exercise intensity and insulin sensitivity was examined in a group of 25 older (73 \pm 10 years), sedentary women (7). This is the only study to date that has examined the effect of exercise intensity on insulin sensitivity in a population comprised solely of women. In this 9 month randomized controlled trial women were placed into 3 groups; 1) control, stretching $(n=7) ; 2)$ moderate intensity exercise, $65 \% \mathrm{VO}_{2}$ peak $(n=9)$; or 3$)$ high intensity exercise, $80 \% \mathrm{VO}_{2}$ peak $(n=9)$. All exercise groups exercised 4 days per week and expended $300 \mathrm{kcal}$ per exercise session. Insulin sensitivity was measured using an OGTT 48 hours post-exercise, and a hyperinsulinemic euglycemic clamp 72 hours post-exercise. Only the high intensity exercise evoked significant changes in insulin sensitivity. It should be noted that despite recruiting sedentary participants, no change in $\mathrm{VO}_{2}$ peak was reported following the 9 months of training. As well, body composition was unchanged despite advising participants to maintain baseline dietary intake. Furthermore, physical activity questionnaires suggest that the moderate intensity training group may have decreased their leisure time physical activity. Lastly, $\mathrm{VO}_{2}$ peak testing was not repeated regularly throughout the intervention. The results from $\mathrm{VO}_{2}$ peak 
tests are used to prescribe exercise and estimate dose and intensity. As participants improve their fitness the results from $\mathrm{VO}_{2}$ peak tests change. Failure to re-measure $\mathrm{VO}_{2}$ peak can result in incorrect estimation of exercise dose and intensity.

Coker et al. completed a 12 week randomized controlled trial. Elderly participants ( $n=21,74 \pm 10$ years) exercised at either $50 \% \operatorname{VO}_{2}$ peak $(n=7), 75 \% \operatorname{VO}_{2}$ peak $(n=7)$, or served as control $(n=7)$ (6). Participants exercised 4 to 5 times per week and expended a total of $1000 \mathrm{kcal}$ per week. A eyglycemic hyperinsulinemic clamp was used to assess insulin sensitivity 72 hours after the last exercise session. Only high intensity exercise increased insulin sensitivity. When considering the results of this trial it is important to note that $\mathrm{VO}_{2}$ peak testing was not completed throughout the intervention. Despite being told to maintain baseline dietary habits throughout the 3 month trial, it appears that there was no change in body composition. Furthermore, it is not clear if the participants were instructed how to accrue the $1000 \mathrm{kcal}$ per week (i.e. were they required to expend $200 \mathrm{kcal}$ per session).

\subsubsection{Continuum vs. Threshold Effect}

An interesting observation from the studies of Kang et al., DiPietro et al., and Coker et al., is that despite being matched for exercise dose, only the high intensity exercise group had improvements in insulin sensitivity. In other words, despite having the same caloric expenditure as the high intensity group, insulin sensitivity did not improve following low intensity exercise. These findings suggest that for a given exercise dose, the effect of exercise intensity on insulin sensitivity may exhibit a threshold relationship. These results may be due to study design limitations. For example, if exercise intensity acts along a continuum, perhaps the sample size was too small in the low intensity exercise groups to detect the lesser effect of low intensity exercise on insulin sensitivity. 


\subsubsection{Exercise Intensity Is Not Associated With the Improvement of Insulin Sensitivity}

Hughes et al. completed a trial in which 18 older (64 \pm 2 years), sedentary men and women, with impaired or non-diagnostic oral glucose tolerance were separated into 2 exercise groups (12). The first 9 participants exercised for 55 minutes at $75 \%$ heart rate reserve, 4 days per week. The other 9 participants exercised for the same duration and frequency at 50\% heart rate reserve. Exercise training lasted 3 months and participants were instructed to consume a weight maintenance diet. Insulin sensitivity increased in both groups similarly as assessed by an OGTT and a hyperinsulinemic euglycemic clamp completed 72 and 96 hours post-exercise, respectively. The authors concluded that the improvements of insulin sensitivity is independent of exercise intensity and, in fact may be determined more by exercise duration. Similar to Seals et al., one limitation of this study design is that exercise dose was not held constant in the exercise groups.

In the Studies of Targeted Risk Reduction Through Defined Exercise (STRRIDE) Houmard and colleagues completed a randomized controlled trial in which 154 sedentary, middle aged ( 52 years), overweight men and women with dyslipidemia were assigned to 4 groups (11). The groups included; low dose / low intensity $(n=41$, $1200 \mathrm{kcal}$ per week at $40-55 \%$ of $\mathrm{VO}_{2}$ peak), low dose / high intensity ( $\mathrm{n}=30,1200 \mathrm{kcal}$ per week at $65-80 \%$ of $\mathrm{VO}_{2}$ peak), high dose / high intensity ( $n=43,2000$ kcal per week at $65-80 \%$ of $\mathrm{VO}_{2}$ peak) and non-exercise control $(n=40)$. Participants chose an appropriate exercise frequency to achieve the weekly dose, and exercise lasted for 6 months. Using blood samples collected 24 hours after the last exercise session, insulin sensitivity was assessed by the minimal model technique. Insulin sensitivity improved similarly in the low dose/ low intensity and high dose / high intensity groups. These 
improvements were greater than those observed in the low dose / high intensity group. Accordingly, similar to Hughes et al., the authors concluded that it is the duration of exercise, rather than the intensity or the dose, which dictates the improvement of insulin sensitivity. Several areas of this investigation must be considered when interpreting the aforementioned findings. Firstly, peak oxygen uptake tests were not repeated during the 6 month intervention to account for improvements in fitness. Although participants were asked to consume a weight maintenance diet, those participants in the low dose / low intensity, and high dose / high intensity had significant reductions in weight. The low dose /high intensity group has less participants than the other training groups. The participants also chose the frequency and duration of exercise, and they were not always supervised.

In a more recent report, O'Donovan et al. found that the dose of exercise, but not the duration or intensity, contributes to the improvement in insulin sensitivity (10). In this well designed 6 month long investigation 64 middle aged ( 41 years), sedentary men were randomly assigned to 3 groups. The groups included; 1$)$ a control group $(n=13)$, 2) a moderate intensity group ( $\mathrm{n}=10,60 \% \mathrm{VO}_{2}$ peak), and 3 ) high intensity group $(\mathrm{n}=$ $13,80 \% \mathrm{VO}_{2}$ peak). In both groups, participants exercised 3 days per week and expended $400 \mathrm{kcal}$ per session. In an attempt to improve on the STRRIDE study design, investigators repeated peak oxygen uptake tests and re-prescribed training heart rates to account for improvements in fitness every month. Insulin sensitivity was measured using the homeostasis model assessment of insulin resistance (HOMA-IR) and the formula of McAuley and Colleagues (143). Blood samples used for the assessment of insulin sensitivity were collected 24 hours post-exercise. The improvements in insulin sensitivity were the same in both groups despite the variation in exercise duration. A few elements of this study design should be considered when interpreting the results. 
First exercise was self reported as it was completed ad libitum at a fitness center. Additionally there were a high number of drop outs (40\%).

\subsubsection{High Intensity Interval Training and the Improvement of Insulin Sensitivity}

A review of the literature regarding the influence of exercise intensity on insulin sensitivity would be incomplete without making reference to high intensity interval training (IT). While these studies do present intriguing evidence regarding the potency of exercise intensity, to date research using this exercise protocol has not been designed to examine the independent effect of exercise intensity. Accordingly, in the studies presented below it is difficult to disentangle whether insulin sensitivity improved as a consequence of the exercise intensity, caloric expenditure, or both.

High intensity interval training (IT) is characterized by brief bursts of physical activity interspersed with periods of rest or low intensity activity (144). Initially studied using highly trained athletes, this novel form of training is recognized for its ability to stimulate metabolic adaptations similar to endurance training in a fraction of the time $(145,146)$. There are several different types of IT. For example, sprint IT consists of 30 second Wingate tests separated by 4 minutes of recovery, repeated 4 - 7 times (147). Conversely, the IT prescribed by Nybo and colleagues consisted of 2 minute intervals completed at $95 \%$ maximum heart rate separated by 1 minute of recovery, repeated 5 times (148). Until recently, little has been known about the effect of IT on insulin sensitivity (144). Below, the results of 5 studies which have examined the ability of IT to stimulate improvements in insulin sensitivity are discussed.

Babraj et al. (149), Richards et al.(150) and Whyte et al.(151) used similar training protocols to examine high intensity interval training as a strategy to improve insulin sensitivity. The training protocol in all 3 studies required participants to complete 6 exercise sessions over 14 days. During each session 4-7 Wingate Tests (30 second 
'all out' high intensity sprints) were completed, each followed by approximately 4 minutes of recovery. Babraj et al. measured insulin sensitivity 48 hours after the last exercise bout using an OGTT whereas Richards et al. used a hyperinsulinemic euglycemic clamp 72 hours after training. In both studies IT significantly improved insulin sensitivity. Interestingly Whyte and colleagues reported that insulin sensitivity, as measured by an OGTT, was significantly improved 24 hours but not 72 hours post training.

Tjønna et al. (152) and Nybo et al. (148) examined the effect of IT versus traditional continuous aerobic type training. The IT protocol used by Nybo is described previously. Tjønna et al. prescribed four, 4 minute intervals at 90\% maximal heart frequency, each separated by 3 minutes of active recovery. Lasting 12 weeks in duration, Nybo et al. recruited healthy young men for their trial whereas Tjønna and colleagues recruited participants with the metabolic syndrome for their 6 weeks investigation. In both studies the interval training evoked significant improvements in insulin sensitivity when compared to controls. Additionally these improvements were significantly greater than those brought on by the continuous aerobic training protocol.

\subsubsection{Mechanism by Which Exercise Intensity Might Independently Effect Insulin Sensitivity}

In addition to serving as a major fuel source for contracting muscles, it has been reported that that skeletal muscle glycogen content may play a regulatory role in the transcription of several genes involved in substrate metabolism (153). Available evidence suggests that the transcription of pyruvate dehydrogenase kinase 4 (154), uncoupling protein 3 (154), citrate synthase (155), interleukin 6 (156), and GS (157) may be potentiated by low pre-exercise muscle glycogen content. While the mechanisms linking glycogen content to the control of gene transcription are not clear, this may have 
important implications for the independent effect of exercise intensity on insulin sensitivity.

When matched for dose, high intensity exercise utilizes more skeletal muscle glycogen than low intensity exercise in both lean (158) and obese individuals (8). Therefore, individuals completing regular high intensity bouts may have lower preexercise skeletal muscle glycogen content. This would result in increased skeletal muscle gene transcription. This elevated gene transcription may participate in chronic exercise induced insulin sensitivity via 2 pathways. Firstly, as was mentioned above, it has recently been proposed that exercise may bring about a compensatory mechanism able to bypass impaired insulin signaling (134). A major component of this mechanism is contraction induced expression of proteins such as GLUT4 and hexokinase. Secondly, the expression of mitochondrial enzymes stimulated by contraction is hypothesized to decrease the accumulation of lipotoxic metabolites within skeletal muscle. Kelley et al. reported that improvements in oxidative capacity following exercise training were the strongest predictor of improvements in insulin sensitivity (78). Thus, if by way of glycogen depletion, increasing exercise intensity stimulates greater expression of proteins directly involved in glucose uptake and/or mitochondrial function, insulin sensitivity might be associated with the intensity at which one exercises.

\subsubsection{Summary: Exercise Intensity and Insulin Sensitivity}

More than a century ago investigators reported that exercise can improve insulin sensitivity $(5,106)$. Since then, researchers have been working to determine the exercise exposure(s) which can evoke the optimal improvement of insulin sensitivity. To date the independent effect of exercise intensity on insulin sensitivity remains unclear. Whereas some have reported that exercise intensity is independently associated with the improvement of insulin sensitivity $(6,7,8,9)$, others have yielded opposing results 
$(10,11,12)$. Glycogen depletion is a mechanism through which exercise intensity might elicit independent effects on insulin sensitivity. However, research is needed in order to verify how glycogen content modulates gene transcription, and which genes are regulated by this process.

\subsection{Summary: Literature Review}

Individuals with adipose tissue insulin resistance have a spillover of energy to ectopic sites including skeletal muscle. The accumulation of lipid in these depots results in the development of lipotoxic metabolites. Lipotoxic metabolites are proposed to directly impair insulin signaling, resulting in decreased insulin stimulated glucose disposal. Impairments in insulin stimulated glucose disposal are associated with physiological abnormalities, such as hypertension. These abnormalities dramatically increase ones risk of developing cardiovascular disease, the number one global cause of mortality.

Given the global burden of cardiovascular disease, identifying strategies for the improvement of insulin sensitivity and thus the attenuation of cardiovascular disease risk is paramount. Exercise is a well recognized as a stimulus for the improvement of insulin sensitivity. However, it is not yet clear how exercise training improves insulin stimulated glucose disposal. Also unclear is the exercise prescription required to evoke the optimal improvement in insulin sensitivity.

The effect of exercise intensity on insulin sensitivity has become a topic of debate. While some research suggests that exercise intensity elicits an independent effect on insulin sensitivity, others have found conflicting results. In other words, assuming all other factors are the same, it is unclear how insulin sensitivity would change following 2 chronic exercise regimens matched for dose but differing in intensity. 
Gaining knowledge about the effect of exercise intensity on insulin sensitivity is necessary, particularly for those prescribing exercise to improve insulin sensitivity and as a preventative strategy for cardiovascular disease.

The following study evaluates the association between exercise intensity and the improvement of insulin sensitivity in abdominally obese sedentary men and women. Opportunistic data from 2 previously published randomized controlled trials were analyzed in order to answer this important question. A novel aspect of this design is that exercise dose was held constant, allowing the effects of exercise intensity to be isolated. Furthermore, this is the first study to compare the effects of exercise intensity on insulin sensitivity between sexes. 


\section{Chapter 3.}

Evidence that the association between exercise intensity and insulin sensitivity is sex dependent. 


\subsection{Introduction}

Impaired insulin sensitivity is a primary risk factor for chronic disease $(4,159)$. While exercise is a well established strategy for improving insulin sensitivity, the exercise exposure that can evoke the optimal benefit is unclear. Specifically, the independent contribution of exercise intensity (\% $\mathrm{VO}_{2}$ peak) towards the improvement of insulin sensitivity is unknown $(6,7,8,9,10,11,12)$. Whereas some report that exercise intensity contributes to the improvement of insulin sensitivity $(6,7,8,9)$, others report evidence to the contrary $(10,11,12)$.

Critical differences in research design may at least partially explain the discrepant findings. The error inherent to the self report of exercise compliance may influence the validity of a study $(9,10)$. Imprecise measurement of exercise dose clouds interpretation of the independent effect of exercise intensity $(9,12)$. Finally, failure to account for improvements in cardiorespiratory fitness consequent to exercise training may result in imprecise determination of exercise dose and intensity $(6,7,11,12)$.

The aim of the present study was to determine the independent effect of exercise intensity on insulin sensitivity. We studied a group of previously sedentary, abdominally obese men and women who participated in prior studies designed such that the independent effect of exercise intensity on insulin sensitivity could be examined.

\subsection{Materials and Methods}

\subsubsection{Participants}

Participants included Caucasian men and women without overt disease who were recruited from the general public and participated in 2 previously published studies at Queen's University (Kingston, Canada) $(117,160)$. The protocols used in both 
investigations were approved by the Queen's University Health Sciences Research Ethics Board. All participants gave informed consent prior to participation.

The investigations included in this report had similar study designs and utilized identical criterion methods. Briefly, 52 men (160) and 54 women (117) were recruited to examine the effect of diet and aerobic exercise-induced weight loss on regional body composition and insulin sensitivity. Participants were randomized to 1 of 4 groups: dietinduced weight loss, exercise-induced weight loss, exercise without weight loss, and control. For the current investigation, data from those participants (men, $n=16$; women, $n=18$ ) who were randomized into the exercise-induced weight loss group was examined (see "Interventions" below for details).

The inclusion criteria for both studies included: $\mathrm{BMI}>27 \mathrm{~kg} / \mathrm{m}^{2}$, waist circumference $>102 \mathrm{~cm}$ for men and $>88 \mathrm{~cm}$ for women, and stable weight $( \pm 2 \mathrm{~kg})$ for at least 6 months prior to study. Participants were sedentary, defined as no structured leisure time physical activity during the year prior. Participants were non-smokers and took no medications known to influence glucose metabolism.

\subsubsection{Interventions}

The men and women performed daily, supervised exercise on a motorized treadmill for 3 and 4 months, respectively. The exercise protocols utilized in both studies were very similar. Participants were asked to self-select their exercise intensity (maximal oxygen uptake, $\mathrm{VO}_{2}$ peak), while the duration of each session was determined by the time required to expend $700 \mathrm{kcal}$ for men and $500 \mathrm{kcal}$ for women. One subtle difference between the studies was that male participants were asked to select intensities below $70 \% \mathrm{VO}_{2}$ peak whereas women were asked to exercise at $\sim 70 \%$ of $\mathrm{VO}_{2}$ peak. Despite the difference in study design both men and women had a similar range of mean exercise intensities $($ men $=49.4-70.6$, women $=57.1-82.6)$. In both trials, heart rate 
was monitored every 5 minutes using an automated heart rate monitor (Polar Oy, Kempele, Finland). During each exercise session, exercise dose (caloric expenditure) and intensity were determined using heart rate and oxygen consumption data obtained from graded, treadmill exercise tests.

In both trials the daily caloric intake required to maintain body weight at baseline was determined and maintained throughout the intervention in attempts to isolate the negative energy balance induced by exercise alone. For the duration of the study, participants kept daily, detailed food records that were analyzed by the subjects and reviewed by the study dietician. For 2 weeks, the participants' diet records were analyzed using a computerized program (Food Processor; Esha Research, Salem, OR).

\subsubsection{Measurement of Cardiorespiratory Fitness}

All participants performed graded treadmill tests at baseline and every 4 weeks thereafter using standard open circuit spirometry techniques (Sensor-Medics, Yorba Linda, California). Each participant was required to participate in a practice graded treadmill test before initial baseline testing. $\mathrm{VO}_{2}$ peak was attained when at least two of the following three criteria were achieved; no increase in $\mathrm{VO}_{2}$ despite further increases in treadmill grade, a heart rate at or above age-predicted maximum (220 - age), and/or a respiratory exchange ratio in excess of 1.0 .

\subsubsection{Measurement of Insulin Sensitivity}

Insulin sensitivity was assessed by a 3-hour hyperinsulinemic euglycemic clamp. Participants in both studies were asked to consume a weight maintaining diet consisting of at least 200 grams of carbohydrate and to avoid strenuous physical activity for a minimum of 3 days prior to testing. Post-treatment measures were obtained 4 days after the last exercise session. All studies were performed at $~ 8$ am after a 10- to 14-hour 
overnight fast. An antecubital vein was catheterized for infusion of insulin and $20 \%$ glucose, and a hand vein was cannulated in a retrograde fashion and placed in a heating pad for sampling of arterialized blood. Insulin was infused at a rate of $40 \mathrm{mU} / \mathrm{m}^{2} / \mathrm{min}$ for 3 hours. Blood glucose was measured using an automated glucose analyzer (YSI 2300 Glucose Analyzer, Yellow Springs, OH, USA) every 5 minutes. Insulin sensitivity was calculated using the average exogenous glucose infusion rate during the final 30 minutes of euglycemia.

\subsubsection{Measurement of Adipose Tissue and Skeletal Muscle Tissue}

Total and regional adipose tissue and skeletal muscle tissue were determined using whole-body magnetic resonance imaging (MRI). MRI data (41 - 47 equidistant images) was obtained with a 1.5 Tesla magnet (General Electric, Milwaukee, Wisconsin, USA). Once acquired the MRI data was analyzed using image analysis software (Tomovision Inc., Montreal, QC, Canada) and established protocols (161).

\subsubsection{Anthropometrics}

Body mass was measured to the nearest $0.1 \mathrm{~kg}$ on a calibrated scale. Standing height was measured to the nearest $0.1 \mathrm{~cm}$ using a wall-mounted stadiometer. Waist circumference was measured at the level of the last (floating) rib.

\subsubsection{Statistics}

Data analysis was performed in men and women separately. Paired samples ttests were used to determine if subject characteristics changed significantly from baseline to follow up. Independent samples t-tests were performed in order to identify sex differences.

Linear regression analyses were used to determine the relationship between exercise intensity and the improvement of insulin sensitivity. A simple regression model 
was performed, followed by 3 multivariate models in which the change in insulin sensitivity was the dependent variable and exercise dose, the change in visceral AT, or the change in total abdominal AT were included as a covariate. The association between exercise intensity and the change in insulin sensitivity was evaluated using unstandardized regression coefficients. To facilitate understanding, Pearson's correlation coefficients, partial correlation coefficients, and incremental squared correlation coefficients were also calculated. Shapiro-Wilk tests were used to determine that the variables were normally distributed. Multicollinearity tests were employed in all regression analyses.

To further examine the relationship between exercise intensity and the change in insulin sensitivity, participants were divided into tertiles based on mean exercise intensity. Differences in the change in insulin sensitivity across tertiles were determined using ANOVA with a post-hoc tukey test. A linear trend test was used to characterize the change in insulin sensitivity across exercise intensity tertiles.

Our sample of 16 men and 18 women provided a power of $70 \%$ and $75 \%$ respectively, to detect a correlation of 0.6 between exercise intensity and the change in insulin sensitivity with an alpha of $p<0.05$.

Statistical procedures were performed using Predictive Analytics Software (PASW, SPSS Inc., Chicago, Illinois).

\subsection{Results}

Descriptive characteristics of the participants are given Table 3-1. Reductions in body weight, skeletal muscle, waist circumference, and all AT depots were observed independent of sex $(p<0.05)$. Insulin sensitivity and $\mathrm{VO}_{2}$ peak improved $(p<0.05)$ in both groups. Women exercised at a greater mean intensity than the men $(p<0.05)$, 
however the range of exercise intensities were similar in both groups (Table 3-2). By design, the average exercise dose, and the total number of exercise session completed, differed significantly in the men and women (Table 3-2).

Table 3-3 shows the results of the regression analyses. In men, exercise intensity was associated with the improvement in insulin sensitivity $(p=0.02$; Table 3-3). The unstandardized regression coefficient demonstrates that after adjusting for dose (caloric expenditure), for every $1 \% \mathrm{VO}_{2}$ peak increase in exercise intensity, there was a corresponding increase in insulin sensitivity of $0.38 \mathrm{mg} / \mathrm{kgskm} / \mathrm{min}(p=0.007$; Table 3-3). Moreover, after controlling for exercise dose, exercise intensity accounted for $25 \%$ of the variance in the improvement of insulin sensitivity $(p<0.05)$. Exercise intensity also remained associated with the improvement of insulin sensitivity after adjusting for the change in total abdominal ( $p=0.02$; Table 3-3), or visceral AT ( $p=0.01$; Table 3-3). After controlling for the change in total abdominal or visceral AT mass, exercise intensity explained $30 \%$ and $33 \%$ of the variance in the improvement of insulin sensitivity respectively $(p<0.05)$.

In women exercise intensity was not associated with the improvement of insulin sensitivity ( $p>0.05$; Table 3-3). Adjusting for exercise dose, the change in total abdominal or visceral AT did not alter this relationship $(p>0.05$; Table 3-3).

Because the women were more sensitive to insulin at baseline $(p<0.05$; Table 3-1), regression analyses were repeated using the relative change in insulin sensitivity as the dependent variable. The same findings were produced (data not shown).

Figure 3-1 depicts the relationship between changes in insulin sensitivity across tertiles of exercise intensity. In men, the mean improvement in insulin sensitivity within the highest exercise intensity tertile was significantly greater than the improvement in the lowest tertile $(p=0.02)$. Furthermore, in men, insulin sensitivity exhibits a significant 
linear trend $(p=0.007)$ across tertiles of increasing exercise intensity. In women, values for insulin sensitivity across tertiles of exercise intensity were not different $(p>0.05)$. 
Table 3-1 Baseline and Follow-Up Participant Characteristics.

\begin{tabular}{|c|c|c|c|c|c|c|}
\hline \multirow[t]{2}{*}{ Variable } & \multicolumn{3}{|c|}{$\begin{array}{l}\text { MEN } \\
(n=16)\end{array}$} & \multicolumn{3}{|c|}{$\begin{array}{c}\text { WOMEN } \\
(n=18)\end{array}$} \\
\hline & Pre & Post & $\Delta$ & Pre & Post & $\Delta$ \\
\hline \multicolumn{7}{|l|}{ Anthropometric } \\
\hline Age & $45.00 \pm 7.46$ & & & $42.28 \pm 6.21$ & & \\
\hline $\mathrm{BMI}\left(\mathrm{kg} / \mathrm{m}^{2}\right)$ & $32.31 \pm 1.91$ & $29.87 \pm 1.83^{\star}$ & $-2.44 \pm 0.38$ & $32.62 \pm 3.86$ & $30.29 \pm 3.62^{*}$ & $-2.33 \pm 0.74$ \\
\hline Waist Circumference (cm) & $108.62 \pm 5.26 \dagger$ & $101.75 \pm 4.88^{*}$ & $-6.86 \pm 2.49$ & $100.06 \pm 8.21$ & $94.07 \pm 8.12^{*}$ & $-5.99 \pm 3.26$ \\
\hline Weight (kg) & $101.54 \pm 7.81 \dagger$ & $93.95 \pm 7.72^{\star}$ & $-7.59 \pm 0.58 \dagger$ & $86.29 \pm 10.94$ & $80.19 \pm 10.77^{*}$ & $-6.10 \pm 1.52$ \\
\hline \multicolumn{7}{|l|}{ MRI (kg) } \\
\hline Skeletal Muscle & $35.10 \pm 2.77 \dagger$ & $33.87 \pm 3.09^{\star}$ & $-1.23 \pm 0.82$ & $22.05 \pm 2.99$ & $21.18 \pm 2.48^{*}$ & $-0.87 \pm 1.32$ \\
\hline Total AT & $33.06 \pm 5.50 \dagger$ & $27.00 \pm 5.37^{\star}$ & $-6.05 \pm 1.46$ & $40.60 \pm 7.77$ & $34.18 \pm 7.62^{*}$ & $-6.42 \pm 2.22$ \\
\hline Abdominal AT & $8.50 \pm 1.24$ & $6.62 \pm 1.33^{*}$ & $-1.89 \pm 0.41 \dagger$ & $8.29 \pm 1.59$ & $6.97 \pm 1.46^{\star}$ & $-1.32 \pm 1.05$ \\
\hline Visceral AT & $3.88 \pm 0.96 \dagger$ & $2.83 \pm 0.84^{*}$ & $-1.05 \pm 0.33 \dagger$ & $2.15 \pm 0.78$ & $1.60 \pm 0.67^{\star}$ & $-0.55 \pm 0.33$ \\
\hline \multicolumn{7}{|l|}{ Cardiometabolic } \\
\hline Insulin Sensitivity (mg/kgskm/min) & $11.20 \pm 4.91 \dagger$ & $18.35 \pm 5.56^{\star}$ & $7.15 \pm 5.35$ & $20.20 \pm 9.40$ & $25.97 \pm 7.85^{*}$ & $5.77 \pm 7.11$ \\
\hline $\mathrm{VO}_{2}$ peak(mL/kg/min) & $37.56 \pm 7.79 \dagger$ & $46.37 \pm 8.11^{\star}$ & $8.81 \pm 3.59$ & $24.66 \pm 5.36$ & $30.94 \pm 4.55^{\star}$ & $6.28 \pm 5.07$ \\
\hline
\end{tabular}


Table 3-2. Exercise Characteristics.

\begin{tabular}{lcc}
\hline Variable & MEN & WOMEN \\
\hline Exercise Intensity & & \\
Mean (\% VO${ }_{2}$ peak) & $61.21 \pm 7.14^{*}$ & $66.86 \pm 6.71$ \\
Range (\% VO ${ }_{2}$ peak) & $49.37-70.64$ & $57.13-82.61$ \\
Exercise Dose & & \\
Mean (kcal) & $727.37 \pm 44.76^{*}$ & $524.45 \pm 52.0$ \\
Range (kcal) & $686.17-814.02$ & $422.91-631.99$
\end{tabular}

Abbreviations - $\mathrm{VO}_{2}$ peak: Peak oxygen consumption

Data is presented as means $\pm \mathrm{SD}$;

* Men significantly different $(p<0.05)$ than women 
Table 3-3. Associations between Exercise Intensity and the Improvement of Insulin Sensitivity.

\begin{tabular}{lcccccccc}
\hline \multirow{2}{*}{ Model } & \multicolumn{4}{c}{ MEN } & \multicolumn{5}{c}{ WOMEN } \\
& $\beta$ & SE & $r$ & $p$ & $\beta$ & SE & $r$ & $p$ \\
\hline Model 1 & 0.43 & 0.17 & 0.57 & 0.02 & -0.11 & 0.26 & -0.10 & 0.7 \\
Model 2 & 0.38 & 0.12 & $0.67^{*}$ & 0.007 & 0.005 & 0.28 & $0.005^{*}$ & 0.9 \\
Model 3 & 0.41 & 0.15 & $0.61^{*}$ & 0.02 & -0.08 & 0.29 & $-0.072^{*}$ & 0.8 \\
Model 4 & 0.43 & 0.14 & $0.64^{*}$ & 0.01 & -0.055 & 0.27 & $-0.052^{*}$ & 0.8 \\
\hline
\end{tabular}

Abbreviations - $\beta$ : Unstandardized regression coefficient, $r$ : Pearson's correlation coefficient, SE: Standard error

Model 1: $Y$ : Change in insulin sensitivity, $X$ : Mean exercise intensity

Model 2: Model 1 adjusted for exercise dose

Model 3: Model 1 adjusted for the change in abdominal adipose tissue mass

Model 4: Model 1 adjusted for the change in visceral adipose tissue mass

* Partial correlation coefficient 
Figure 3-1. Exercise Intensity (Solid Bars) and the Improvement in Insulin Sensitivity (Open Bars) In Men (A) and Women (B).

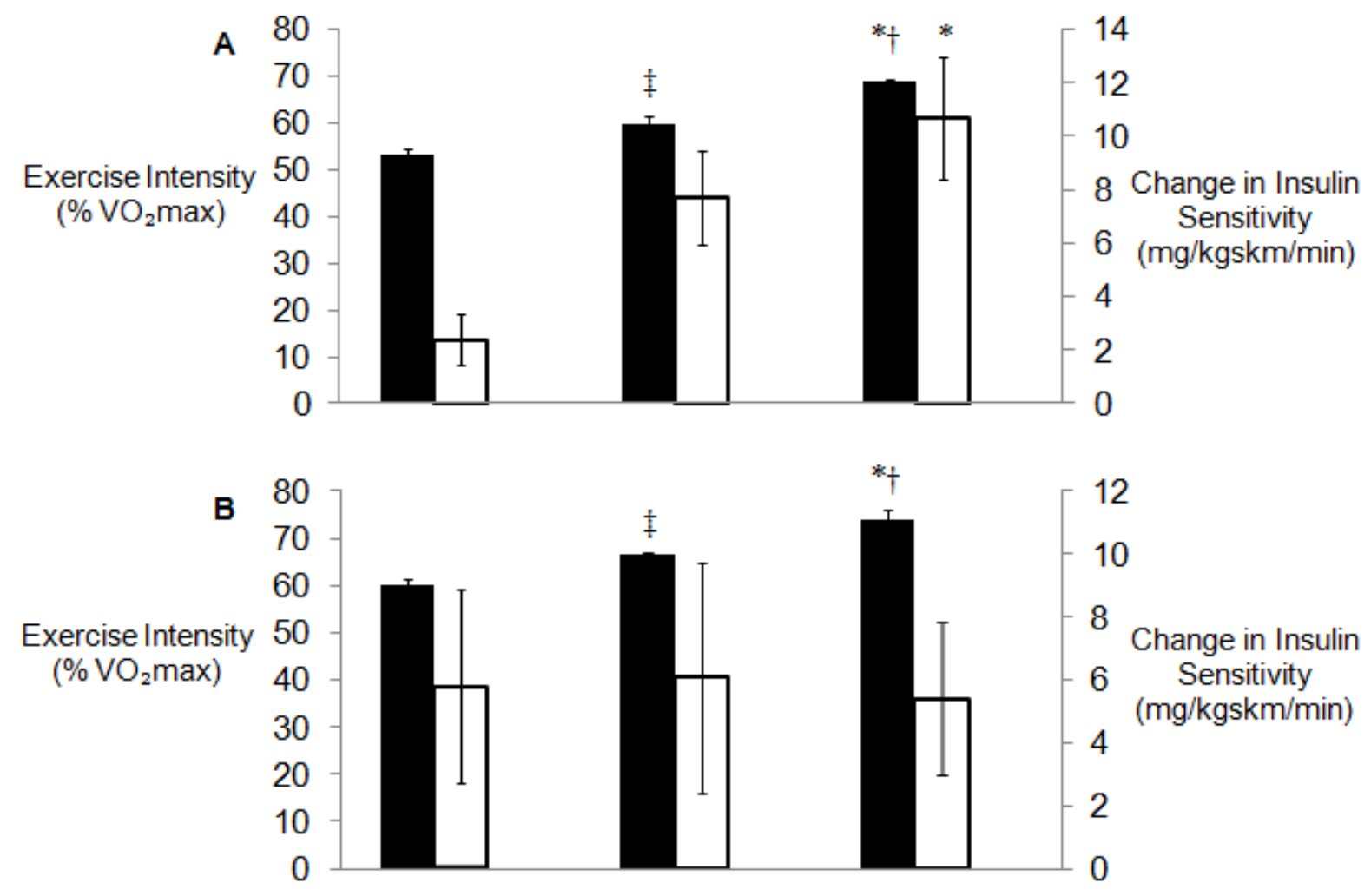

Participants were separated into tertiles according to mean exercise intensity.

Men: 1) $n=5,49-55 \% \mathrm{VO}_{2}$ peak. 2) $n=5,56-65 \% \mathrm{VO}_{2}$ peak. 3) $n=6,66-70 \% \mathrm{VO}_{2}$ peak

Women: 1) $n=6,57-64 \% \mathrm{VO}_{2}$ peak. 2) $n=6,65-70 \% \mathrm{VO}_{2}$ peak. 3) $\mathrm{n}=6,71-80 \% \mathrm{VO}_{2}$ peak

Data is presented as the mean and the standard error of the mean.

Tests for linear trend across tertiles of mean change in insulin sensitivity: Men $(p<0.01)$ women $(p>0.05)$.

* 3 is significantly different than $1(p<0.05)$

+3 is significantly different than $2(p<0.05)$

$\ddagger 2$ is significantly different than $1(p<0.05)$ 


\subsection{Discussion}

From this investigation come two primary findings. First, that for a given dose of exercise, exercise intensity is positively associated with improvement in insulin sensitivity in men. Second, that exercise intensity is not associated with the improvement of insulin sensitivity for a given exercise dose in women. This suggests that the association between exercise intensity and insulin sensitivity may be sex dependent.

Our finding that exercise intensity is independently associated with the corresponding improvement in insulin sensitivity in men is supported in part by the findings of Kang and colleagues (8). Using a counterbalanced design, they found that exercising at $70 \% \mathrm{VO}_{2}$ peak significantly improved insulin sensitivity in men whereas the same dose of exercise performed at $50 \% \mathrm{VO}_{2}$ peak did not (8). However, counter to our finding that exercise intensity is associated with improvement in insulin sensitivity across a continuum of exercise intensities (range from $50 \% \mathrm{VO}_{2}$ peak $-70 \% \mathrm{VO}_{2}$ peak) in men, the findings of Kang et al. suggest that a threshold relationship exists between exercise intensity and insulin sensitivity. In contrast to our findings and those of Kang et al., O'Donovan and colleagues (10) report that the improvement of insulin sensitivity in men following 6 months of exercise at $80 \% \mathrm{VO}_{2}$ peak was no different than the improvement following the same dose of exercise performed at $60 \% \mathrm{VO}_{2}$ peak. It is apparent that in men, the independent contribution of exercise intensity towards the improvement of insulin sensitivity for a given exercise dose remains to be firmly resolved.

To our knowledge only one other investigation has examined the effect of exercise intensity on insulin sensitivity in women alone (7). In this 9 month randomized controlled trial older women were placed into 3 groups; 1 ) control, stretching $(n=7) ; 2)$ moderate intensity exercise, $65 \% \mathrm{VO}_{2}$ peak $(n=9)$; or 3 ) high intensity exercise, $80 \%$ $\mathrm{VO}_{2}$ peak $(\mathrm{n}=9)$. Participants exercise 4 days per week and the duration was 
determined by the time required to expend $300 \mathrm{kcal}$. The authors observed improvements in insulin sensitivity in both exercise groups; however these improvements only reached statistical significance in the high intensity group. In contrast to our findings, these results suggest that exercise intensity may be associated with insulin sensitivity in women. Furthermore, similar to the findings of Kang et al. in men, these findings suggest that the independent effect of exercise intensity on insulin sensitivity may not occur along a continuum of exercise intensities but rather, may be restricted to exercise at higher intensities $(7,8)$.

The mechanisms that may explain an independent effect of exercise intensity on insulin sensitivity are unclear. However, alterations in glycogen kinetics consequent to exercise are a biologically plausible explanation. The utilization of skeletal muscle glycogen is positively correlated with exercise intensity. Decreased pre-exercise skeletal muscle glycogen content increases the transcription of several genes, including those involved in energy substrate metabolism $(154,156)$. Accordingly, if the reduction in glycogen brought about by high intensity exercise is maintained between exercise sessions, high intensity exercise may result in heightened gene expression and thereby a greater improvement of insulin sensitivity. This is supported by our observation that the association between intensity and the improvement of insulin sensitivity remained significant after adjusting for changes in adipose tissue mass.

Gender differences in glycogen utilization may partially explain why we did not observe an association between exercise intensity and insulin sensitivity in women. At identical exercise intensities, women preferentially oxidize more lipid than men (162, 163) and consequentially utilize less glycogen, as has been evidenced during endurance exercise $(164,165)$.

Limitations of our study include a small sample size and thus it is possible that our results may reflect a type 2 error. As we did not collect free-living physical activity 
data, it is possible that the association between exercise intensity and the change in insulin sensitivity was confounded by changes in leisure time physical activity. Lastly, the use of heart rate and oxygen consumption relationships, obtained from graded exercise testing, to determine exercise dose and intensity requires further validation.

In summary, our findings suggest that in men, after adjusting for exercise dose, exercise intensity accounts for $25 \%$ of the variance in the improvement of insulin sensitivity. This is relevant given that exercise intensity in this trial was self-selected and well tolerated by participants. Conversely, a similar range of exercise intensities in women does not appear to influence insulin sensitivity thereby suggesting that the association between exercise intensity and insulin sensitivity may be sex dependent. 


\section{Chapter 4. General Discussion}

\subsection{Clinical Implications of the Study}

While it is well accepted that chronic exercise improves insulin sensitivity, the independent effect of exercise intensity on insulin sensitivity is a contentious issue. The results of this research suggest that when prescribing exercise as a treatment strategy for the improvement of insulin sensitivity, clinicians may need to give sex specific recommendations. More specifically, in order to achieve the optimal improvement in insulin sensitivity for a given exercise dose, men should be prescribed high intensity exercise. Conversely, because our results give no indication that the intensity of exercise influences insulin sensitivity when dose is held constant, women should be advised to select their exercise intensity according to personal preference.

The aforementioned recommendations resulting from this preliminary study would likely alter exercise performance, and compliance. It has been reported that it is more difficult to engage sedentary individuals in high intensity exercise regimes (166). Consequentially, the number of men choosing to partake in exercise for the purpose of improving insulin sensitivity may be attenuated due to the emphasis on exercise intensity. Conversely, because our results suggest that women can achieve optimal improvements in insulin sensitivity without participating in high intensity exercise, more women may choose to adopt structured exercise as a treatment for insulin resistance. As a note of caution however, although the appeal of self-selecting lower exercise intensities may initially increase the number of women taking part in structured exercise, the additional time required for women to complete the same dose of exercise at a lower intensity may ultimately decrease compliance. Indeed research has found that time constraints are one of the largest barriers people report when trying to adopt an exercise 
regimen (167) thus developing individually tailored programs is critical for long-term success.

A discussion of the clinical implications of this research would not be complete without comparing our findings to current guidelines. While guidelines have yet to be created specifically for the utility of exercise as a treatment strategy for insulin resistance, recommendations have been published for the use of exercise in the prevention of cardiovascular disease $(168,169)$. These recommendations are relevant because insulin sensitivity is a primary antecedent for cardiovascular disease $(3,4)$. Importantly, the results of our trial partially refute these exercise recommendations. To prevent cardiovascular disease it is suggested that men and women participate in either; 1) 150 minutes of moderate intensity physical activity per week, or 2) 75 minutes of vigorous physical activity per weekly, or 3 ) a combination of 1 and $2(168,169)$. Given that the elevated exercise intensity in the later exercise prescription is paired with a lesser duration, it is likely that these treatment options have a similar exercise dose. Accordingly, as the guidelines encourage individuals to participate in treatment option 1 or 2, it is implied that at a given exercise dose, elevations in exercise intensity are not associated with additional reductions in cardiovascular disease risk. Thus, given the strong association between insulin resistance and cardiovascular disease, the results of our investigation challenge the applicability of these recommendations for men while supporting their use for women.

\subsection{Future Research}

This is the first study to examine sex differences in the effect of exercise intensity on insulin sensitivity. There are limitations inherent to using a convenience sample of data. Accordingly, future endeavors should re-examine this question using a prospective study design. Well designed study groups would allow investigators to characterize the 
relationship between exercise intensity and insulin sensitivity (e.g. continuous, threshold). As alluded to previously, our results suggest that a mechanism other than the loss of visceral adipose tissue volume mediates the relationship between exercise intensity and insulin sensitivity. Thus, it is advisable that future work also examine the cellular mechanisms, particularly within the skeletal muscle, by which exercise intensity might independently alter insulin sensitivity. More specifically, it would be useful to examine the independent effects of exercise intensity on glycogen utilization, as well as the associations between glycogen use and the expression of proteins involved in insulin stimulated glucose disposal. 


\section{Summary and Conclusions}

Chronic exercise is a well established strategy for the improvement of insulin sensitivity. However, the optimal exercise exposure for the improvement of insulin sensitivity remains an issue of considerable debate. This is an important area of inquiry as impaired insulin sensitivity is a primary risk factor for the development of cardiovascular disease, the number one global cause of mortality. The findings of the present research suggest that for a given exercise dose, increasing exercise intensity results in a greater improvement of insulin sensitivity in men. As similar results were not observed in women, this study suggests that the effect of exercise intensity on insulin sensitivity might be sex dependent. Additionally, the results of this study imply that the independent effect of exercise intensity on insulin sensitivity in men might occur at the level of the myocyte. While this study warrants replication, our results are novel and they contribute to current knowledge regarding the independent effect of exercise intensity on insulin sensitivity. 


\section{References}

1. Holloszy JO. Exercise-induced increase in muscle insulin sensitivity. J Appl Physiol. 2005;99: 338-343.

2. DeFronzo RA, Jacot E, Jequier E, et al. The effect of insulin on the disposal of intravenous glucose. Results from indirect calorimetry and hepatic and femoral venous catheterization. Diabetes. 1981;30: 1000-1007.

3. Yip J, Facchini FS, Reaven GM. Resistance to insulin-mediated glucose disposal as a predictor of cardiovascular disease. J Clin Endocrinol Metab. 1998;83: 2773-2776.

4. Rutter MK, Meigs JB, Sullivan LM, et al. Insulin Resistance, the Metabolic Syndrome, and Incident Cardiovascular Events in the Framingham Offspring Study. Diabetes. 2005;54: 3252-3257.

5. Bjorntorp $\mathrm{P}$, De Jounge K, Sjostrom $\mathrm{L}$, et al. The effect of physical training on insulin production in obesity. Metabolism. 1970;19: 631-638.

6. Coker $\mathrm{RH}$, Hays NP, Williams $\mathrm{RH}$, et al. Exercise-induced changes in insulin action and glycogen metabolism in elderly adults. Med Sci Sports Exerc. 2006;38: 433-438.

7. DiPietro L, Dziura J, Yeckel CW, et al. Exercise and improved insulin sensitivity in older women: evidence of the enduring benefits of higher intensity training. $J$ Appl Physiol. 2006;100: 142-149.

8. Kang J, Robertson RJ, Hagberg JM, et al. Effect of exercise intensity on glucose and insulin metabolism in obese individuals and obese NIDDM patients. Diabetes Care. 1996;19: 341-349.

9. Seals DR, Hagberg JM, Hurley BF, et al. Effects of endurance training on glucose tolerance and plasma lipid levels in older men and women. JAMA. 1984;252: 645-649.

10. O'Donovan G, Kearney EM, Nevill AM, et al. The effects of 24 weeks of moderate- or high-intensity exercise on insulin resistance. Eur J Appl Physiol. 2005;95: 522-528.

11. Houmard JA, Tanner CJ, Slentz CA, et al. Effect of the volume and intensity of exercise training on insulin sensitivity. J Appl Physiol. 2004;96: 101-106.

12. Hughes VA, Fiatarone MA, Fielding RA, et al. Exercise increases muscle GLUT-4 levels and insulin action in subjects with impaired glucose tolerance. Am J Physiol Endocrinol Metab. 1993;264: E855-E862.

13. Mathers CD, Fat MD, Boerma JT. The Global Burdan of Disease: 2004 Update. World Health Organization: Geneva, 2008. 
14. Banting FG, Best $\mathrm{CH}$. The internal secretion of the pancreas. J Lab Clin Med. 1922;7: 251-266.

15. Kasuga M, Karlsson FA, Kahn CR. Insulin stimulates the phosphorylation of the 95,000-dalton subunit of its own receptor. Science. 1982;215: 185-187.

16. Ullrich A, Bell JR, Chen EY, et al. Human insulin receptor and its relationship to the tyrosine kinase family of oncogenes. Nature. 1985;313: 756-761.

17. Sun XJ, Rothenberg P, Kahn CR, et al. Structure of the insulin receptor substrate IRS-1 defines a unique signal transduction protein. Nature. 1991;352: 73-77.

18. Myers MG,Jr, Backer JM, Sun XJ, et al. IRS-1 activates phosphatidylinositol 3'kinase by associating with src homology 2 domains of p85. Proc Natl Acad Sci U S A. 1992;89: 10350-10354.

19. Martin SS, Haruta T, Morris AJ, et al. Activated phosphatidylinositol 3-kinase is sufficient to mediate actin rearrangement and GLUT4 translocation in 3T3-L1 adipocytes. J Biol Chem. 1996;271: 17605-17608.

20. Cross DA, Alessi DR, Cohen $P$, et al. Inhibition of glycogen synthase kinase-3 by insulin mediated by protein kinase B. Nature. 1995;378: 785-789.

21. Syed NA, Khandelwal RL. Reciprocal regulation of glycogen phosphorylase and glycogen synthase by insulin involving phosphatidylinositol-3 kinase and protein phosphatase-1 in HepG2 cells. Mol Cell Biochem. 2000;211: 123-136.

22. Mandarino LJ, Printz RL, Cusi KA, et al. Regulation of hexokinase II and glycogen synthase mRNA, protein, and activity in human muscle. Am J Physiol. 1995;269: E701E708.

23. Saltiel AR, Kahn CR. Insulin signalling and the regulation of glucose and lipid metabolism. Nature. 2001;414: 799-806.

24. Ferrannini E, Mari A. How to measure insulin sensitivity. J Hypertens. 1998;16: 895906.

25. Muniyappa $\mathrm{R}$, Lee $\mathrm{S}$, Chen $\mathrm{H}$, et al. Current approaches for assessing insulin sensitivity and resistance in vivo: advantages, limitations, and appropriate usage. $A m \mathrm{~J}$ Physiol Endocrinol Metab. 2008;294: E15-E26.

26. Wallace TM, Matthews DR. The assessment of insulin resistance in man. Diabet Med. 2002;19: 527-534.

27. Wang D, Sul HS. Insulin stimulation of the fatty acid synthase promoter is mediated by the phosphatidylinositol 3-kinase pathway. Involvement of protein kinase B/Akt. J Biol Chem. 1998;273: 25420-25426. 
28. O'Brien RM, Lucas PC, Forest CD, et al. Identification of a sequence in the PEPCK gene that mediates a negative effect of insulin on transcription. Science. 1990;249: 533537.

29. Lund S, Holman GD, Schmitz O, et al. Contraction stimulates translocation of glucose transporter GLUT4 in skeletal muscle through a mechanism distinct from that of insulin. Proc Natl Acad Sci U S A. 1995;92: 5817-5821.

30. Mandarino LJ, Wright KS, Verity LS, et al. Effects of insulin infusion on human skeletal muscle pyruvate dehydrogenase, phosphofructokinase, and glycogen synthase. Evidence for their role in oxidative and nonoxidative glucose metabolism. J Clin Invest. 1987;80: 655-663.

31. Stralfors $P$, Bjorgell $P$, Belfrage $P$. Hormonal regulation of hormone-sensitive lipase in intact adipocytes: identification of phosphorylated sites and effects on the phosphorylation by lipolytic hormones and insulin. Proc Natl Acad Sci U S A. 1984;81: 3317-3321.

32. Ritchie SA, Kohlhaas CF, Boyd AR, et al. Insulin-stimulated phosphorylation of endothelial nitric oxide synthase at serine-615 contributes to nitric oxide synthesis. Biochem J. 2010;426: 85-90.

33. Le DS, Brookshire T, Krakoff J, et al. Repeatability and reproducibility of the hyperinsulinemic-euglycemic clamp and the tracer dilution technique in a controlled inpatient setting. Metabolism. 2009;58: 304-310.

34. Mather KJ, Hunt AE, Steinberg HO, et al. Repeatability Characteristics of Simple Indices of Insulin Resistance: Implications for Research Applications. J Clin Endocrinol Metab. 2001;86: 5457-5464.

35. Bonora E, Targher G, Alberiche M, et al. Homeostasis model assessment closely mirrors the glucose clamp technique in the assessment of insulin sensitivity: studies in subjects with various degrees of glucose tolerance and insulin sensitivity. Diabetes Care. 2000;23: 57-63.

36. Katz A, Nambi SS, Mather K, et al. Quantitative Insulin Sensitivity Check Index: A Simple, Accurate Method for Assessing Insulin Sensitivity In Humans. J Clin Endocrinol Metab. 2000;85: 2402-2410.

37. Sheu WH, Hou JC, Jeng CY, et al. Reproducibility of the measurement of insulin sensitivity by the modified insulin suppression test. J Formos Med Assoc. 1992;91: 859863.

38. Greenfield MS, Doberne L, Kraemer F, et al. Assessment of insulin resistance with the insulin suppression test and the euglycemic clamp. Diabetes. 1981;30: 387-392.

39. Steil GM, Murray J, Bergman RN, et al. Repeatability of insulin sensitivity and glucose effectiveness from the minimal model. Implications for study design. Diabetes. 1994;43: 1365-1371. 
40. Bergman RN, Prager R, Volund A, et al. Equivalence of the insulin sensitivity index in man derived by the minimal model method and the euglycemic glucose clamp. $J$ Clin Invest. 1987;79: 790-800.

41. Saad MF, Steil GM, Kades WW, et al. Differences between the tolbutamide-boosted and the insulin-modified minimal model protocols. Diabetes. 1997;46: 1167-1171.

42. Mooy JM, Grootenhuis PA, de Vries $\mathrm{H}$, et al. Intra-individual variation of glucose, specific insulin and proinsulin concentrations measured by two oral glucose tolerance tests in a general Caucasian population: the Hoorn Study. Diabetologia. 1996;39: 298305.

43. Feskens EJM, Bowles $\mathrm{CH}$, Kromhout D. Intra- and interindividual variability of glucose tolerance in an elderly population. J Clin Epidemiol. 1991;44: 947-953.

44. Matsuda M, DeFronzo RA. Insulin sensitivity indices obtained from oral glucose tolerance testing: comparison with the euglycemic insulin clamp. Diabetes Care. 1999;22: 1462-1470.

45. Soonthornpun S, Setasuban W, Thamprasit A, et al. Novel Insulin Sensitivity Index Derived from Oral Glucose Tolerance Test. J Clin Endocrinol Metab. 2003;88: 10191023.

46. Abdul-Ghani MA, DeFronzo RA. Pathogenesis of insulin resistance in skeletal muscle. J Biomed Biotechnol. 2010.

47. DeFronzo RA, Ferrannini E. Insulin resistance. A multifaceted syndrome responsible for NIDDM, obesity, hypertension, dyslipidemia, and atherosclerotic cardiovascular disease. Diabetes Care. 1991;14: 173-194.

48. Damsbo P, Vaag A, Hother-Nielsen $O$, et al. Reduced glycogen synthase activity in skeletal muscle from obese patients with and without type 2 (non-insulin-dependent) diabetes mellitus. Diabetologia. 1991;34: 239-245.

49. Vaag A, Henriksen JE, Beck-Nielsen H. Decreased insulin activation of glycogen synthase in skeletal muscles in young nonobese Caucasian first-degree relatives of patients with non-insulin-dependent diabetes mellitus. J Clin Invest. 1992;89: 782-788.

50. Petersen KF, Dufour S, Savage DB, et al. The role of skeletal muscle insulin resistance in the pathogenesis of the metabolic syndrome. Proc Natl Acad Sci U S A. 2007;104: 12587-12594.

51. He J, Kelley DE. Muscle glycogen content in type 2 diabetes mellitus. Am J Physiol Endocrinol Metab. 2004;287: E1002-E1007.

52. Rothman DL, Shulman RG, Shulman GI. 31P nuclear magnetic resonance measurements of muscle glucose-6-phosphate. Evidence for reduced insulin-dependent muscle glucose transport or phosphorylation activity in non-insulin-dependent diabetes mellitus. J Clin Invest. 1992;89: 1069-1075. 
53. Savage DB, Petersen KF, Shulman GI. Disordered lipid metabolism and the pathogenesis of insulin resistance. Physiol Rev. 2007;87: 507-520.

54. Cline GW, Petersen KF, Krssak M, et al. Impaired glucose transport as a cause of decreased insulin-stimulated muscle glycogen synthesis in type 2 diabetes. $N$ Engl $J$ Med. 1999;341: 240-246.

55. Bonadonna RC, Del Prato S, Bonora E, et al. Roles of glucose transport and glucose phosphorylation in muscle insulin resistance of NIDDM. Diabetes. 1996;45: 915-925.

56. Pendergrass $\mathrm{M}$, Koval J, Vogt $\mathrm{C}$, et al. Insulin-induced hexokinase II expression is reduced in obesity and NIDDM. Diabetes. 1998;47: 387-394.

57. Yu YH, Ginsberg HN. Adipocyte signaling and lipid homeostasis: sequelae of insulinresistant adipose tissue. Circ Res. 2005;96: 1042-1052.

58. Raynolds MV, Awald PD, Gordon DF, et al. Lipoprotein lipase gene expression in rat adipocytes is regulated by isoproterenol and insulin through different mechanisms. Mol Endocrinol. 1990;4: 1416-1422.

59. Moustaid N, Beyer RS, Sul HS. Identification of an insulin response element in the fatty acid synthase promoter. J Biol Chem. 1994;269: 5629-5634.

60. Coppack SW, Evans RD, Fisher RM, et al. Adipose tissue metabolism in obesity: lipase action in vivo before and after a mixed meal. Metabolism. 1992;41: 264-272.

61. Despres JP, Lemieux I. Abdominal obesity and metabolic syndrome. Nature. 2006;444: 881-887.

62. Ross R, Aru J, Freeman J, et al. Abdominal adiposity and insulin resistance in obese men. Am J Physiol Endocrinol Metab. 2002;282: E657-E663.

63. Pouliot MC, Despres JP, Nadeau A, et al. Visceral obesity in men. Associations with glucose tolerance, plasma insulin, and lipoprotein levels. Diabetes. 1992;41: 826-834.

64. Lewis GF, Carpentier A, Adeli K, et al. Disordered fat storage and mobilization in the pathogenesis of insulin resistance and type 2 diabetes. Endocr Rev. 2002;23: 201-229.

65. Bouchard C, Tremblay A. Genetic influences on the response of body fat and fat distribution to positive and negative energy balances in human identical twins. $J$ Nutr. 1997;127: 943S-947S.

66. Canoy D, Wareham N, Luben R, et al. Cigarette smoking and fat distribution in 21,828 British men and women: a population-based study. Obes Res. 2005;13: 14661475.

67. Hegele RA. Familial partial lipodystrophy: a monogenic form of the insulin resistance syndrome. Mol Genet Metab. 2000;71: 539-544. 
68. Gavrilova O, Marcus-Samuels B, Graham D, et al. Surgical implantation of adipose tissue reverses diabetes in lipoatrophic mice. J Clin Invest. 2000;105: 271-278.

69. Mittelman SD, Van Citters GW, Kirkman EL, et al. Extreme insulin resistance of the central adipose depot in vivo. Diabetes. 2002;51: 755-761.

70. Hellmer J, Marcus C, Sonnenfeld T, et al. Mechanisms for differences in lipolysis between human subcutaneous and omental fat cells. J Clin Endocrinol Metab. 1992;75: $15-20$.

71. Belfort R, Mandarino L, Kashyap S, et al. Dose-response effect of elevated plasma free fatty acid on insulin signaling. Diabetes. 2005;54: 1640-1648.

72. Kelley DE, Goodpaster B, Wing RR, et al. Skeletal muscle fatty acid metabolism in association with insulin resistance, obesity, and weight loss. Am J Physiol. 1999;277: E1130-E1141.

73. Boden G, Lebed B, Schatz M, et al. Effects of acute changes of plasma free fatty acids on intramyocellular fat content and insulin resistance in healthy subjects. Diabetes. 2001;50: 1612-1617.

74. Goodpaster BH, He J, Watkins S, et al. Skeletal muscle lipid content and insulin resistance: evidence for a paradox in endurance-trained athletes. J Clin Endocrinol Metab. 2001;86: 5755-5761.

75. Moro C, Bajpeyi S, Smith SR. Determinants of intramyocellular triglyceride turnover: implications for insulin sensitivity. Am J Physiol Endocrinol Metab. 2008;294: E203E213.

76. Itani SI, Ruderman NB, Schmieder F, et al. Lipid-induced insulin resistance in human muscle is associated with changes in diacylglycerol, protein kinase $\mathrm{C}$, and lkappaBalpha. Diabetes. 2002;51: 2005-2011.

77. Griffin ME, Marcucci MJ, Cline GW, et al. Free fatty acid-induced insulin resistance is associated with activation of protein kinase $\mathrm{C}$ theta and alterations in the insulin signaling cascade. Diabetes. 1999;48: 1270-1274.

78. Kelley DE, He J, Menshikova EV, et al. Dysfunction of mitochondria in human skeletal muscle in type 2 diabetes. Diabetes. 2002;51: 2944-2950.

79. Morino K, Petersen KF, Dufour S, et al. Reduced mitochondrial density and increased IRS-1 serine phosphorylation in muscle of insulin-resistant offspring of type 2 diabetic parents. J Clin Invest. 2005;115: 3587-3593.

80. Holloszy JO. Skeletal muscle "mitochondrial deficiency" does not mediate insulin resistance. Am J Clin Nutr. 2009;89: 463S-466S.

81. Tarnopolsky MA, Rennie CD, Robertshaw HA, et al. Influence of endurance exercise training and sex on intramyocellular lipid and mitochondrial ultrastructure, substrate use, 
and mitochondrial enzyme activity. Am J Physiol Regul Integr Comp Physiol. 2007;292: R1271-R1278.

82. Crane JD, Devries MC, Safdar A, et al. The effect of aging on human skeletal muscle mitochondrial and intramyocellular lipid ultrastructure. J Gerontol A Biol Sci Med Sci. 2010;65: 119-128.

83. Choi WH, O'Rahilly S, Buse JB, et al. Molecular scanning of insulin-responsive glucose transporter (GLUT4) gene in NIDDM subjects. Diabetes. 1991;40: 1712-1718.

84. Laakso M, Malkki M, Kekalainen P, et al. Polymorphisms of the human hexokinase II gene: lack of association with NIDDM and insulin resistance. Diabetologia. 1995;38: 617-622.

85. Bjorbaek C, Echwald SM, Hubricht $P$, et al. Genetic variants in promoters and coding regions of the muscle glycogen synthase and the insulin-responsive GLUT4 genes in NIDDM. Diabetes. 1994;43: 976-983.

86. Ganong BR, Loomis CR, Hannun YA, et al. Specificity and mechanism of protein kinase C activation by sn-1,2-diacylglycerols. Proc Natl Acad Sci U S A. 1986;83: 11841188.

87. Kim JK, Fillmore JJ, Sunshine MJ, et al. PKC-theta knockout mice are protected from fat-induced insulin resistance. J Clin Invest. 2004;114: 823-827.

88. Yu C, Chen Y, Cline GW, et al. Mechanism by which fatty acids inhibit insulin activation of insulin receptor substrate-1 (IRS-1)-associated phosphatidylinositol 3kinase activity in muscle. J Biol Chem. 2002;277: 50230-50236.

89. Mothe I, Van Obberghen E. Phosphorylation of insulin receptor substrate-1 on multiple serine residues, $612,632,662$, and 731 , modulates insulin action. $J$ Biol Chem. 1996;271: 11222-11227.

90. Pederson TM, Kramer DL, Rondinone CM. Serine/threonine phosphorylation of IRS1 triggers its degradation: possible regulation by tyrosine phosphorylation. Diabetes. 2001;50: 24-31.

91. Cusi K, Maezono K, Osman A, et al. Insulin resistance differentially affects the PI 3kinase- and MAP kinase-mediated signaling in human muscle. J Clin Invest. 2000;105: 311-320.

92. Morino K, Neschen S, Bilz S, et al. Muscle-specific IRS-1 Ser->Ala transgenic mice are protected from fat-induced insulin resistance in skeletal muscle. Diabetes. 2008;57: 2644-2651.

93. Antuna-Puente B, Feve B, Fellahi S, et al. Adipokines: the missing link between insulin resistance and obesity. Diabetes Metab. 2008;34: 2-11. 
94. Rabe K, Lehrke M, Parhofer KG, et al. Adipokines and insulin resistance. Mol Med. 2008;14: 741-751.

95. Wozniak SE, Gee LL, Wachtel MS, et al. Adipose tissue: the new endocrine organ? A review article. Dig Dis Sci. 2009;54: 1847-1856.

96. Ronti T, Lupattelli G, Mannarino E. The endocrine function of adipose tissue: an update. Clin Endocrinol (Oxf). 2006;64: 355-365.

97. Hotamisligil GS, Shargill NS, Spiegelman BM. Adipose expression of tumor necrosis factor-alpha: direct role in obesity-linked insulin resistance. Science. 1993;259: 87-91.

98. Reaven G. Metabolic syndrome: pathophysiology and implications for management of cardiovascular disease. Circulation. 2002;106: 286-288.

99. Facchini F, Chen YD, Hollenbeck CB, et al. Relationship between resistance to insulin-mediated glucose uptake, urinary uric acid clearance, and plasma uric acid concentration. JAMA. 1991;266: 3008-3011.

100. Abbasi F, Brown BW,Jr, Lamendola C, et al. Relationship between obesity, insulin resistance, and coronary heart disease risk. J Am Coll Cardiol. 2002;40: 937-943.

101. Reaven GM, Chen YD, Jeppesen J, et al. Insulin resistance and hyperinsulinemia in individuals with small, dense low density lipoprotein particles. J Clin Invest. 1993;92: 141-146.

102. Ferrannini E, Natali A, Capaldo B, et al. Insulin resistance, hyperinsulinemia, and blood pressure: role of age and obesity. European Group for the Study of Insulin Resistance (EGIR). Hypertension. 1997;30: 1144-1149.

103. Festa A, D'Agostino R,Jr, Mykkanen L, et al. Relative contribution of insulin and its precursors to fibrinogen and PAI-1 in a large population with different states of glucose tolerance. The Insulin Resistance Atherosclerosis Study (IRAS). Arterioscler Thromb Vasc Biol. 1999;19: 562-568.

104. Chen NG, Holmes M, Reaven GM. Relationship between insulin resistance, soluble adhesion molecules, and mononuclear cell binding in healthy volunteers. J Clin Endocrinol Metab. 1999;84: 3485-3489.

105. Colley RC, Garriguet D, Janssen I, et al. Physical activity of Canadian adults: accelerometer results from the 2007 to 2009 Canadian Health Measures Survey. Health Rep. 2011;22: 7-14.

106. Richter EA, Garetto LP, Goodman MN, et al. Muscle glucose metabolism following exercise in the rat: increased sensitivity to insulin. J Clin Invest. 1982;69: 785-793.

107. Lauritzen HP, Galbo H, Toyoda T, et al. Kinetics of contraction-induced GLUT4 translocation in skeletal muscle fibers from living mice. Diabetes. 2010;59: 2134-2144. 
108. Hansen PA, Nolte LA, Chen MM, et al. Increased GLUT-4 translocation mediates enhanced insulin sensitivity of muscle glucose transport after exercise. J Appl Physiol. 1998;85: 1218-1222.

109. Gulve EA, Cartee GD, Zierath JR, et al. Reversal of enhanced muscle glucose transport after exercise: roles of insulin and glucose. Am J Physiol. 1990;259: E685E691.

110. Cartee GD, Young DA, Sleeper MD, et al. Prolonged increase in insulin-stimulated glucose transport in muscle after exercise. Am J Physiol. 1989;256: E494-E499.

111. Cartee GD, Holloszy JO. Exercise increases susceptibility of muscle glucose transport to activation by various stimuli. Am J Physiol. 1990;258: E390-393.

112. Ren JM, Semenkovich CF, Gulve EA, et al. Exercise induces rapid increases in GLUT4 expression, glucose transport capacity, and insulin-stimulated glycogen storage in muscle. J Biol Chem. 1994;269: 14396-14401.

113. Kraniou GN, Cameron-Smith D, Hargreaves M. Acute exercise and GLUT4 expression in human skeletal muscle: influence of exercise intensity. J Appl Physiol. 2006;101: 934-937.

114. Perseghin G, Price TB, Petersen KF, et al. Increased glucose transportphosphorylation and muscle glycogen synthesis after exercise training in insulinresistant subjects. N Engl J Med. 1996;335: 1357-1362.

115. Dubé JJ, Amati F, Stefanovic-Racic M, et al. Exercise-induced alterations in intramyocellular lipids and insulin resistance: the athlete's paradox revisited. $A m \mathrm{~J}$ Physiol Endocrinol Metab. 2008;294: E882-E888.

116. Rice B, Janssen I, Hudson R, et al. Effects of aerobic or resistance exercise and/or diet on glucose tolerance and plasma insulin levels in obese men. Diabetes Care. 1999;22: 684-691.

117. Ross R, Janssen I, Dawson J, et al. Exercise-Induced Reduction in Obesity and Insulin Resistance in Women: a Randomized Controlled Trial. Obes Res. 2004;12: 789798.

118. Ross R, Rissanen J, Pedwell H, et al. Influence of diet and exercise on skeletal muscle and visceral adipose tissue in men. J Appl Physiol. 1996;81: 2445-2455.

119. Thomas EL, Brynes AE, McCarthy J, et al. Preferential loss of visceral fat following aerobic exercise, measured by magnetic resonance imaging. Lipids. 2000;35: 769-776.

120. You T, Murphy KM, Lyles MF, et al. Addition of aerobic exercise to dietary weight loss preferentially reduces abdominal adipocyte size. Int J Obes. 2006;30: 1211-1216. 
121. Hickner RC, Racette SB, Binder EF, et al. Suppression of whole body and regional lipolysis by insulin: effects of obesity and exercise. J Clin Endocrinol Metab. 1999;84: 3886-3895.

122. Shojaee-Moradie F, Baynes KC, Pentecost C, et al. Exercise training reduces fatty acid availability and improves the insulin sensitivity of glucose metabolism. Diabetologia. 2007;50: 404-413.

123. Halle M, Berg A, Garwers U, et al. Influence of 4 weeks' intervention by exercise and diet on low-density lipoprotein subfractions in obese men with type 2 diabetes. Metabolism. 1999;48: 641-644.

124. Bruce CR, Thrush AB, Mertz VA, et al. Endurance training in obese humans improves glucose tolerance and mitochondrial fatty acid oxidation and alters muscle lipid content. Am J Physiol Endocrinol Metab. 2006;291: E99-E107.

125. Toledo FG, Watkins S, Kelley DE. Changes induced by physical activity and weight loss in the morphology of intermyofibrillar mitochondria in obese men and women. $J$ Clin Endocrinol Metab. 2006;91: 3224-3227.

126. Menshikova EV, Ritov VB, Toledo FG, et al. Effects of weight loss and physical activity on skeletal muscle mitochondrial function in obesity. Am J Physiol Endocrinol Metab. 2005;288: E818-E825.

127. Hawley JA, Lessard SJ. Exercise training-induced improvements in insulin action. Acta Physiol (Oxf). 2008;192: 127-135.

128. Kirwan JP, del Aguila LF, Hernandez JM, et al. Regular exercise enhances insulin activation of IRS-1-associated PI3-kinase in human skeletal muscle. J Appl Physiol. 2000;88: 797-803.

129. Luciano E, Carneiro EM, Carvalho CR, et al. Endurance training improves responsiveness to insulin and modulates insulin signal transduction through the phosphatidylinositol 3-kinase/Akt-1 pathway. Eur J Endocrinol. 2002;147: 149-157.

130. Houmard JA, Shaw CD, Hickey MS, et al. Effect of short-term exercise training on insulin-stimulated PI 3-kinase activity in human skeletal muscle. Am J Physiol. 1999;277: E1055-E1060.

131. Frosig C, Rose AJ, Treebak JT, et al. Effects of endurance exercise training on insulin signaling in human skeletal muscle: interactions at the level of phosphatidylinositol 3-kinase, Akt, and AS160. Diabetes. 2007;56: 2093-2102.

132. Christ-Roberts CY, Pratipanawatr T, Pratipanawatr W, et al. Exercise training increases glycogen synthase activity and GLUT4 expression but not insulin signaling in overweight nondiabetic and type 2 diabetic subjects. Metabolism. 2004;53: 1233-1242. 
133. Christ CY, Hunt D, Hancock J, et al. Exercise training improves muscle insulin resistance but not insulin receptor signaling in obese Zucker rats. J Appl Physiol. 2002;92: 736-744.

134. Ivy JL. Muscle insulin resistance amended with exercise training: role of GLUT4 expression. Med Sci Sports Exerc. 2004;36: 1207-1211.

135. MacLean PS, Zheng D, Jones JP, et al. Exercise-induced transcription of the muscle glucose transporter (GLUT 4) gene. Biochem Biophys Res Commun. 2002;292: 409-414.

136. Talanian JL, Holloway GP, Snook LA, et al. Exercise training increases sarcolemmal and mitochondrial fatty acid transport proteins in human skeletal muscle. Am J Physiol Endocrinol Metab. 2010;299: E180-E188.

137. Brozinick JT,Jr, Etgen GJ,Jr, Yaspelkis BB,3rd, et al. Effects of exercise training on muscle GLUT-4 protein content and translocation in obese Zucker rats. Am J Physiol. 1993;265: E419-27.

138. Egan B, Carson BP, Garcia-Roves PM, et al. Exercise intensity-dependent regulation of PGC-1 $\alpha$ mRNA abundance is associated with differential activation of upstream signalling kinases in human skeletal muscle. J Physiol. 2010;588: 1779-1790.

139. Rockl KS, Hirshman MF, Brandauer J, et al. Skeletal muscle adaptation to exercise training: AMP-activated protein kinase mediates muscle fiber type shift. Diabetes. 2007;56: 2062-2069.

140. Markuns JF, Wojtaszewski JF, Goodyear LJ. Insulin and exercise decrease glycogen synthase kinase-3 activity by different mechanisms in rat skeletal muscle. $J$ Biol Chem. 1999;274: 24896-24900.

141. Kruszynska YT, Mulford MI, Baloga J, et al. Regulation of skeletal muscle hexokinase II by insulin in nondiabetic and NIDDM subjects. Diabetes. 1998;47: 11071113.

142. Lichtman SW, Pisarska K, Berman ER, et al. Discrepancy between self-reported and actual caloric intake and exercise in obese subjects. N Engl J Med. 1992;327: 18931898.

143. McAuley KA, Williams SM, Mann JI, et al. Diagnosing insulin resistance in the general population. Diabetes Care. 2001;24: 460-464.

144. Gibala MJ, Little JP. Just HIT it! A time-efficient exercise strategy to improve muscle insulin sensitivity. J Physiol. 2010;588: 3341-3342.

145. Gibala MJ, Little JP, van Essen M, et al. Short-term sprint interval versus traditional endurance training: similar initial adaptations in human skeletal muscle and exercise performance. J Physiol. 2006;575: 901-911. 
146. Burgomaster KA, Howarth KR, Phillips SM, et al. Similar metabolic adaptations during exercise after low volume sprint interval and traditional endurance training in humans. J Physiol. 2008;586: 151-160.

147. Gibala MJ, McGee SL. Metabolic adaptations to short-term high-intensity interval training: a little pain for a lot of gain? Exerc Sport Sci Rev. 2008;36: 58-63.

148. Nybo L, Sundstrup E, Jakobsen MD, et al. High-intensity training versus traditional exercise interventions for promoting health. Med Sci Sports Exerc. 2010;42: 1951-1958.

149. Babraj JA, Vollaard NBJ, Keast C, et al. Extremely short duration high intensity interval training substantially improves insulin action in young healthy males. $B M C$ Endocr Disord. 2009;9.

150. Richards JC, Johnson TK, Kuzma JN, et al. Short-term sprint interval training increases insulin sensitivity in healthy adults but does not affect the thermogenic response to $\beta$-adrenergic stimulation. J Physiol. 2010;588: 2961-2972.

151. Whyte LJ, Gill JM, Cathcart AJ. Effect of 2 weeks of sprint interval training on health-related outcomes in sedentary overweight/obese men. Metabolism. 2010;59: 1421-1428.

152. Tjonna $A E$, Lee SJ, Rognmo O, et al. Aerobic interval training versus continuous moderate exercise as a treatment for the metabolic syndrome: a pilot study. Circulation. 2008;118: 346-354.

153. Hargreaves M. Muscle glycogen and metabolic regulation. Proc Nutr Soc. 2004;63: 217-220.

154. Pilegaard $\mathrm{H}$, Keller $\mathrm{C}$, Steensberg A, et al. Influence of pre-exercise muscle glycogen content on exercise-induced transcriptional regulation of metabolic genes. $J$ Physiol. 2002;541: 261-271.

155. Hansen AK, Fischer CP, Plomgaard $P$, et al. Skeletal muscle adaptation: training twice every second day vs. training once daily. J Appl Physiol. 2005;98: 93-99.

156. Keller C, Steensberg A, Pilegaard H, et al. Transcriptional activation of the IL-6 gene in human contracting skeletal muscle: influence of muscle glycogen content. FASEB J. 2001;15: 2748-2750.

157. Nielsen JN, Derave W, Kristiansen S, et al. Glycogen synthase localization and activity in rat skeletal muscle is strongly dependent on glycogen content. $J$ Physiol. 2001;531: 757-769.

158. van Loon LJ, Greenhaff PL, Constantin-Teodosiu D, et al. The effects of increasing exercise intensity on muscle fuel utilisation in humans. J Physiol. 2001;536: 295-304. 
159. Jeppesen J, Hansen TW, Rasmussen S, et al. Insulin Resistance, the Metabolic Syndrome, and Risk of Incident Cardiovascular Disease: A Population-Based Study. J Am Coll Cardiol. 2007;49: 2112-2119.

160. Ross R, Dagnone D, Jones PJH, et al. Reduction in Obesity and Related Comorbid Conditions after Diet-Induced Weight Loss or Exercise-Induced Weight Loss in Men. Ann Intern Med. 2000;133: 92-103.

161. Ross R, Rissanen J, Pedwell $\mathrm{H}$, et al. Influence of diet and exercise on skeletal muscle and visceral adipose tissue in men. J Appl Physiol. 1996;81: 2445-2455.

162. Tarnopolsky MA. Sex differences in exercise metabolism and the role of 17-beta estradiol. Med Sci Sports Exerc. 2008;40: 648-654.

163. Moro C, Pillard F, de Glisezinski I, et al. Sex differences in lipolysis-regulating mechanisms in overweight subjects: effect of exercise intensity. Obesity (Silver Spring). 2007;15: 2245-2255.

164. Devries MC, Hamadeh MJ, Phillips SM, et al. Menstrual cycle phase and sex influence muscle glycogen utilization and glucose turnover during moderate-intensity endurance exercise. Am J Physiol Regul Integr Comp Physiol. 2006;291: R1120-R1128.

165. D'Eon TM, Sharoff C, Chipkin SR, et al. Regulation of exercise carbohydrate metabolism by estrogen and progesterone in women. Am J Physiol Endocrinol Metab. 2002;283: E1046-E1055.

166. Perri MG, Anton SD, Durning PE, et al. Adherence to Exercise Prescriptions: Effects of Prescribing Moderate Versus Higher Levels of Intensity and Frequency. Health Psychol. 2002;21: 452-458.

167. King AC, Taylor CB, Haskell WL, et al. Identifying strategies for increasing employee physical activity levels: findings from the Stanford/Lockheed Exercise Survey. Health Educ Q. 1990;17: 269-285.

168. Mosca L, Benjamin EJ, Berra K, et al. Effectiveness-Based Guidelines for the Prevention of Cardiovascular Disease in Women--2011 Update: A Guideline From the American Heart Association. Circulation. 2011;123: 1243-1262.

169. Lloyd-Jones DM, Hong Y, Labarthe D, et al. Defining and setting national goals for cardiovascular health promotion and disease reduction: the American Heart Association's strategic Impact Goal through 2020 and beyond. Circulation. 2010;121: $586-613$. 
Appendix A

Example of a Consent Form 


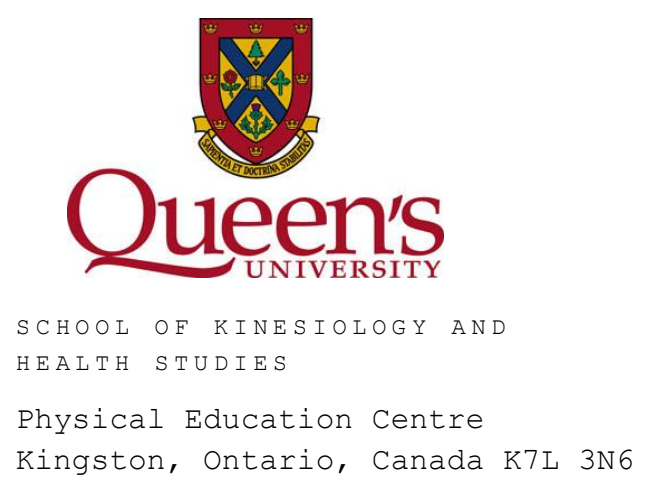

CONSENT TO VOLUNTEER FOR PARTICIPATION IN A STUDY

TITLE: Dose-response effects of exercise on abdominal obesity and risk factors for cardiovascular disease in women and men

PRINCIPAL INVESTIGATOR:

Robert M.J. Ross, Ph.D.

Queen's University

School of Kinesiology and Health Studies/

Medicine, Division of Endocrinology and

Metabolism

Kingston, Ontario, K7L 3N6

(613) 533-6583

CO-INVESTIGATORS:

Robert Hudson, M.D., Ph.D., FRCPC

Kingston General Hospital

Medicine, Division of Endocrinology and Metabolism

Kingston, Ontario, K7L 3N6

(613) 533-2973

Miu Lam, Ph.D.

Queen's University

Department of Community Health and Epidemiology

Kingston, Ontario, K7L 3N6 
You are invited to participate in a research study on the influence of different doses (amounts) of exercise on abdominal fat and related health risk. The following brief is intended to provide you with the details you should be aware of prior to your consent as a participant in this study. Please read the following information carefully and feel free to ask any question that you may have.

\section{BACKGROUND INFORMATION}

Obesity is a major risk factor for disease and a public health problem. Recent information suggests that body fat located in the upper body region (abdominal fat) conveys a very strong health risk. Exercise is thought to be a good treatment option for reducing both abdominal fat and cardiovascular risk factors (e.g., blood fats (cholesterol), blood sugar and blood pressure). However, the specific exercise strategy or program required to achieve optimal benefit continues to be the source of considerable debate. At present, health professionals are unsure of the specific type, amount, pattern, and intensity of exercise that provides optimal health benefits. Therefore, you are invited to participate in a study to assess the relationships between exercise dose (how much) and intensity (how hard) on abdominal fat, and cardiovascular risk factors (e.g., blood sugar and fats). The results of the study may have important implications for development of public health messages and clinical guidelines for prevention and treatment of obesity and associated health risks through exercise.

\section{EXPLANATION OF PROCEDURES \\ Pre-participation screening}

You will be required to complete a medical questionnaire and make an appointment with your family physician prior to participation in this study. Your physician will also complete a medical questionnaire and may perform a medical examination on you. If your family physician charges you for completion of this exam, an invoice can be faxed to the Project Coordinator 613-533-2580 for payment or, the study investigators will reimburse you fully. In addition to the medical exam, you will have a fasting blood test to measure your blood fat and sugar levels. We will also measure your waist circumference. These measures are explained in further detail on pages four (4) and five (5) of this form.

\section{Study Protocol}

The exercise study will be approximately 7 months in duration. The 6-month exercise period will begin and end with a 1 to 2 week weight maintenance period. By volunteering to participate in this study, your name will be selected by chance and placed into one of the following four groups: (1) Control - no exercise, (2) Low volume-Low intensity exercise, (3) High volume- Low intensity exercise, (4) Low volume-High intensity exercise. You will have a 1 in 4 chance of being placed in one of the four study groups. You will not be able to choose which group you will be in.

The follow-up study will take place during Months 7-13. During this part of the study, you will be asked to continue the same exercise routine that you followed for the first six months. The reason for the 6-month follow-up is to find out whether you have been able to maintain the exercise level prescribed at start of the study. 


\section{Expectations}

You will be expected to:

1. Accept your group assignment

2. Participate fully in your assigned groups for the duration of the study

3. Keep all testing appointments

4. Provide accurate answers on all questionnaires

You can expect:

1. Full disclosure of all procedures required for participation in this study

2. To be treated fairly and with respect

3. Any information that is disclosed will be private and confidential

4. No one will be coerced or forced to do anything they wish not to do

5. To have all your questions answered fully and as promptly as possible

6. To not be penalized for choosing to withdraw from the study for any reason

Control Group: For the entire study the men and women in this group will consume a healthful diet. Thus there will be no weight loss or exercise.

Low volume-Low intensity group: As a participant in this exercise group you will be asked to perform walking type exercise on a motorized treadmill for around 30 minutes, 5 times per week, at about $50 \%$ of your maximum fitness level (e.g., low-to-moderate paced walking) for the duration of the 6 month treatment period. During each exercise session we will measure your heart rate every 5 minutes using an automated heart rate monitor. All of your exercise sessions will be by appointment and performed under supervision of a trained professional within our laboratory at Queen's.

High volume-Low intensity group: As a participant in the aerobic exercise group you will be asked to perform walking type exercise on a motorized treadmill for around 60 minutes, 5 times per week, at about $50 \%$ of your cardiovascular fitness level (e.g., lowto-moderate paced walking) for the duration of the 6 month treatment period. During each exercise session we will measure your heart rate every 5 minutes using an automated heart rate monitor. All of your exercise sessions will be by appointment and performed under supervision within our laboratory at Queen's.

Low volume-High intensity group: As a participant in the aerobic exercise group you will be asked to perform walking and/or jogging type exercise on a motorized treadmill for around 30 minutes, 5 times per week, at about $75 \%$ of your cardiovascular fitness level (e.g., brisk walking) for the duration of the 6 month treatment period. During each exercise session we will measure your heart rate every 5 minutes using an automated heart rate monitor. All of your exercise sessions will be by appointment and performed under supervision within our laboratory at Queen's.

Diet Program: All participants in each group will eat the same type of foods. The diet will consist of regular foods that you will buy and prepare yourself. All aspects of the diet plan will be explained to you by a nutritionist. The session will take place at the beginning of the study, with several additional sessions planned throughout to help you follow the diet plan. If someone else shops for your food or prepares your meals, or if 
you share those tasks with someone else, that person is invited to meet with the nutritionist as well. You will be required to record the food you eat each day for the duration of the study. All of your meetings with the nutritionist will be in Dr. Ross's laboratory within the School of Kinesiology \& Health Studies at Queen's.

At the beginning of the study, using the diet records that you complete, the number of calories required to maintain your body weight will be determined. During the study the nutritionist will work with you to help you to maintain this caloric (number of calories) intake. In other words, the nutritionist will help you eat an amount of food that would normally maintain your body weight. Thus any weight loss you experience will be the result of an increase in exercise.

\section{Magnetic Resonance Imaging}

Magnetic resonance imaging (MRI) is a method for creating pictures of body structures or organs. MRI gives pictures (images) in slices comparable to those produced by x-ray tomography (e.g., CT scan). One of the primary advantages of MRI is that it does not use x-rays or other forms of radiation. Instead, a large magnet, a radio transmitter/receiver and a computer are used to gather information from the body, and to produce pictures of internal anatomy. No harmful effects have been associated with MRI under existing conditions of use. However, if you feel claustrophobic during the scan you can end the test immediately.

As mentioned, the MRI procedure is very similar to a scanner examination. You will be placed on a table and moved smoothly into the scanner. A loud-speaker within the magnet makes it possible for you to keep in constant contact with the staff. At all times the operator can see and hear you and if you need help or have questions, you can be removed from the machine if necessary. The whole procedure takes about 30 minutes and will be performed by appointment at Kingston General Hospital once at the beginning of the study and one at the end of the exercise study (week 24).

\section{Anthropometry (Skinfolds and Circumferences)}

Many circumference measurements will be taken at numerous places on your body. These measurements can be used to derive estimates of body composition. Skinfold callipers (skinfold thickness) will be measured at 4 different places on your body. Circumferences measurements using a measuring tape will also be obtained at different places on the body. These measurements require about 45 minutes to complete and will be obtained at Dr. Ross's laboratory within the School of Kinesiology \& Health Studies at Queen's.

We will collect these measurements five times throughout the study: at the beginning (week 0), then after two months (week 8), four months (week 16), at the end of the exercise training period (week 24), and at follow-up (week 48, six months after the end of the exercise training period).

\section{Assessment of Cardiovascular Fitness}

We will measure your cardiovascular fitness (endurance) using a treadmill $\left(\mathrm{VO}_{2}\right)$ test. The test will begin at a level you can easily accomplish and will be advanced in stages, depending on your capacity to do so. We may stop the test at any time because of 
signs of fatigue or you may stop the test because of personal feelings of fatigue or discomfort.

The treadmill test involves risks comparable to any strenuous exercise situation. They include very rare instances of abnormal blood pressure, fainting, disorders of the heartbeat, and heart attack. Every effort will be made to minimize your risk by preliminary medical examination and observation during the test. A Research Assistant at Hotel Dieu Hospital, with a trained paramedic or medical doctor on-site, will conduct your fitness test. You will perform the exercise test 6 times: at the beginning (Week 0), after one month (week 4), after two months (week 8), after four months (week 16), at the end of the exercise training period (week 24), and at follow-up (week 48, six months after the end of the exercise training period).

\section{Assessment of Daily Physical Activity}

How physically active you are throughout the day will be measured by two small devices known as accelerometers: one is worn on your arm (armband) and one is worn on your hip (Actigraph). The armband involves wearing a monitor that is worn on your upper right arm that will track the amount of energy you burn and the amount of physical activity that you perform. The Actigraph is a small unit that you wear on your belt at the level of your hip and this device also measures the amount of physical activity that you perform. You will wear these monitors during all of your waking hours and will remove the monitor when you sleep or participate in water activities such as showering, bathing, or swimming. You will wear this device for 7 consecutive days at $0,8,16$, and 24 weeks.

\section{Laboratory measurements (blood glucose (sugar) and lipid (fat) tests)}

The measurement of how much sugar and fat are in your blood will be done at Dr. Ross's laboratory within the School of Kinesiology \& Health Studies at Queen's. To determine your ability to manage blood sugar you will be asked to perform an Oral Glucose Tolerance Test. You will be asked to arrive at the lab in the morning after an overnight fast (no eating after $7 \mathrm{pm}$ the night before). The first step of this test will be the insertion of a saline lock into a vein in your arm. This allows the nurse to take blood at different times without having to re-puncture each time. She will then remove about 30 $\mathrm{ml}$ (3 tablespoons) of blood. The only risk from this procedure is possible local pain and bruising at the time of the blood test. In addition, you will be asked to drink a fluid that contains 75 grams of sugar (like an orange drink). At 30-minute intervals for 2 hours after drinking the sugar solution, a small amount of blood will be taken (through the saline lock) for the purpose of measuring the amount of sugar in the blood. This test will be performed four times during the study: at week 0, after four months (week 16), at the end of the exercise period (week 24) and at the end of the follow-up (week 48).

\section{Summary of Appointments and Time Requirements}

All appointments will be scheduled at a time that is convenient for you. For the testing you will be required to make six 45-minute appointments at the Hotel Dieu Hospital to complete the cardiovascular fitness ( $\mathrm{VO}_{2}$ peak). We will also arrange two 30minute appointments to complete the MRI (Kingston General Hospital). The other testing will be done at Dr. Ross's laboratory in the School of Kinesiology \& Health 
Studies at Queen's. This includes: four 2.5-hour appointments for the oral glucose tolerance test and blood lipid/cholesterol tests (fasting blood draw); and five 45-minute anthropometric measurement appointments. In addition, we will ask you to make appointments for dietary counselling and for exercise (if you are randomized into one of the exercise groups). The total time commitment for all testing appointments and exercise sessions over the total 13-month study will be between 86 and 149 hours.

Time commitment per participant

\begin{tabular}{lccc}
\hline \multicolumn{1}{c}{ Measure/Task } & Time per session & Number of sessions & Total time \\
\hline Anthropometrics & $1 \mathrm{hr}$ & 5 & $5 \mathrm{hr}$ \\
Fitness $\left(\mathrm{VO}_{2}\right.$ ) test & $1 \mathrm{hr}$ & 6 & $6 \mathrm{hr}$ \\
OGTT & $2.5 \mathrm{hr}$ & 4 & $10 \mathrm{hr}$ \\
MRI & $0.75 \mathrm{hr}$ & 2 & $1.5 \mathrm{hr}$ \\
Dietary Counsel & $0.5-1 \mathrm{hr}$ & $6-12$ & $3-6 \mathrm{hr}$ \\
Exercise & $0.5-1 \mathrm{hr}$ & 120 & $60-120 \mathrm{hr}$ \\
\hline TOTAL & & & $\mathbf{8 6 - 1 4 9} \mathbf{h o u r s}$ \\
\hline
\end{tabular}

\section{Benefits of Participation}

You will gain no direct benefit through participation in this study.

\section{Risks of Participation}

Participation may involve some risks. The known risks are:

1) Insertion of a catheter in your arm or hand vein may cause bruising, bleeding, soreness or infection.

2) For MRI, there are certain conditions that would exclude you from participating in this study. These include cardiac pacer, aneurysm clip, cochlear implant, intrauterine device (IUD), shrapnel, neurostimulators or other metal devices. Metal objects present in the body could be moved by the large magnet involved in the MRI, and such movement could cause serious injury. Fear of closed spaces (claustrophobia) is also a reason you would be excluded from the study. No serious biological effects have been reported from being in a magnet. If you experience a fear of the confined space while in the magnet, you can terminate the study. Trained personnel are always in attendance during these studies.

3) The exercise test may cause muscle soreness or fatigue. In any individual, there is a minute risk of a heart attack or death from the exercise test. A trained paramedic or medical doctor will be on-site. If you develop chest pain, the test will be stopped immediately.

4) Risk of Wearing the Activity Monitor: Some people may experience mild skin irritation at the site where the activity monitor is worn. One cause of skin irritation has already been identified in people who wear the armband for extensive periods of time (i.e., more than 24 hours). Specifically, the build-up of sweat that can be trapped between the skin and the armband can cause pink pustules or pimples to appear. This condition is named miliaria, or prickly heat. This condition is common and occurs in $10 \%$ to $25 \%$ of people (10 to 25 out of 100 people) that wear the armband. To help to prevent this condition you should clean your arm using rubbing alcohol before putting on the activity monitor. Also, you should use soap and water to clean the elastic strap that attaches the 
monitor to your arm before each use. You should also wipe off the monitor using rubbing alcohol and allow this to dry before putting it on your arm.

You should inform the investigators if you have participated in any other research study during the previous year. This will help to ensure that you have not been exposed to a procedure in another study that may influence your ability or eligibility to participate in this one. You should understand that this study is a research study and may not be of direct benefit to you. If requested, a report will be generated for your medical record, which will include any information important for your medical care.

\section{CONFIDENTIALITY}

All information obtained during the course of this study is strictly confidential and your anonymity will be protected at all times. Your information will be kept in locked files and will be available only to Dr. Robert Ross and those working within his laboratory. Your identity will not be revealed in any description or publication. In the event you that you are injured as a result of the study procedures, medical care will be provided to you until resolution of the medical problem. By signing this consent form, you do not waive your legal rights nor release the investigator(s) and sponsors from their legal and professional responsibilities.

Financial remuneration (\$100) for parking, gas, and other costs associated with participation in the study will be provided to you. 


\section{VOLUNTARY CONSENT}

I have been given an opportunity to ask any questions concerning the procedures. All of my questions regarding the research project have been satisfactorily answered. I understand that my test results are considered confidential and will never be released in a form that is traceable to me, with the exception of my family physician or myself. I understand that all my lab results will be sent to my family physician. I do understand that I am free to deny consent if I so desire, and may withdraw from the study at any time without prejudicing current or future medical care.

Should I have any questions about the study, I know that I can contact any of the following: Dr. Robert Ross (613 533-6583), Dr. Jean Coté, Head, School of Kinesiology and Health Studies (613 533-6601), or Dr. Albert Clark, Chair, Queen's Health Sciences \& Affiliated Teaching Hospitals Research Ethics Board (613 533-6081). A copy of this consent form will be provided me for my records. My signature below means that I freely agreed to participate in this study.

\section{Volunteer's Signature}

\section{Date:}

\section{STATEMENT OF INVESTIGATOR}

I, or one of my colleagues, have carefully explained to the subject the nature of the above research study. I certify that, to the best of my knowledge, the subject understands clearly the nature of the study and demands, benefits, and risks involved to participants in this study. 
Appendix B

Example of a Medical Questionnaire 


\section{School of Kinesiology and Health Studies}

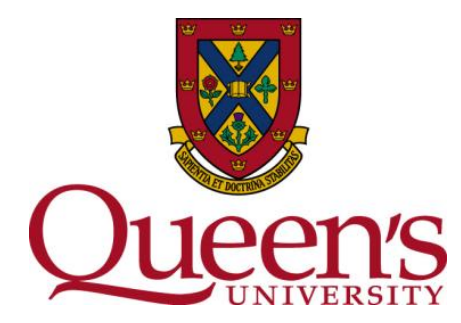

MEDICAL QUESTIONNAIRE FOR RESEARCH STUDY

\section{DOSE-RESPONSE EFFECTS OF EXERCISE ON ABDOMINAL OBESITY AND RISK FACTORS FOR CARDIOVASCULAR DISEASE IN WOMEN AND MEN}

To the study participant: Please answer all questions in sections 1 and 2 of this form. Have your family doctor fill out section 3 .

To the physician: Please fill out section 3 of this form (pages 4-6). Completing this form may not require a medical re-evaluation of your patient. If the results of recent tests are readily available that might prove useful to study personnel while dealing with the participant, please include that information in this questionnaire.

Please return sections 1 to 3 to the Project Manager via fax at (613)5332580 along with an invoice for any costs associated with completing the form. 


\section{SECTION 1: PERSONAL DATA (please print)}

Name:

Date of Birth:

Date:

\section{SECTION 2: MEDICAL HISTORY}

Yes No

A. Has your doctor ever said you have heart trouble?

B. Do you get pains, pressure or tightness in your chest?

C. Do you often feel faint or experience dizziness?

D. Has you doctor ever told you that you have high blood pressure?

E. Is there a good reason, not mentioned above, why you should avoid exercise?

F. Have you ever had blood taken?

G. Have you ever had any negative experiences with a blood draw? If yes, please describe:

H. Do you have any allergies (i.e. latex, medications, etc)?

I. Do you have diabetes? $\quad$ YES $\square \quad$ NO $\square$

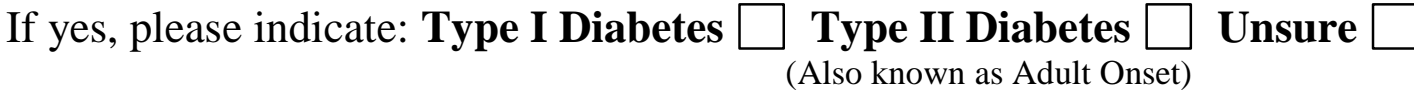

$\square$ Diet Controlled $\square$ Oral Diabetic Medication $\square$ Insulin Required 
J. Do you have, or have you ever had, problems with any of the following?
Yes
No
i. Heart or blood vessels
ii. Nerves or brain
iii. Breathing or lungs
iv. Hormones, thyroid, or diabetes
v. Muscles, joints, or bones
vi. Other (please list)

K. Please list any serious injuries suffered, or surgeries you have had.

L. If you have had surgery, was any metal (e.g., pins or screws) left in your body?

M. Are you presently taking any medications? If yes, please list.

N. Are you presently undergoing physiotherapy, or any other sort of treatment? If yes, please list.

I hereby authorize the my family physician to complete Section 3 of this medical questionnaire and to fax or send to the SERENA exercise study researchers at Queen's University. 


\section{SECTION 3: MEDICAL REFERRAL}

Physician: The applicant is considering participation in a research study that is investigating the effects of exercise dose (amount) on abdominal obesity and related cardiovascular disease risk factors. As a participant in this study, your patient would undergo a cardiorespiratory fitness appraisal (see explanation on last page) and a number of other tests to assess body composition and metabolic health risk. We will forward any test results to you with your patient's consent.

Should you have any questions regarding the participation of your patient in this project, please contact Robert Ross Ph.D., School of Kinesiology and Health Studies, Queen's University (613-533-6583). Please return completed sections 1 to 3 to the Project Manager via fax at (613-533-2580) along with an invoice for any costs associated with completing this form.

\section{Review of Systems - please include diagnoses.}
a) Cardiovascular
b) Respiratory
c) Neurological
d) Gastrointestinal
e) Genitourinary
f) Endocrine
g) Musculoskeletal
h) Skin
i) Gynecological

\section{Physical Examination}

Blood Pressure:

Pulse:

Cardiovascular:

Respiratory:

Head and Neck: 
MSK:

Abdomen:

12-lead ECG (not mandatory):

Neurological:

\section{Laboratory findings (not mandatory) Date of Test(s):}

$\mathrm{Hb}$ WBC

Plts

Total Cholesterol

HDL

Chol:HDL ratio

LDL Triglycerides Uric Acid

TSH Glucose fasting $\square$ random

75 g OGTT @ 120 min

IV. Additional abnormalities of which you are aware

IV. Current medications and doses

VI. On the basis of your knowledge and medical evaluation of the applicant, you would recommend (mark the appropriate answer):

Participation in a fitness appraisal supervised by a physical education graduate, or Participation in a fitness appraisal only when a physician or paramedic is present, or Participation in a fitness appraisal is not recommended

Note: An explanation of the fitness appraisal protocol, as well as absolute and relative contraindications to exercise testing, is provided on page 7 of this form. 
Physician's Name:

Physician's Signature:

Date:

Phone Number:

Address:

Thank you very much for your help. We hope that this study and its results will be beneficial to you and your patient 


\title{
Appraisal of Cardiorespiratory Fitness $\left(\mathrm{VO}_{2}\right.$ peak)
}

Cardiorespiratory fitness is assessed using a maximal oxygen uptake $\left(\mathrm{VO}_{2}\right.$ peak $)$ test, which is routinely employed within the laboratory of the study investigators. The treadmill test begins at a level the study participant can easily accomplish (comfortable walking pace with no incline) and is slowly increased in intensity (by increasing treadmill incline) until the participant reaches volitional fatigue. We may stop the test at any time because of signs of fatigue or the subject may stop the test because of personal feelings of fatigue or discomfort.

The maximal oxygen uptake test involves risks comparable to very strenuous aerobic exercise. Every effort is made to minimize the risk by preliminary medical examination and close observation during the test by physical education graduate students and a physician.

\section{American College of Sports Medicine Contraindications to Exercise Testing}

\author{
Absolute Contraindications \\ A recent change in the resting ECG suggesting infarction or other acute cardiac events \\ Recent complicated myocardial infarction \\ Unstable angina \\ Uncontrolled ventricular dysrhythmia \\ Uncontrolled atrial dysrhythmia that compromises cardiac function \\ Third-degree A-V block \\ Acute congestive heart failure \\ Severe aortic stenosis \\ Suspected or know dissecting aneurysm \\ Active or suspected myocarditis or pericarditis \\ Thrombophlebitis or intracardiac thrombi \\ Recent systemic or pulmonary embolus \\ Acute infection \\ Significant emotion distress (psychosis)

\section{Relative Contraindications} \\ Resting diastolic blood pressure $>120 \mathrm{~mm} \mathrm{Hg}$ or systolic blood pressure $>200 \mathrm{~mm} \mathrm{Hg}$. \\ Moderate valvular heart disease \\ Known electrolyte abnormalities (hypokalemia, hypomagnesemia) \\ Fixed-rate pacemaker (rarely used) \\ Frequent of complex ventricular ectopy \\ Ventricular aneurysm \\ Cardiomyopathy, including hypertrophic cardiomyopathy \\ Uncontrolled metabolic disease (e.g., diabetes, thyrotoxicosis, or myxoedema) \\ Chronic infectious disease (e.g., mononucleosis, hepatitis, AIDS) \\ Neuromuscular, musculoskeletal, or rheumatoid disorders that are exacerbated by \\ exercise
}




\section{Appendix C}

Example of an Anthropometric Data Acquisition Protocol 


\section{List of Measured Variables:}

- Height $(\mathrm{cm})$

- Waist Circumference $(\mathrm{cm})$

- Weight $(\mathrm{kg})$

\section{Measurement Devices:}

- Anthropometric tape (Gullick II) - contains a tension indicator device

- Detecto weight scale

- Stadiometer

\section{Measurement Procedures:}

The participant changed into an athletic shirt and shorts, and a pair of comfortable shoes suitable for all anthropometric measurements.

Weight $(\mathbf{k g})$ : measured on the Detecto weight scale with shoes removed, wearing the clothing provided.

Standing Height (cm): measured with shoes removed, standing with heels close to the wall, feet together, eyes looking straight ahead, back, and buttocks touching the back rest of the stadiometer. The participant was instructed to stand tall and take a normal breath in, at which time the measurement given on the dial was recorded.

\section{Waist Circumference (cm):}

1. The participant's abdomen was cleared of all clothing and accessories. If the participant was resistant to the suggestion to fully removing their shirt, the shirt was rolled up partially and held in place with a clip.

2. The participant was positioned with feet shoulder width apart and arms crossed over the chest in a relaxed manner. 
3. The Research Assistant took a position to the right side of the participant's body on one knee (Appendix C - Figure 1).

4. The tape was positioned directly around the abdomen so that the inferior edge of the tape was at the level of the bottom of rib cage on right side. This landmark was identified by palpating the lower right rib cage and drawing a line at the site of the lowest lateral border of the ribs.

5. A cross-handed technique was used to bring the zero line of the tape in line with the measuring aspect of the tape. Before recording the measurement the Research Assistant ensured that the measuring tape was positioned in a straight horizontal plane around the abdomen (Appendix C - Figure 2).

6. At the end of a normal expiration, the waist circumference measurement was recorded. 
Appendix C - Figure 1. Research Assistant Preparing To Measure Waist Circumference.

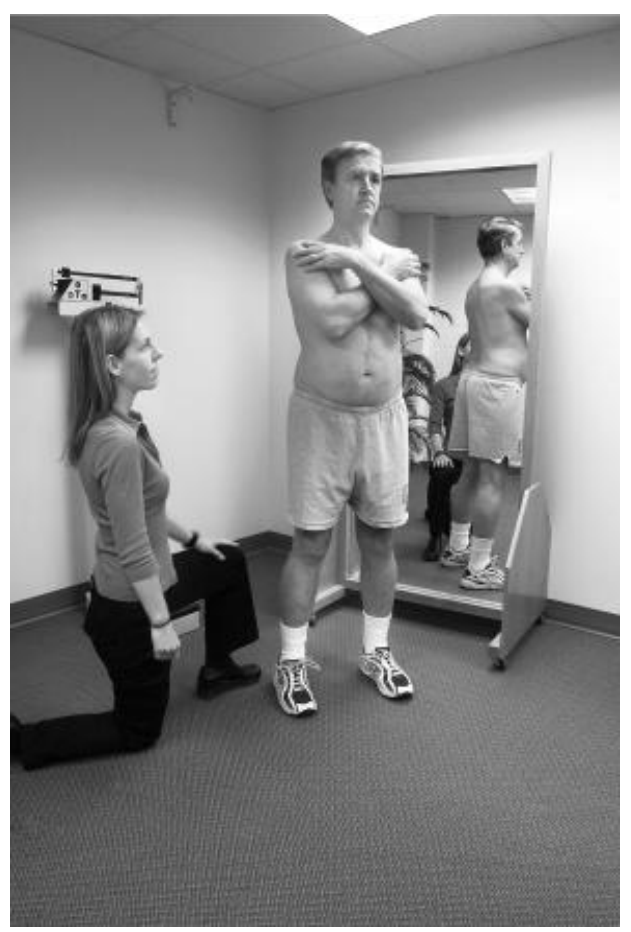

Appendix C - Figure 2. Measurement of Waist Circumference.

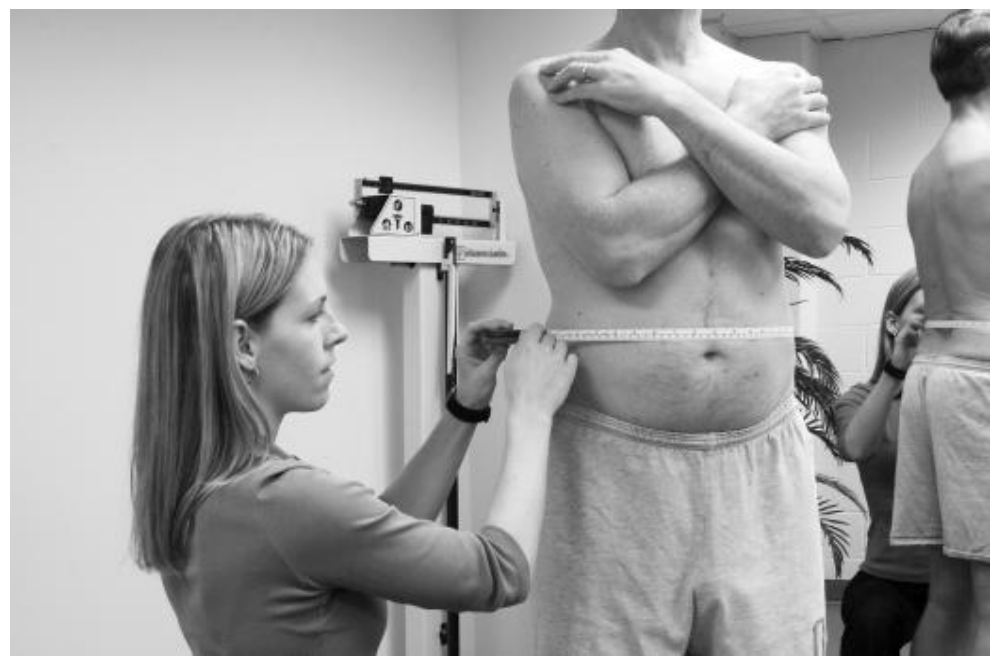


Appendix D

Example of a Graded Exercise Test Protocol 
Peak oxygen consumption $\left(\mathrm{VO}_{2}\right.$ peak) was determined using a graded treadmill exercise test. The test was performed at the Hotel Dieu Hospital and was repeated at 4 week intervals.

\section{List of Measured Variables:}

- Peak oxygen consumption $(\mathrm{mL} / \mathrm{kg} / \mathrm{min})$

\section{Measurement Devices:}

- Calibration gas tanks (with sufficient gas)

- Polar heart rate monitor

- Sensor Medics Vmax29 Metabolic Cart

- Treadmill

\section{Measurement Procedures:}

1. The Vmax system was turned on 30 minutes in advance of attempting system calibration.

2. Flow volume and gas analyzer calibration was performed. This took between 30 to 45 minutes.

3. The participant changed into an athletic shirt and shorts, and a pair of comfortable shoes suitable for brisk walking or jogging. At this time the participant was provided with a Polar heart rate monitor.

4. The entire procedure was thoroughly explained to the participant. Instructions included; how to stop the test upon reaching exhaustion, and to stop exercising immediately if chest pain or dizziness ensues.

5. The participant familiarized themselves with the treadmill and equipment during a warm up lasting approximately 5 minutes. 
6. The test began with participant walking at a relatively brisk pace while at level grade. During every step hereafter, heart rate was recorded every 20 seconds by a Research Assistant. Breath-by-breath analysis of respiratory gases was also recorded throughout the test.

7. The grade was increased to $5 \%$ at the $3^{\text {rd }}$ minute.

8. The grade was further increased by $2 \%$ every 2 minutes.

9. After 2 minutes at the maximal incline of $15 \%$, if the participant had not reached exhaustion, the speed was increased (generally by 0.2 miles per hour).

\section{Criteria for a successful Graded Treadmill Exercise Test:}

Several criteria were used to determine whether the participant achieved $\mathrm{VO}_{2}$ peak. In order to a test to be considered successful, it was required to meet at least 3 of the following criteria:

- Plateau in oxygen uptake with increasing work rate (increasing treadmill incline, speed or both).

- Respiratory Quotient greater than 1.10.

- Heart rate exceeding age predicted max HR [(220 - age) - 12 beats per minute]. 


\section{Appendix E}

Example of a Hyperinsulinemic Euglycemic Clamp Protocol 
Hyperinsulinemic Euglycemic Clamp, also called clamp hereafter, is the gold standard for quantifying insulin sensitivity. The test provides a direct measure of whole body glucose disposal in response to exogenous hyperinsulinemia. The clamp was performed at Hotel Dieu Hospital. Insulin sensitivity was assessed at baseline and postexercise.

\section{List of Measured Variables:}

- Glucose disposal (mg/kgskm/min)

\section{Measurement Devices:}

- Glucose $(20 \%)$

- Catheters

- Heating pads

- Insulin (Novolin, Toronto)

- Potassium (42 mEq)

- Saline $(0.9 \% \mathrm{NaCl})$

- YSI 2300 Glucose Analyzer

\section{Measurement Procedures:}

During the 3 days prior to the test the participant was advised to abstain from exercise. The clamp was scheduled between 4 days after the final exercise session. The participant fasted for 12 hours prior to the clamp, and followed a specific meal plan for the night before the test.

1. The participant changed into an athletic shirt and shorts.

2. The participant was asked to lie in the bed located within the clamp room. They were encouraged to relax or sleep. 
3. Clamp documentation was prepared by the Research Assistant. This included the calculation of body surface area.

4. The heating pads were plugged in and used to warm the participant's arms.

5. A catheter was placed in an antecubital vein for the infusion of a normal saline drip, as well as for the infusion of insulin, glucose, and potassium.

6. A hand vein was cannulated in a retrograde fashion for the collection of blood samples.

7. The venous sample site (the hand) was heated to increase blood flow so that venous blood more closely approximated arterial blood.

8. A pre-clamp fasting blood draw was taken to obtain baseline concentrations of circulating insulin and glucose. At this time a sample was also collected for analysis of plasma lipids.

9. Upon commencing the clamp insulin was infused at a rate of $40 \mathrm{mU} / \mathrm{m} 2 /$ minute, potassium was infused at a rate of $7.5 \mathrm{ml} \cdot \mathrm{minute}^{-1}$, and blood glucose was clamped at $5.0-5.5 \mathrm{mmol} / \mathrm{L}$.

10. Blood glucose was measured using an automated glucose analyzer (YSI 2300 Glucose Analyzer; YSI, Yellow Springs, $\mathrm{OH}$ ) every 5 minutes in arterialized blood. Glucose infusion rate was adjusted accordingly.

11. A sample was taken from the venous sample site partway through the clamp for analysis of the blood gases. If the oxygen content was lower in the sample (below 0.90 ), we would adjust the heating pads, wait at least 10 minutes, and then do another sample

12. After approximately $150-180$ minutes, once the physician was certain that the participant is "clamped" (glucose infusion rate had reached a steady state), the test 
was continued for a final 30 minutes. Glucose disposal rate was calculated as the average exogenous glucose infusion rate during these final 30 minutes of euglycemia.

13. Lunch was served to the participant at the end of the clamp. The participant was not allowed to leave until at least 30 minutes after lunch is completed and blood glucose readings indicate normal for post-prandial state. 


\section{Appendix $\mathbf{F}$ \\ Example of a MRI Acquisition Protocol}


Body composition was assessed by whole body magnetic resonance imaging (MRI). The MR images were obtained within the Department of Radiology at Kingston General Hospital. Whole body MRI was performed at baseline and post-exercise.

\section{List of Measured Variables:}

- Skeletal muscle mass $(\mathrm{kg})$

- Total abdominal adipose tissue mass $(\mathrm{kg})$

- Total adipose tissue mass $(\mathrm{kg})$

- $\quad$ Visceral adipose tissue mass $(\mathrm{kg})$

\section{Measurement Device:}

General Electric 1.5 Tesla magnet (Milwaukee, WI)

\section{Measurement Procedures:}

Preparing the participant

In order to determine if the participant had any contraindications preventing them from being examined with the MRI scanner, they were asked to fill out consent forms prior to the appointment. Upon arrival at the hospital, participants changed into hospital gowns and removed any metal objects (e.g. jewelry, glasses etc.) to eliminate artifact in the images.

\section{Image Acquisition}

The data acquisition process takes 20-30 minutes. The participant was placed prone, feet first into the MRI machine. A saggital scout was taken to locate the L4-L5 disk. Once the L4-L5 disk was landmarked, axial images were acquired from the L4-L5 disk to the toes at $50 \mathrm{~mm}(5 \mathrm{~cm})$ intervals. Each interval consisted of a $10 \mathrm{~mm}(1 \mathrm{~cm})$ thick image with $40 \mathrm{~mm}(4 \mathrm{~cm})$ of interspace between. Images were gathered in sets of 7 (310 $\mathrm{mm}$ total). Acquiring a set of 7 images took approximately 26 seconds. The set of 7 
images taken in the pelvis required the participant to hold their breath. Purpose of breath hold was to reduce the amount of movement so that noise is minimized in the resulting image. Generally 3-4 sets were acquired depending on the participant's height.

The participant was then removed from the MRI machine and asked to change their orientation so that they enter the MRI machine face down and head first. Their arms were to be extended over their head. Another saggital scout was taken to locate the L4-L5 disk. The L4-L5 disk was landmarked once again, and then the images were acquired from L4-L5 up to the tips of the fingers also at $50 \mathrm{~mm}(5 \mathrm{~cm})$ intervals. Generally 3-4 sets were acquired during this stage as well. The participant was asked to hold their breath for the images taken in abdomen, and the chest.

\section{Data Analysis:}

The acquired images were burned onto a compact disk and taken back to an image analysis computer at Queen's University. The scouts were removed and the images to be used for analysis were identified and arranged sequentially from inferior (foot images) to superior (finger images). Once the sequence was determined, a script file was created. The script file was created so that the images could be retrieved in the pre-determined sequence without the scouting images for the tissue analysis.

Determination of tissue area (muscle, fat, organ, etc.) on each image was accomplished using specially-designed image analysis software called Slice-O-Matic, a product of Tomovision (Montreal, Canada). Each grey level image is composed of voxels. A voxel represents a 1 centimeter thick cross section of tissue. The tissues depicted on each voxel were tagged with specific colors. The total number of voxels with each tag labeling was quantified (Appendix F - Figure 1). 
If the images were contiguous, simply adding the voxels of a specific tissue tag throughout the body would have yielded whole body tissue volume. However, since the images were not contiguous, but rather separated by $40 \mathrm{~mm}$, the $4 \mathrm{~cm}$ of body tissue between images was interpolated mathematically using data from adjacent images. Further, because each tissue varies in density, we employed tissue-specific conversions to express volumes as mass (in kilograms). For example, skeletal muscle and adipose tissue volumes were converted to mass by multiplying them by 1.04 and 0.92 , respectively. A visual representation of inter-image interpolation and formulas used for the volume calculations is found in Appendix F - Figure 2.

Appendix F - Figure 1. Tagging Tissues on MR Images Using Slice-O-Matic Software.

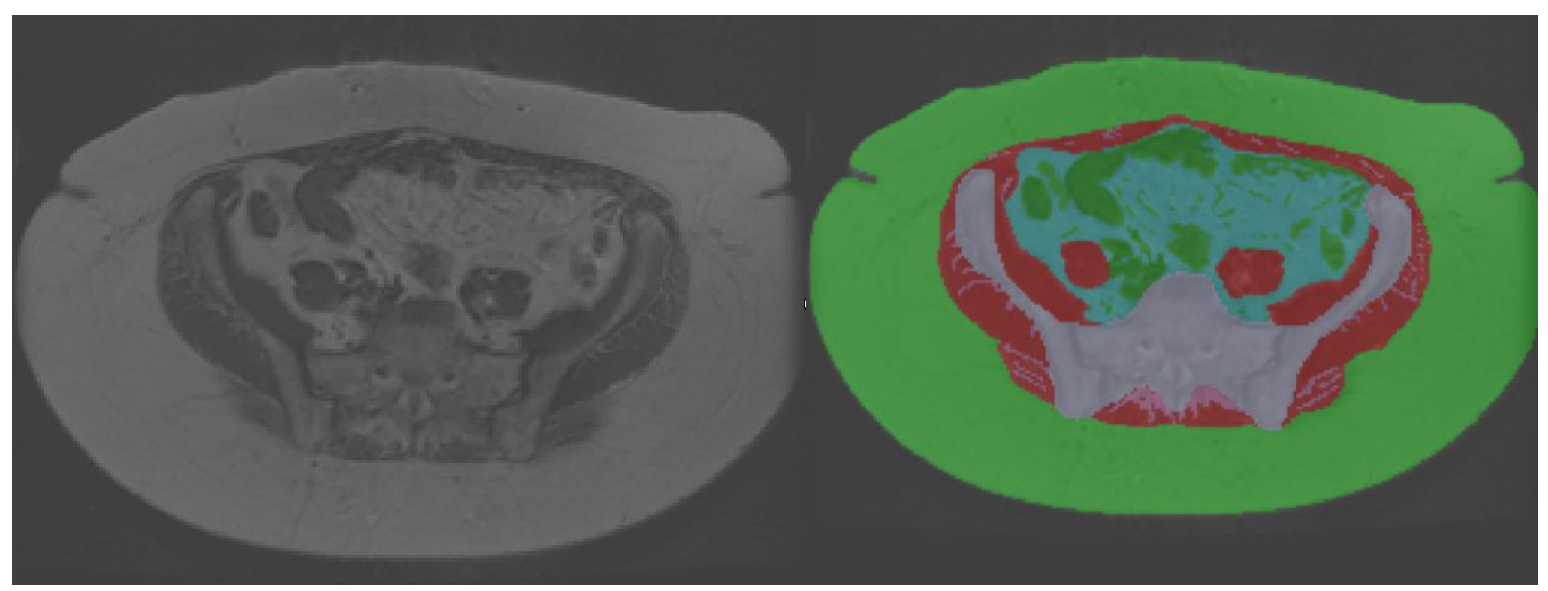


Appendix F - Figure 2. Determination of Tissue Mass Using MR Images and Slice-O-Matic Software.

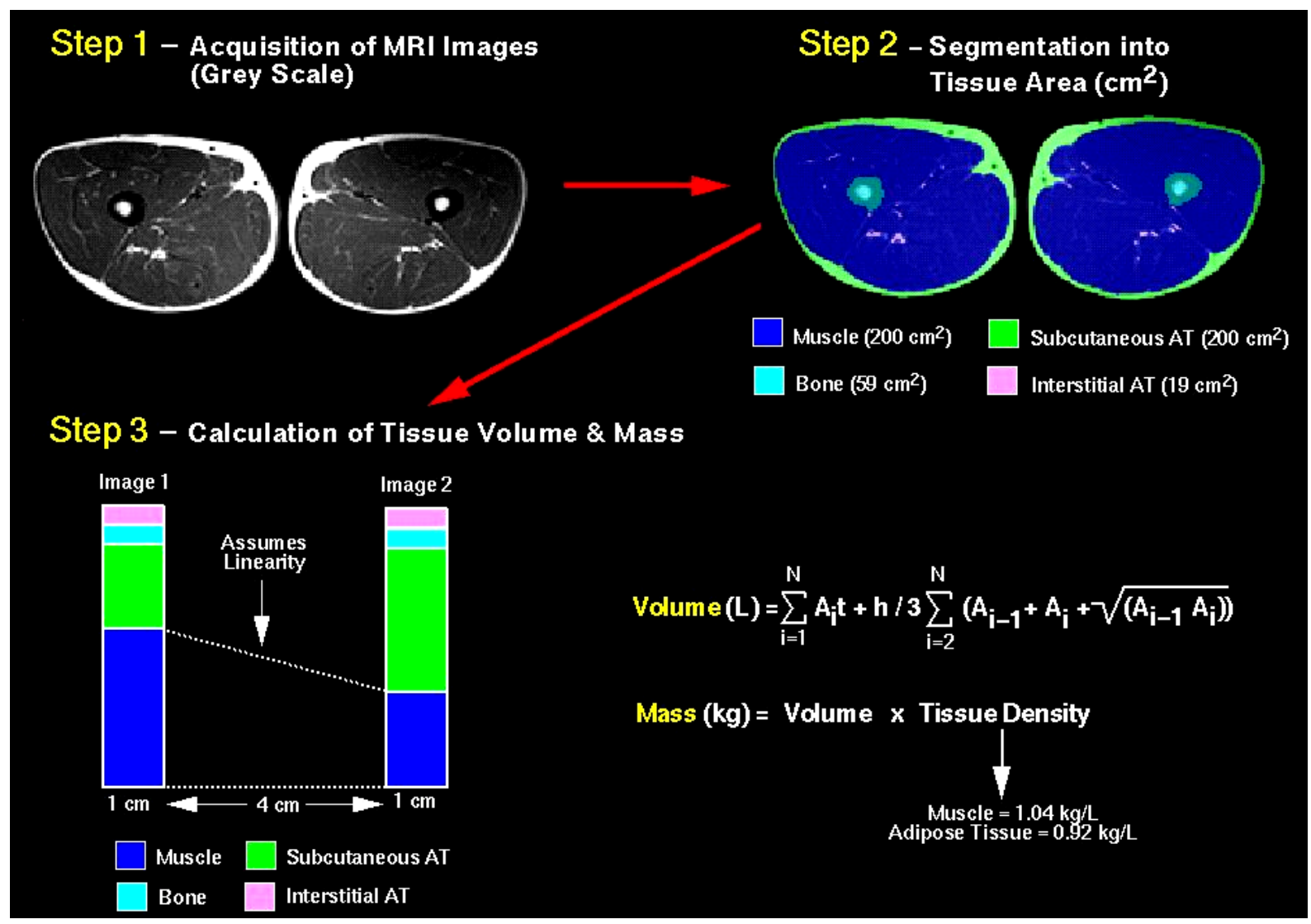




\section{Appendix G}

Example of Statistical Analysis Used to Derive Results for Manuscript 


\section{Statistical Output for Model 1 - The Unadjusted Association between Exercise Intensity and Insulin Sensitivity}

Abbreviations: MkgskmD: Mean change in skeletal muscle glucose disposal (mg/kgskm/min), PerVO2max: Exercise intensity (\% $\mathrm{VO}_{2}$ peak).

MEN:

Descriptive Statistics ${ }^{a}$

\begin{tabular}{|l|r|r|r|}
\hline & \multicolumn{1}{|c|}{ Mean } & Std. Deviation & \multicolumn{1}{|c|}{ N } \\
\hline MkgskmD & 7.1538 & 5.35269 & 16 \\
PerVO2max & 61.213058750 & 7.13712291311 & 16 \\
& 34466 & 1376 & \\
\hline
\end{tabular}

a. $\mathrm{SEX}=\mathrm{M}$

\section{Correlations $^{a}$}

\begin{tabular}{|ll|r|r|}
\hline & & MkgskmD & PerVO2max \\
\hline Pearson Correlation & MkgskmD & 1.000 & .567 \\
& PerVO2max & .567 & 1.000 \\
\hline Sig. (1-tailed) & MkgskmD &. & .011 \\
& PerVO2max & .011 &. \\
\hline $\mathrm{N}$ & MkgskmD & 16 & 16 \\
& PerVO2max & 16 & 16 \\
\hline
\end{tabular}

a. $\mathrm{SEX}=\mathrm{M}$

Variables Entered/Removed ${ }^{\mathrm{b}, \mathrm{c}}$

\begin{tabular}{|l|c|c|l|}
\hline Model & $\begin{array}{c}\text { Variables } \\
\text { Entered }\end{array}$ & $\begin{array}{c}\text { Variables } \\
\text { Removed }\end{array}$ & \multicolumn{1}{|c|}{ Method } \\
\hline 1 & PerVO2max $^{\mathrm{a}}$ & & Enter \\
\hline
\end{tabular}
a. All requested variables entered.
b. SEX = M
c. Dependent Variable: MkgskmD 


\begin{tabular}{|l|r|r|r|r|}
\hline \multicolumn{7}{|c|}{ Model Summary } \\
Model & \multicolumn{1}{c|}{$\mathrm{R}$} & R Square & $\begin{array}{c}\text { Adjusted R } \\
\text { Square }\end{array}$ & $\begin{array}{c}\text { Std. Error of } \\
\text { the Estimate }\end{array}$ \\
\hline 1 & $.567^{\mathrm{a}}$ & .321 & .273 & 4.56511 \\
\hline
\end{tabular}

a. Predictors: (Constant), PerVO2max

b. $\operatorname{SEX}=\mathrm{M}$

\begin{tabular}{|c|c|c|c|c|c|c|}
\hline \multicolumn{7}{|c|}{ ANOVA $^{b, c}$} \\
\hline \multicolumn{2}{|c|}{ Model } & $\begin{array}{l}\text { Sum of } \\
\text { Squares }\end{array}$ & $d f$ & Mean Square & $\mathrm{F}$ & Sig. \\
\hline \multirow[t]{3}{*}{1} & Regression & 138.005 & 1 & 138.005 & 6.622 & $.022^{a}$ \\
\hline & Residual & 291.764 & 14 & 20.840 & & \\
\hline & Total & 429.769 & 15 & & & \\
\hline
\end{tabular}

a. Predictors: (Constant), PerVO2max

b. $\operatorname{SEX}=\mathrm{M}$

c. Dependent Variable: MkgskmD

\begin{tabular}{|c|c|c|c|c|c|c|}
\hline \multicolumn{7}{|c|}{ Coefficients $^{a, b}$} \\
\hline \multirow{2}{*}{\multicolumn{2}{|c|}{ Model }} & \multicolumn{2}{|c|}{$\begin{array}{c}\text { Unstandardized } \\
\text { Coefficients }\end{array}$} & \multirow{2}{*}{$\begin{array}{l}\text { Standardized } \\
\text { Coefficients } \\
\text { Beta }\end{array}$} & \multirow[b]{2}{*}{$\mathrm{t}$} & \multirow[b]{2}{*}{ Sig. } \\
\hline & & $B$ & Std. Error & & & \\
\hline \multirow[t]{2}{*}{1} & (Constant) & -18.861 & 10.174 & & -1.854 & .085 \\
\hline & PerVO2max & .425 & .165 & .567 & 2.573 & .022 \\
\hline
\end{tabular}

a. $\operatorname{SEX}=\mathrm{M}$

b. Dependent Variable: MkgskmD 


\section{WOMEN:}

\begin{tabular}{|l|r|r|r|}
\hline \multicolumn{1}{|c|}{ Descriptive Statistics $^{\text {a }}$} \\
\hline Mkan & \multicolumn{1}{|c|}{ Std. Deviation } & \multicolumn{1}{c|}{ Mean } \\
PerVO2max & 5.7707 & 7.11757 & 18 \\
& 66.862488647 & 6.70963414514 & 18 \\
& 19218 & 4388 & \\
\hline
\end{tabular}

a. $\operatorname{SEX}=\mathrm{F}$

\section{Correlations $^{\mathrm{a}}$}

\begin{tabular}{|ll|r|r|}
\hline & & MkgskmD & PerVO2max \\
\hline Pearson Correlation & MkgskmD & 1.000 & -.104 \\
& PerVO2max & -.104 & 1.000 \\
\hline Sig. (1-tailed) & MkgskmD &. & .340 \\
& PerVO2max & .340 &. \\
\hline $\mathrm{N}$ & MkgskmD & 18 & 18 \\
& PerVO2max & 18 & 18 \\
\hline
\end{tabular}

a. $\mathrm{SEX}=\mathrm{F}$

\begin{tabular}{|l|l|l|l|}
\multicolumn{4}{|c|}{ Variables Entered/Removed $^{\text {b,c }}$} \\
\hline Model & $\begin{array}{c}\text { Variables } \\
\text { Entered }\end{array}$ & $\begin{array}{c}\text { Variables } \\
\text { Removed }\end{array}$ & Method \\
\hline 1 & PerVO2max & & Enter \\
\hline
\end{tabular}

a. All requested variables entered.

b. SEX = F

c. Dependent Variable: MkgskmD

\begin{tabular}{|l|c|r|r|c|}
\hline & Model Summary \\
\hline Model & $\mathrm{R}$ & R Square & $\begin{array}{c}\text { Adjusted R } \\
\text { Square }\end{array}$ & $\begin{array}{c}\text { Std. Error of the } \\
\text { Estimate }\end{array}$ \\
\hline 1 & $.104^{\mathrm{a}}$ & .011 & -.051 & 7.29675 \\
\hline
\end{tabular}
a. Predictors: (Constant), PerVO2max
b. SEX $=F$ 


\begin{tabular}{|c|c|c|c|c|c|c|}
\hline \multicolumn{7}{|c|}{ ANOVA $^{b, c}$} \\
\hline \multicolumn{2}{|c|}{ Model } & $\begin{array}{l}\text { Sum of } \\
\text { Squares }\end{array}$ & $d f$ & Mean Square & $\mathrm{F}$ & Sig. \\
\hline \multirow[t]{3}{*}{1} & Regression & 9.337 & 1 & 9.337 & .175 & $.681^{a}$ \\
\hline & Residual & 851.881 & 16 & 53.243 & & \\
\hline & Total & 861.218 & 17 & & & \\
\hline
\end{tabular}

a. Predictors: (Constant), PerVO2max

b. SEX = F

c. Dependent Variable: MkgskmD

\begin{tabular}{|c|c|c|c|c|c|c|}
\hline \multicolumn{7}{|c|}{ Coefficients $^{\mathrm{a}, \mathrm{b}}$} \\
\hline \multirow{2}{*}{\multicolumn{2}{|c|}{ Model }} & \multicolumn{2}{|c|}{$\begin{array}{c}\text { Unstandardized } \\
\text { Coefficients }\end{array}$} & \multirow{2}{*}{$\begin{array}{c}\begin{array}{c}\text { Standardized } \\
\text { Coefficients }\end{array} \\
\text { Beta } \\
\end{array}$} & \multirow[b]{2}{*}{$\mathrm{t}$} & \multirow[b]{2}{*}{ Sig. } \\
\hline & & $\mathrm{B}$ & Std. Error & & & \\
\hline \multirow[t]{2}{*}{1} & (Constant) & 13.156 & 17.719 & & .742 & .469 \\
\hline & PerVO2max & -.110 & .264 & -.104 & -.419 & .681 \\
\hline
\end{tabular}

a. $\mathrm{SEX}=\mathrm{F}$

b. Dependent Variable: MkgskmD 